\title{
Novel insights in the pathophysiology of insulin resistance : a molecular genetic approach
}

Citation for published version (APA):

Meex, S. J. R. (2008). Novel insights in the pathophysiology of insulin resistance : a molecular genetic approach. [Doctoral Thesis, Maastricht University]. Universiteit Maastricht. https://doi.org/10.26481/dis.20080307sm

Document status and date:

Published: 01/01/2008

DOI:

10.26481/dis.20080307sm

Document Version:

Publisher's PDF, also known as Version of record

\section{Please check the document version of this publication:}

- A submitted manuscript is the version of the article upon submission and before peer-review. There can be important differences between the submitted version and the official published version of record.

People interested in the research are advised to contact the author for the final version of the publication, or visit the DOI to the publisher's website.

- The final author version and the galley proof are versions of the publication after peer review.

- The final published version features the final layout of the paper including the volume, issue and page numbers.

Link to publication

\footnotetext{
General rights rights.

- You may freely distribute the URL identifying the publication in the public portal. please follow below link for the End User Agreement:

www.umlib.nl/taverne-license

Take down policy

If you believe that this document breaches copyright please contact us at:

repository@maastrichtuniversity.nl

providing details and we will investigate your claim.
}

Copyright and moral rights for the publications made accessible in the public portal are retained by the authors and/or other copyright owners and it is a condition of accessing publications that users recognise and abide by the legal requirements associated with these

- Users may download and print one copy of any publication from the public portal for the purpose of private study or research.

- You may not further distribute the material or use it for any profit-making activity or commercial gain

If the publication is distributed under the terms of Article $25 \mathrm{fa}$ of the Dutch Copyright Act, indicated by the "Taverne" license above, 


\section{Novel insights in the pathophysiology of insulin resistance}

A molecular genetic approach 
Cover illustration by Jeroen Maesen, $\mathrm{Ma}^{\circ} \mathrm{Mu}$ architecten bvba, Hasselt, België (C) Copyright Steven J.R. Meex, Maastricht 2008 


\title{
Novel insights in the pathophysiology of insulin resistance
}

\author{
A molecular genetic approach
}

Proefschrift

Ter verkrijging van de graad van doctor aan de Universiteit Maastricht, op gezag van de Rector Magnificus, prof. Mr. G.P.M.F. Mols

volgens het besluit van het College van Decanen,

in het openbaar te verdedigen op

vrijdag 7 maart 2008 om 12.00uur

door

Steven Johan Renate Meex

geboren op 3 december 1979 te Genk 


\section{PROMOTORES}

Prof. dr. C.D.A. Stehouwer

Prof. dr. T.W.A. de Bruin

\section{COPROMOTORES}

Dr. C.J.H. van der Kallen

Dr. M.M.J. van Greevenbroek

\section{BEOORDELINGSCOMMISSIE}

Prof. dr. M.J.A.P. Daemen (voorzitter)

Prof. dr. W.A. Buurman

Prof. dr. N.C. Schaper

Prof. dr. P.E.. Slagboom (Universiteit Leiden)

Prof. dr. B.G. Wouters

Financial support by the Netherlands Heart Foundation and the Dutch Diabetes Research Foundation for the publication of this thesis is gratefully acknowledged.

Part of the research described in this thesis was supported by an EFSD/Novo Nordisk research grant

Also Astellas, AstraZeneca, Biomedbooster, Boehringer Ingelheim, BristolMeyers Squibb, De Clercq Brants \& Partners, Eli Lilly, Genzyme, GlaxoSmithKline, Greiner Bio-One, J.E. Jurriaanse Stichting, Medtronic, Merck Sharp \& Dohme, Novo Nordisk, Pfizer and Servier are gratefully acknowledged for their financial support. 


\section{Contents}

Chapter $1 \quad$ Introduction 9

Chapter 2 Genetic Approaches to the Molecular Understanding of Type 2 Diabetes and Familial Combined Hyperlipidemia $\quad 27$

Chapter 3 Up-regulation of CD36/FAT in Pre-adipocytes in Familial Combined Hyperlipidemia 51

Chapter $4 \quad$ Activating Transcription Factor 6 Polymorphisms and Haplotypes Are Associated with Impaired Glucose Homeostasis and Type 2 Diabetes in Dutch Caucasians $\mathbf{7 1}$

Chapter 5 The ATF6-Met[67]Val Substitution is Associated with Increased Apolipoprotein B Levels and Plasma Cholesterol

Chapter $6 \quad$ Upstream Transcription Factor 1 (USF1) in Risk of Type 2 Diabetes: Association Study in 2000 Dutch Caucasians 109

Chapter $7 \quad$ General Discussion $\mathbf{1 1 9}$

Summary 139

Samenvatting 141

Dankwoord 143

Curriculum Vitae 146 


\section{List of abbreviations}

\begin{tabular}{|c|c|}
\hline AACE & American Association of Clinical Endocrinology \\
\hline ABCA1 & ATB-binding cassette transporter A1-gene \\
\hline AHA & American Heart Association \\
\hline AIC & Akaike information criterion \\
\hline apoB & apolipoprotein B \\
\hline ATF6 & activating transcription factor 6 \\
\hline BMI & Body Mass Index \\
\hline CAD & coronary artery disease \\
\hline CAPN10 & calpain 10 \\
\hline CETP & cholesteryl ester transfer protein \\
\hline ChREBP & carbohydrate responsive element binding protein \\
\hline CVD & cardiovascular disease \\
\hline CVR & cardiovascular risk \\
\hline DAG & diacylglycerol \\
\hline DM2 & Type 2 Diabetes \\
\hline EGIR & European Group for Study of Insulin Resistance \\
\hline eiF2 & eukaryotic translation initiation factor 2 \\
\hline ER & endoplasmic reticulum \\
\hline FCHL & familial combined hyperlipidemia \\
\hline FCS & fetal calf serum \\
\hline FFA & free fatty acids \\
\hline $\mathrm{FH}$ & familial hypercholesterolemia \\
\hline GRP78 & glucose regulated protein 78 \\
\hline GRP94 & glucose regulated protein 94 \\
\hline GSP & glutamine/streptomycine/peniciline \\
\hline HDL & high density lipoproteins \\
\hline IDF & International Diabetes Federation \\
\hline IDL & intermediate density lipoproteins \\
\hline IFG & impaired fasting glucose \\
\hline IGT & impaired glucose tolerance \\
\hline IRE1 & inositol requiring 1 \\
\hline IRS & insulin receptor substrate \\
\hline ISR & integrated stress response \\
\hline LCFA & long chain fatty acid \\
\hline LD & linkage disequilibrium \\
\hline LDL & low density lipoproteins \\
\hline MAF & minor allele frequency \\
\hline MCP1 & monocyte chemoattractant protein 1 \\
\hline MODY & maturity onset diabetes of the young \\
\hline NAFLD & non alcoholic fatty liver disease \\
\hline NCEP:ATP3III & National Cholesterol Education Program Adult Treatment Panel III \\
\hline
\end{tabular}




$\begin{array}{ll}\text { NHLBI } & \text { National Heart Lung and Blood Institute } \\ \text { OR } & \text { odds ratio } \\ \text { ORP150 } & \text { oxygen regulated potein } \\ \text { PAI1 } & \text { plasminogen activator inhibitor-1 } \\ \text { PAR } & \text { population attributable risk } \\ \text { PCSK9 } & \text { proprotein convertase subtilisin/kexin type } 9 \\ \text { PERK } & \text { protein kinase R-like ER kinase } \\ \text { PGC1 } \alpha & \text { peroxysome proliferator activated receptor gamma co-activator } 1 \text { alpha } \\ \text { PPAR } \alpha & \text { peroxisomal proliferator activated receptor alpha } \\ \text { PPAR } \gamma & \text { peroxisomal proliferator activated receptor gamma } \\ \text { RBP4 } & \text { retinol binding protein } 4 \\ \text { RIP } & \text { regulated intramembrane proteolysis } \\ \text { SAA } & \text { serum amyloid A } \\ \text { SELS } & \text { selenoprotein S } \\ \text { SNP } & \text { single nucleotide polymorphism } \\ \text { SRE } & \text { sterol response element } \\ \text { SREBP } & \text { sterol regulatory element binding protein } \\ \text { SSH } & \text { suppression subtractive hybridisation } \\ \text { SSO } & \text { Sulfo-N-succinimidyl ester } \\ \text { TC } & \text { total cholesterol } \\ \text { TG } & \text { triglycerides } \\ \text { TNF } \alpha & \text { tumor necrosis factor } \alpha \\ \text { UPR } & \text { unfolded protein response } \\ \text { USF1 } & \text { upstream transcription factor 1 } \\ \text { VLDL } & \text { very low density lipoproteins } \\ \text { VP16 } & \text { Worion protein } 16 \\ \text { WHO } & \text { X-box-binding-protein } 1 \\ \text { XBP1 } & \end{array}$



Chapter 1

Introduction 


\section{INTRODUCTION}

Over the past two decades, a dramatic worldwide increase in the number of people with the metabolic syndrome has been observed. The term "metabolic syndrome" defines the clustering of risk factors that often accompany obesity and associate with increased risk for cardiovascular disease and type 2 diabetes. Although a constellation of closely related metabolic risk factors for cardiovascular disease was first recognized more than 80 years ago, it was reintroduced by Reaven in the Banting lecture in 1988, under the term Syndrome $X$ or insulin resistance syndrome (1). The present common designation is "metabolic syndrome".

The cluster of metabolic abnormalities associated with the metabolic syndrome includes insulin resistance, central obesity, disturbed glucose homeostasis (type 2 diabetes, impaired fasting glucose or impaired glucose tolerance), atherogenic dyslipidemia, hypertension, and a pro-thrombotic and proinflammatory state (2-5). These are all well documented risk factors for cardiovascular disease. With advancing medical science, other diseases are being linked to the metabolic syndrome including non-alcoholic fatty liver disease, polycystic ovarian syndrome, cancer, gallstones, gout, and obstructive sleep apnoea (6).

\section{DEFINITION OF THE METABOLIC SYNDROME}

The ultimate importance of defining the metabolic syndrome is to identify subjects at high risk for cardiovascular disease. There has been much discussion and several attempts by experts groups to define standardized diagnostic criteria. The World Health Organisation (WHO) was the first to publish their definition in 1998 (7), which was slightly modified in 1999 (8). A mandatory criterion of the WHO was insulin resistance and/or disturbed glucose homeostasis. In addition two of the following four risk factors needed to be present: hypertension, dyslipidemia, central obesity and microalbuminuria. The European Group for Study of Insulin Resistance (EGIR) published their criteria in 1999 (9). They excluded people with type 2 diabetes, but analogous to the WHO-criteria put forward insulin resistance, reflected by hyperinsulinemia, as the central mandatory component. In addition, presence of two of four other risk factors (hyperglycemia, hypertension, dyslipidemia and central obesity) 
needed to be fulfilled (9). The National Cholesterol Education Program Adult Treatment Panel III (NCEP:ATPIII) criteria were published in 2001(10). These criteria did not make insulin resistance strictly required for diagnosis. Instead, three of the following five risk factors (Increased waist circumference, low HDL-cholesterol, high triglycerides, hypertension and impaired fasting glucose), needed to be present to meet the diagnostic criteria for the metabolic syndrome. The NCEP:ATPIII-criteria were more suitable for clinical practice as it required only fasting assessment of blood glucose, whereas WHO and EGIR required an oral glucose tolerance for their diagnostic procedure. In 2003, the American Association of Clinical Endocrinology (AACE) refocused on insulin resistance as the primary cause of metabolic risk factors, and used the name "insulin resistance syndrome"(11). Remarkably, the AACE statement deliberately does not provide a specific definition of the syndrome and allows the diagnosis to rely on clinical judgment, irrespective of the number of risk factors present. Also according to the AACE's definition, once a person develops type 2 diabetes mellitus, the term insulin resistance syndrome no longer applies.

The different definitions described above reflect the discussion in the scientific world on the conceptual framework that underlies the metabolic syndrome. Due to an incomplete understanding of the biological background, opinions vary on whether the metabolic syndrome should be defined to mainly indicate insulin resistance, consequences of obesity, risk for cardiovascular disease, or just a collection of statistically related factors. The parallel use of different definitions led to confusion and hampered the comparability of studies. In May 2004 the International Diabetes Federation (IDF) convened a workshop with representatives from the WHO, the NCEP-ATPIII, and members from all IDF regions to attempt to establish a new unified definition for the metabolic syndrome (12). Put first was that the new definition should be simple for clinical practice and easily to be used in any country worldwide. From this prerequisite, the clinically simple NCEP-ATPIII criteria were chosen as a starting point. Furthermore it was considered that abdominal obesity is so highly correlated with insulin resistance that other, more laborious measures of insulin resistance are unnecessary. Abdominal obesity, assessed by waist circumference, was the mandatory central trait in the new diagnosis. Importantly, waist circumference cut-off values were specified by nationality or ethnicity based on best available population estimates. Two additional risk factors from the 
NCEP-ATPIII criteria are sufficient to establish the diagnosis "metabolic syndrome" (12).

It is certain that the most recent criteria from the IDF are not the final word. Almost simultaneously with the new IDF consensus, the National Heart Lung and Blood Institute (NHLBI), together with the American Heart Association (AHA) reaffirmed the utility of ATPIII criteria, with minor modifications (13). Although the last ATPIII-update and the IDF criteria harmonize more on the clinical diagnosis than all previous definitions, the ultimate goal of one global definition has apparently not been achieved yet. Despite the fact that definitions differ in detail, and handle different cut-off levels for several components of the metabolic syndrome, they agree on the following central traits: obesity, disturbed glucose homeostasis, dyslipidemia and hypertension.

Part of the scientific community is sceptical about the term "metabolic syndrome", especially the ill-considered use thereof. They agree that the term may have some utility to refer to a cluster of correlated risk factors for cardiovascular disease, but are strongly set against its representation as a specific algorithm that should be used to diagnose a unique disease. Their view is supported by the absence of scientific observations, showing that the risk imparted by the metabolic syndrome is higher than the simple additive effects of its separate components $(14,15)$. On the contrary, several reports document that the risk of cardiovascular disease, associated with the metabolic syndrome, can be fully explained by the presence of the separate factors (16-19). In spite of all this, most important from a clinicians perspective is to realize that occurrence of one risk factor may portend the presence of others, and that each of these risk factors confer additional cardiovascular risk.

\section{PREVALENCE OF THE METABOLIC SYNDROME}

The prevalence of the metabolic syndrome varies between different populations and is highly age-dependent. In studies that include subjects of 20 years and older, the prevalence in men varies from $8 \%$ in urban populations in India to $24 \%$ in the USA, and for women from $7 \%$ in France to $43 \%$ in Iran (3). Notably, in age categories of 60 years and older the prevalence can rise to $67 \%$ (3). Obesity is the driving force behind the pandemic proportions of the metabolic syndrome and type 2 diabetes. In 2005, about 1.6 billion adults (15 years and 
older) were overweight (BMI 25$)$ and approximately 400 million were obese (BMI $\geq 30$ ). The WHO further projects that by 2015, approximately 2.3 billion adults will be overweight and more than 700 million adults will be obese. Obesity has become to diabetes what tobacco is to lung cancer and roughly $60 \%$ of all cases of diabetes can be directly attributed to weight gain (20). The total number of people with diabetes was estimated at 171 million in 2000 $(2.8 \%)$ and is projected to rise to 366 million (4.4\%) in 2030 (21), with biggest increases expected in India and China (20). Notably, the majority of patients with type 2 diabetes fulfill the criteria of the metabolic syndrome. The other way around, many subjects with the metabolic syndrome do not have type 2 diabetes although they often are insulin resistant.

\section{PATHOPHYSIOLOGY OF THE METABOLIC SYNDROME}

\section{INSULIN RESISTANCE}

The pathophysiology of the metabolic syndrome is extremely complex. There is considerable controversy regarding the initiating factor, but the most accepted and unifying hypothesis to describe the pathophysiology of the metabolic syndrome is insulin resistance. It is postulated that an overabundance of circulating non esterified fatty acids (NEFA), mainly derived from adipose tissue, is a very early and major contributor to the development of insulin resistance. Excessive caloric intake and sedentary life style are on the basis of excessive accumulation of body fat. Especially the increase of visceral adipose tissue is strongly associated with the development of insulin resistance (22) and the metabolic syndrome (23-30). A potential explanation is that lipolysis in visceral adipose tissue is less suppressed by insulin than peripheral fat depots, and because visceral fatty acids drain into the portal circulation directly to the liver.

The hepatic uptake of fatty acids is not regulated and as a result, plasma fatty acid concentrations are directly related to the influx of fatty acids to the liver. This leads to hepatic insulin resistance, relative systemic hyperinsulinemia (due to reduced hepatic insulin clearance) and eventually Non Alcoholic Fatty Liver Disease (NAFLD), which is strongly related to hepatic insulin resistance. In the fasted state, adipose tissue contributes approximately $80 \%$ of fatty acid content to the plasma NEFA pool, and even in the fed state, this contribution remains at approximately $60 \%(31,32)$. This plasma FFA pool in turn accounts 
for approximately $65 \%$ of hepatic triglyceride content in subjects with NAFLD, illustrating the importance of free fatty acids in the pathogenesis of NAFLD and hepatic insulin resistance. Also increased de-novo synthesis of triglycerides contributes to hepatic fat content in insulin resistance. This occurs because hyperinsulinemia and hyperglycemia induce the expression of sterol regulatory element binding protein 1c (SREBP1c), and carbohydrate responsive element binding protein (ChREBP), respectively (33-35). Both transcription factors activate genes involved in de-novo lipogenesis in liver. The contribution of this pathway to hepatic triglyceride content is marginal in healthy subjects, but in hyperinsulinemia subjects with NAFLD, it accounts for $25 \%$ of liver triglycerides (31).

Fat accumulation in muscle is also strongly correlated with insulin resistance. A proposed mechanism in muscle is that increased plasma FFA levels lead to increased intracellular long-chain fatty acyl-CoA (LCFA-CoA) concentration, which in turn results in diacylglycerol (DAG) and triglyceride formation. DAG is a known activator of protein kinase $\mathrm{C} \theta$ ( $\mathrm{PKC} \theta)$, which is linked to insulin resistance $(36,37)$.

Insulin resistance may thus be viewed as a consequence of increased NEFA flux, mainly released from the visceral adipose tissue depot. Muscle insulin resistance results in hyperglycemia, whereas insulin resistance in the liver it underlies NAFLD, increased hepatic glucose output, dyslipidemia, and a procoagulant and pro-inflammatory state.

\section{INFLAMMATION AND A PRO-THROMBOTIC STATE}

Obesity is associated with increased production of inflammatory cytokines, particularly from visceral adipose tissue. Despite the fact that considerable insight has been acquired in the many inflammatory factors that mediate insulin resistance, and the intracellular pathways involved, it is unclear whether inflammation is a primary event which links obesity with insulin resistance, or rather secondary to hyperlipidemia or hyperglycemia.

The first pro-inflammatory cytokine shown to be able to induce insulin resistance was $\operatorname{TNF} \alpha(38,39)$. At present, adipose tissue has been shown to induce expression and secretion of many cytokines and bioactive compounds, including monocyte chemoattractant protein-1 (MCP-1), plasminogen activator inhibitor-1 (PAI-1), resistin, adiponectin, serum amyloid A (SAA), leptin, IL-1 $\beta$, IL6, angiotensinogen, visfatin, retinol binding protein-4 (RBP4) and others (40, 41). Adiponectin has anti-inflammatory properties, and its expression decreas- 
es with increased adiposity (42). Anti-inflammatory features of adiponectin include suppression of TNF $\alpha$ and induction of the anti-inflammatory cytokines IL-10 and IL-1-receptor antagonist (43). Adiponectin and leptin appear to be true adipokines, exclusively produced by adipocytes, whereas the other molecules are also expressed in activated macrophages or other cell types (40). Inflammation of adipose tissue is characterized by macrophage infiltration (44, 45). It has been suggested that secretion of MCP1 by adipocytes may play a role in the recruitment of macrophages to adipose tissue. Infiltrated macrophages may in turn secrete a variety of other cytokines and chemokines that further promote a local inflammatory response $(46,47)$.

Also in liver, pro-inflammatory gene expression (PAI, CRP and others) increases with increasing adiposity (48). This suggests either that hepatocyte lipid accumulation might induce an inflammatory response similar to that observed in lipid-laden adipose tissue, or alternatively, that pro-inflammatory substances, released from the abdominal fat depot in the portal circulation elicit an inflammatory response in liver (40). Whatever mechanism is applicable, the final outcome is a further development of a pro-thrombotic and proinflammatory state $(40,49)$.

Many of the pro-inflammatory stimuli can provoke insulin resistance via activating IKK $\beta / N F-\kappa B$ and JNK pathways $(48,50,51)$. Activated JNK provokes insulin resistance through phosphorylation of serine residues in IRS-1. Unlike JNK, IKK $\beta$ does not phosphorylate IRS-1 to cause insulin resistance, but instead liberates NF- $\kappa \mathrm{B}$ for translocation to the nucleus where it promotes the transcription of target genes whose products induce insulin resistance.

\section{DYSLIPIDEMIA}

Lipid and lipoprotein abnormalities in the metabolic syndrome can be summarized as follows 1) increased triglyceride levels, 2) increased small, dense LDL levels, 3) increased apolipoprotein B (apoB) levels, and 4) decreased HDL cholesterol levels. It has been suggested that NAFLD plays a central and causal role in the atherogenic lipid profile seen in the metabolic syndrome (52-54). The hypertriglyceridemia which accompanies abdominal obesity, insulin resistance and NAFLD is related to hepatic over secretion of apoB containing triglyceride-rich VLDL particles. $(55,56)$ ApoB enhances assembly and secretion of VLDL particles. Furthermore, apoB is the structural protein of atherogenic lipoproteins including VLDL, intermediate density lipoproteins (IDL), and low density lipoproteins (LDL). Each of these lipoproteins contains one apoB mo- 
lecule, and the plasma apoB level reflects the total number of atherogenic particles in the blood (57). Production of apoB is regulated at the posttranslational level. Insulin can degrade apoB via a phosphotidylinositol 3kinase dependent pathway (58). Hepatic insulin resistance, combined with the abundant availability of lipids in the liver dampen posttranslational degradation of apoB, and lead to increased secretion of VLDL and formation of larger VLDL particles (VLDL1) $(53,59)$. The result is hypertriglyceridemia. Under normal conditions, VLDL is hydrolyzed by lipoprotein lipase to IDL and LDL in the peripheral circulation, thereby generating FFA for energy use or storage. Lipoprotein lipase activity is also decreased in insulin resistance $(60,61)$. Hence, elevated VLDL (and thus hypertriglyceridemia), IDL and LDL particles in insulin resistance are due to a combination of increased VLDL production and decreased clearance.

Low HDL-cholesterol and an increased number of small, dense LDL particles is an integral feature of dyslipidemia, and strongly linked to VLDL overproduction (52). Increased levels of triglyceride rich lipoproteins, in combination with reduced lipoprotein lipase activity increase the residence time of these particles in the circulation. Under conditions of hypertriglyceridemia, cholesteryl esters in LDL and HDL particles are exchanged for triglycerides from VLDL particles, by action of cholesteryl ester transfer protein (CETP), which is increased in insulin resistance (52). The transfer of triglycerides into LDL and HDL particles makes them triglyceride-rich and hence a better substrate for hepatic lipase, which is also increased in insulin resistance (57). The result is a predominance of small, dense LDL particles and a reduction of HDL cholesterol. This reduction is a consequence of changes in HDL metabolism (small HDL has an enhanced catabolic rate) and composition (especially HDL2, the large buoyant anti-atherogenic subspecies of total HDL is reduced) $(53,57)$.

Small dense LDL particles can contribute to the risk conferred by LDL cholesterol for increased cardiovascular disease (62-65). A potential mechanistic explanation for the association of small, dense LDL with an additionally increased risk of cardiovascular disease is that it may enter the arterial wall more easily, binds better to proteoglycans, $(66,67)$, and is more susceptible to oxidative modification, leading to macrophage uptake and eventually foam cell formation $(68,69)$. 


\section{DISTURBED GLUCOSE HOMEOSTASIS AND TYPE 2 DIABETES}

The conversion from normoglycemia to clinical type 2 diabetes can take a few years or even decades and requires two separate defects simultaneously: insulin resistance and $\beta$-cell failure. Insulin resistance may be present many years before the diagnosis of type 2 diabetes, and it is believed that the pathological course towards developing type 2 diabetes starts with a gradual increase in insulin resistance, which results in compensatory hyperinsulinemia (70). This state can be maintained as long as pancreatic $\beta$-cells are able secrete enough insulin to compensate for cellular insulin resistance by boosting their secretion capacity and increasing their $\beta$-cell mass (71-73). However at some point, modulated by the presence of genetic or acquired factors, $\beta$-cells become exhausted. This results in impaired glucose tolerance and early type 2 diabetes. Hyperglycemia or glucotoxicity, once established promotes a series of events that contribute to severe $\beta$-cell failure and apoptosis, and ultimately overt type 2 diabetes (74). Plasma free fatty acids do not only play a central role in insulin resistance (described above), but also contribute to pancreatic $\beta$-cell failure. Short term exposure of pancreatic islands to free fatty acids increases insulin secretion, but long term exposure inhibits insulin biosynthesis and secretion in response to glucose, and may eventually lead to $\beta$-cell death (75-78). The deleterious effect of excess free fatty acids on the $\beta$-cell is called lipotoxicity (79).

\section{HYPERTENSION}

The relation between insulin resistance and hypertension is less clear. Risk estimates from the Framingham Heart Study attributes excess weight as the cause of hypertension in $78 \%$ of men and $65 \%$ of women (80). A central feature of hypertension is increased sodium re-absorption in the kidney and extracellular fluid volume expansion, which initiates hypertension. In insulin sensitive subjects insulin acts as a vasodilatator with secondary effects on sodium reabsorption. In the setting of insulin resistance the vasodilatory effect of insulin can be lost (81), whereas the effect on sodium re-absorption by the kidney is preserved (82). Insulin also activates the sympathetic nervous system, even under conditions of insulin resistance (83). Fatty acids themselves can mediate vasoconstriction in humans (84) and infusion of fatty acids in the portal vein in rodents activates the sympathetic nervous system and increases blood pressure (85). Elevated leptin levels may also increase blood pressure $(86,87)$. 


\section{GENETIC PREDISPOSITION TO THE METABOLIC $S Y N D R O M E$}

Two subgroups of patients with the metabolic syndrome, those with type 2 diabetes and Familial Combined Hyperlipidemia (FCHL), are at particularly high risk for premature $\operatorname{CAD}(57,88)$. They share many of the phenotypic features of the metabolic syndrome including insulin resistance, abdominal obesity, hypertension and dyslipidemia. A recent report exemplified that nearly two-thirds of individuals with FCHL, and the vast majority of patients with type 2 diabetes, meet the diagnostic criteria of the metabolic syndrome (figure 1) (89).

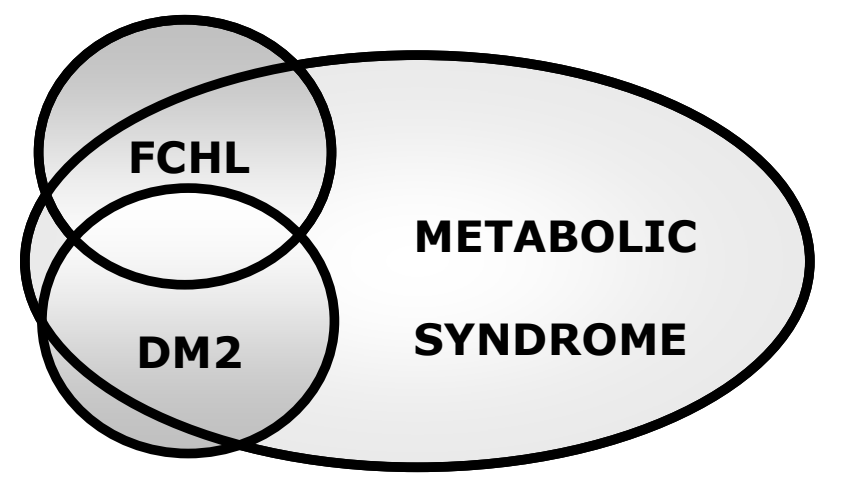

Figure 1: The metabolic syndrome comprises a heterogeneous group of oligogenic disorders, such as familial combined hyperlipidemia and type 2 diabetes.

Therefore, an improved understanding of the genetic background of FCHL and type 2 diabetes may benefit millions of people with the metabolic syndrome. The marked presence of a genetic component in type 2 diabetes and FCHL, reflected by their familial clustering, provides us with two excellent models to study the genetic background of insulin resistance and the metabolic syndrome.

\section{FAMILIAL COMBINED HYPERLIPIDEMIA}

FCHL is a combination of heterogeneous dyslipidemias, segregating in families and predisposing affected individuals to early-onset cardiovascular disease. It is the most common familial dyslipidemia, and estimated to be responsible for $10-20 \%$ of cardiovascular events before the age of 50 in Western societies (88). The metabolic features of subjects with FCHL are very similar to those of the metabolic syndrome, and most of the patients with FCHL, espe- 
cially the hypertriglyceridemic subjects, meet the NCEP criteria for the metabolic syndrome (57). In fact, FCHL patients develop multiple characteristics of the metabolic syndrome when waist circumference and body mass index are only slightly increased, reflecting their strong genetic predisposition to insulin resistance $(90,91)$. Purnell and colleagues showed that for any level of insulin sensitivity or abdominal obesity, apoB levels were higher in the FCHL subjects than in control subjects. They concluded that, although visceral obesity and insulin resistance are important determinants of increased apoB levels and the hyperlipidemic phenotype in FCHL, they cannot fully account for them, and that additive, genetic determinants are involved in the etiology of the lipid phenotype (92). Data from our own lab provided confirmatory evidence. For any level of abdominal obesity, apoB- and lipid levels were higher in FCHLpatients than in their spouses (91). The strong genetic component in FCHL makes it an excellent model to study the genetic background of metabolic syndrome and insulin resistance. Conversely, FCHL-related research findings can be highly relevant for our understanding of the pathogenesis of the metabolic syndrome and insulin resistance. Of note, although overt insulin resistance is obvious, FCHL patients are not particularly prone to develop type 2 diabetes.

\section{TYPE 2 DIABETES}

The vast majority $(80-90 \%)$ of patients with type 2 diabetes meet the criteria of the metabolic syndrome. Several lines of evidence further support the view that genetic components also play an important role in the pathogenesis of type 2 diabetes. Data from the Framingham Offspring study showed that, when one parent was affected, the risk of type 2 diabetes in the offspring was 3.5 fold increased compared to subjects in the general population, and even 6 fold when both parents were affected (93). Furthermore, the high concordance rate in monozygotic twins, and the $50 \%$ fall in dizygotic twins further strengthen the concept that DM2 has a strong genetic component of (94-98). Additional evidence comes from admixture studies. The prevalence of type 2 diabetes varies greatly in different ethnic groups, from $1 \%$ in rural Chinese areas to $50 \%$ in Nauruans and Pima Indians (99). Moreover, the prevalence of type 2 diabetes in Pima Indians is inversely related to the extent of interbreeding with European Americans (100). Similar findings have been reported for Nauruans (101). The ultimate proof for inherited risk to type 2 diabetes and Familial 
Combined Hyperlipidemia comes from the identification of susceptibility genes predisposing to these diseases.

\section{OUTLINE OF THIS THESIS}

The central aim of this thesis was to identify novel genes and pathways that underlie the pathophysiology of insulin resistance, using FCHL and type 2 diabetes as a model. Since FCHL and type 2 diabetes are postulated to share substantial genetic overlap, our side by side research design also provides an unique opportunity to investigate whether established and novel susceptibility genes for FCHL confer also increased risk to type 2 diabetes and vice versa. In Chapter 2 we provide an update on the present understanding of genes that underlie FCHL and type 2 diabetes. The first experimental chapter (Chapter 3) is the basis of this thesis. It describes a gene expression study conducted on cultured pre-adipocytes from patients with FCHL and healthy control subjects. The use of cultured human cells instead of freshly isolated adipocytes allowed us to suppress adaptive gene expression differences and preserve the (epi)genetic effects. This approach revealed increased CD36-expression and CD36-functionality as a novel, potentially important feature of FCHL adipose tissue. Furthermore gene-expression data of chapter 3 and another expression array were integrated with results from linkage analyses and led to the identification of Activating Transcription Factor 6 (ATF6) as a new candidate gene for type 2 diabetes in Chapter 4. The potential significance of ATF6 is extended in Chapter 5 were we demonstrate association of an exonic variant in ATF6 with FCHL in three independent samples from Dutch and Finnish origin. In vitro studies support the genetic data and unequivocally implicate the ATF6 exon polymorphism as a causal variant. Together, results from chapter 4 and 5 provide proof for the postulated shared genetic background in FCHL and type 2 diabetes, and highlight the endoplasmic reticulum stress response, a novel pathway in the pathophysiology of insulin resistance and dyslipidemia. Chapter 6 evaluates the well-established FCHL-susceptibility gene Upstream Stimulatory Factor 1 (USF1), for its potential role in type 2 diabetes in two large Dutch case control samples comprising more than 2000 individuals. In Chapter 7 we put all data in perspective, discuss their potential relevance for diagnostic or screening purposes, and integrate them with emerging insights in the field 
of insulin resistance, with emphasis on the endoplasmic reticulum stress response.

\section{REFERENCES}

1. Reaven GM 1988 Banting lecture 1988. Role of insulin resistance in human disease. Diabetes 37:1595-607

2. Grundy SM, Hansen B, Smith SC, Jr., Cleeman JI, Kahn RA 2004 Clinical management of metabolic syndrome: report of the American Heart Association/National Heart, Lung, and Blood Institute/American Diabetes Association conference on scientific issues related to management. Circulation 109:551-6

3. Eckel RH, Grundy SM, Zimmet PZ 2005 The metabolic syndrome. Lancet 365:1415-28

4. Haffner S, Taegtmeyer H 2003 Epidemic obesity and the metabolic syndrome. Circulation 108:1541-5

5. Grundy SM 2006 Metabolic syndrome: connecting and reconciling cardiovascular and diabetes worlds. J Am Coll Cardiol 47:1093-100

6. Babu A, Fogelfeld L 2006 Metabolic syndrome and prediabetes. Dis Mon 52:55-144

7. Alberti KG, Zimmet PZ 1998 Definition, diagnosis and classification of diabetes mellitus and its complications. Part 1: diagnosis and classification of diabetes mellitus provisional report of a WHO consultation. Diabet Med 15:539-53

8. 1999 World Health Organisation. Definition, Diagnosis and Classification of Diabetes Mellitus and its Complications: report of a WHO consultation.

9. Balkau B, Charles MA 1999 Comment on the provisional report from the WHO consultation. European Group for the Study of Insulin Resistance (EGIR). Diabet Med 16:442-3

10. 2001 Executive Summary of The Third Report of The National Cholesterol Education Program (NCEP) Expert Panel on Detection, Evaluation, And Treatment of High Blood Cholesterol In Adults (Adult Treatment Panel III). Jama 285:2486-97

11. Einhorn D, Reaven GM, Cobin RH, et al. 2003 American College of Endocrinology position statement on the insulin resistance syndrome. Endocr Pract 9:237-52

12. Alberti KG, Zimmet P, Shaw J 2005 The metabolic syndrome--a new worldwide definition. Lancet 366:1059-62

13. Grundy SM, Cleeman JI, Daniels SR, et al. 2005 Diagnosis and management of the metabolic syndrome: an American Heart Association/National Heart, Lung, and Blood Institute Scientific Statement. Circulation 112:2735-52

14. Kahn R, Buse J, Ferrannini E, Stern M 2005 The metabolic syndrome: time for a critical appraisal. Joint statement from the American Diabetes Association and the European Association for the Study of Diabetes. Diabetologia 48:1684-99

15. Kahn R 2007 Metabolic syndrome: is it a syndrome? Does it matter? Circulation 115:180610; discussion 1811

16. Wang J, Ruotsalainen S, Moilanen L, Lepisto P, Laakso M, Kuusisto J 2007 The metabolic syndrome predicts cardiovascular mortality: a 13-year follow-up study in elderly nondiabetic Finns. Eur Heart J 
17. Yarnell JW, Patterson CC, Bainton D, Sweetnam PM 1998 Is metabolic syndrome a discrete entity in the general population? Evidence from the Caerphilly and Speedwell population studies. Heart 79:248-52

18. McNeill AM, Rosamond WD, Girman CJ, et al. 2005 The metabolic syndrome and 11year risk of incident cardiovascular disease in the atherosclerosis risk in communities study. Diabetes Care 28:385-90

19. Sundstrom J, Vallhagen E, Riserus U, et al. 2006 Risk associated with the metabolic syndrome versus the sum of its individual components. Diabetes Care 29:1673-4

20. Yach D, Stuckler D, Brownell KD 2006 Epidemiologic and economic consequences of the global epidemics of obesity and diabetes. Nat Med 12:62-6

21. Wild S, Roglic G, Green A, Sicree R, King H 2004 Global prevalence of diabetes: estimates for the year 2000 and projections for 2030. Diabetes Care 27:1047-53

22. Carey DG, Jenkins AB, Campbell LV, Freund J, Chisholm DJ 1996 Abdominal fat and insulin resistance in normal and overweight women: Direct measurements reveal a strong relationship in subjects at both low and high risk of NIDDM. Diabetes 45:633-8

23. Park YW, Zhu S, Palaniappan L, Heshka S, Carnethon MR, Heymsfield SB 2003 The metabolic syndrome: prevalence and associated risk factor findings in the US population from the Third National Health and Nutrition Examination Survey, 1988-1994. Arch Intern Med 163:427-36

24. Lemieux I, Pascot A, Couillard C, et al. 2000 Hypertriglyceridemic waist: A marker of the atherogenic metabolic triad (hyperinsulinemia; hyperapolipoprotein B; small, dense LDL) in men? Circulation 102:179-84

25. Carr DB, Utzschneider KM, Hull RL, et al. 2004 Intra-abdominal fat is a major determinant of the National Cholesterol Education Program Adult Treatment Panel III criteria for the metabolic syndrome. Diabetes 53:2087-94

26. Doll S, Paccaud F, Bovet P, Burnier M, Wietlisbach V 2002 Body mass index, abdominal adiposity and blood pressure: consistency of their association across developing and developed countries. Int J Obes Relat Metab Disord 26:48-57

27. Rexrode KM, Buring JE, Manson JE 2001 Abdominal and total adiposity and risk of coronary heart disease in men. Int J Obes Relat Metab Disord 25:1047-56

28. Rexrode KM, Carey VJ, Hennekens CH, et al. 1998 Abdominal adiposity and coronary heart disease in women. Jama 280:1843-8

29. Folsom AR, Kushi LH, Anderson KE, et al. 2000 Associations of general and abdominal obesity with multiple health outcomes in older women: the Iowa Women's Health Study. Arch Intern Med 160:2117-28

30. Bergman RN, Van Citters GW, Mittelman SD, et al. 2001 Central role of the adipocyte in the metabolic syndrome. J Investig Med 49:119-26

31. Donnelly KL, Smith CI, Schwarzenberg SJ, Jessurun J, Boldt MD, Parks EJ 2005 Sources of fatty acids stored in liver and secreted via lipoproteins in patients with nonalcoholic fatty liver disease. J Clin Invest 115:1343-51

32. Tamura S, Shimomura I 2005 Contribution of adipose tissue and de novo lipogenesis to nonalcoholic fatty liver disease. J Clin Invest 115:1139-42

33. Browning JD, Horton JD 2004 Molecular mediators of hepatic steatosis and liver injury. J Clin Invest 114:147-52

34. Shimomura I, Bashmakov Y, Horton JD 1999 Increased levels of nuclear SREBP-1c associated with fatty livers in two mouse models of diabetes mellitus. J Biol Chem 274:3002832 
35. Koo SH, Dutcher AK, Towle HC 2001 Glucose and insulin function through two distinct transcription factors to stimulate expression of lipogenic enzyme genes in liver. J Biol Chem 276:9437-45

36. Itani SI, Ruderman NB, Schmieder F, Boden G 2002 Lipid-induced insulin resistance in human muscle is associated with changes in diacylglycerol, protein kinase $C$, and IkappaB-alpha. Diabetes 51:2005-11

37. Kim JK, Fillmore JJ, Sunshine MJ, et al. 2004 PKC-theta knockout mice are protected from fat-induced insulin resistance. J Clin Invest 114:823-7

38. Hotamisligil GS, Shargill NS, Spiegelman BM 1993 Adipose expression of tumor necrosis factor-alpha: direct role in obesity-linked insulin resistance. Science 259:87-91

39. Feinstein R, Kanety H, Papa MZ, Lunenfeld B, Karasik A 1993 Tumor necrosis factoralpha suppresses insulin-induced tyrosine phosphorylation of insulin receptor and its substrates. J Biol Chem 268:26055-8

40. Shoelson SE, Lee J, Goldfine AB 2006 Inflammation and insulin resistance. J Clin Invest 116:1793-801

41. Berg AH, Scherer PE 2005 Adipose tissue, inflammation, and cardiovascular disease. Circ Res 96:939-49

42. Scherer PE, Williams S, Fogliano M, Baldini G, Lodish HF 1995 A novel serum protein similar to C1q, produced exclusively in adipocytes. J Biol Chem 270:26746-9

43. Tilg H, Hotamisligil GS 2006 Nonalcoholic fatty liver disease: Cytokine-adipokine interplay and regulation of insulin resistance. Gastroenterology 131:934-45

44. Weisberg SP, McCann D, Desai M, Rosenbaum M, Leibel RL, Ferrante AW, Jr. 2003 Obesity is associated with macrophage accumulation in adipose tissue. J Clin Invest 112:1796-808

45. Xu H, Barnes GT, Yang Q, et al. 2003 Chronic inflammation in fat plays a crucial role in the development of obesity-related insulin resistance. J Clin Invest 112:1821-30

46. Kanda H, Tateya S, Tamori Y, et al. 2006 MCP-1 contributes to macrophage infiltration into adipose tissue, insulin resistance, and hepatic steatosis in obesity. J Clin Invest 116:1494-505

47. Weisberg SP, Hunter D, Huber R, et al. 2006 CCR2 modulates inflammatory and metabolic effects of high-fat feeding. J Clin Invest 116:115-24

48. Cai D, Yuan M, Frantz DF, et al. 2005 Local and systemic insulin resistance resulting from hepatic activation of IKK-beta and NF-kappaB. Nat Med 11:183-90

49. Juhan-Vague I, Morange PE, Alessi MC 2002 The insulin resistance syndrome: implications for thrombosis and cardiovascular disease. Pathophysiol Haemost Thromb 32:26973

50. Aguirre V, Uchida T, Yenush L, Davis R, White MF 2000 The c-Jun NH(2)-terminal kinase promotes insulin resistance during association with insulin receptor substrate- 1 and phosphorylation of Ser(307). J Biol Chem 275:9047-54

51. Hirosumi J, Tuncman G, Chang L, et al. 2002 A central role for JNK in obesity and insulin resistance. Nature 420:333-6

52. Adiels M, Olofsson SO, Taskinen MR, Boren J 2006 Diabetic dyslipidaemia. Curr Opin Lipidol 17:238-46

53. Taskinen MR 2003 Diabetic dyslipidaemia: from basic research to clinical practice. Diabetologia 46:733-49 
54. Kelley DE, McKolanis TM, Hegazi RA, Kuller LH, Kalhan SC 2003 Fatty liver in type 2 diabetes mellitus: relation to regional adiposity, fatty acids, and insulin resistance. Am J Physiol Endocrinol Metab 285:E906-16

55. Marsh JB 2003 Lipoprotein metabolism in obesity and diabetes: insights from stable isotope kinetic studies in humans. Nutr Rev 61:363-75

56. Lewis GF, Uffelman KD, Szeto LW, Weller B, Steiner G 1995 Interaction between free fatty acids and insulin in the acute control of very low density lipoprotein production in humans. J Clin Invest 95:158-66

57. Carr MC, Brunzell JD 2004 Abdominal obesity and dyslipidemia in the metabolic syndrome: importance of type 2 diabetes and familial combined hyperlipidemia in coronary artery disease risk. J Clin Endocrinol Metab 89:2601-7

58. Malmstrom R, Packard CJ, Caslake M, et al. 1997 Defective regulation of triglyceride metabolism by insulin in the liver in NIDDM. Diabetologia 40:454-62

59. Ginsberg HN 2006 REVIEW: Efficacy and mechanisms of action of statins in the treatment of diabetic dyslipidemia. J Clin Endocrinol Metab 91:383-92

60. Pykalisto OJ, Smith PH, Brunzell JD 1975 Determinants of human adipose tissue lipoprotein lipase. Effect of diabetes and obesity on basal- and diet-induced activity. J Clin Invest 56:1108-17

61. Taskinen MR, Nikkila EA, Kuusi T, Harmo K 1982 Lipoprotein lipase activity and serum lipoproteins in untreated type 2 (insulin-independent) diabetes associated with obesity. Diabetologia 22:46-50

62. Austin MA, Breslow JL, Hennekens CH, Buring JE, Willett WC, Krauss RM 1988 Lowdensity lipoprotein subclass patterns and risk of myocardial infarction. Jama 260:1917-21

63. Stampfer MJ, Krauss RM, Ma J, et al. 1996 A prospective study of triglyceride level, lowdensity lipoprotein particle diameter, and risk of myocardial infarction. Jama 276:882-8

64. Lamarche B, Tchernof A, Moorjani S, et al. 1997 Small, dense low-density lipoprotein particles as a predictor of the risk of ischemic heart disease in men. Prospective results from the Quebec Cardiovascular Study. Circulation 95:69-75

65. Zambon A, Hokanson JE, Brown BG, Brunzell JD 1999 Evidence for a new pathophysiological mechanism for coronary artery disease regression: hepatic lipase-mediated changes in LDL density. Circulation 99:1959-64

66. Bjornheden T, Babyi A, Bondjers G, Wiklund O 1996 Accumulation of lipoprotein fractions and subfractions in the arterial wall, determined in an in vitro perfusion system. Atherosclerosis 123:43-56

67. Hurt-Camejo E, Camejo G, Rosengren B, Lopez F, Wiklund O, Bondjers G 1990 Differential uptake of proteoglycan-selected subfractions of low density lipoprotein by human macrophages. J Lipid Res 31:1387-98

68. Chait A, Brazg RL, Tribble DL, Krauss RM 1993 Susceptibility of small, dense, lowdensity lipoproteins to oxidative modification in subjects with the atherogenic lipoprotein phenotype, pattern B. Am J Med 94:350-6

69. Tribble DL, Rizzo M, Chait A, Lewis DM, Blanche PJ, Krauss RM 2001 Enhanced oxidative susceptibility and reduced antioxidant content of metabolic precursors of small, dense low-density lipoproteins. Am J Med 110:103-10

70. DeFronzo RA, Bonadonna RC, Ferrannini E 1992 Pathogenesis of NIDDM. A balanced overview. Diabetes Care 15:318-68 
71. Steil GM, Trivedi N, Jonas JC, et al. 2001 Adaptation of beta-cell mass to substrate oversupply: enhanced function with normal gene expression. Am J Physiol Endocrinol Metab 280:E788-96

72. Chen C, Hosokawa H, Bumbalo LM, Leahy JL 1994 Mechanism of compensatory hyperinsulinemia in normoglycemic insulin-resistant spontaneously hypertensive rats. Augmented enzymatic activity of glucokinase in beta-cells. J Clin Invest 94:399-404

73. Cavaghan MK, Ehrmann DA, Polonsky KS 2000 Interactions between insulin resistance and insulin secretion in the development of glucose intolerance. J Clin Invest 106:329-33

74. Prentki M, Nolan CJ 2006 Islet beta cell failure in type 2 diabetes. J Clin Invest 116:180212

75. Crespin SR, Greenough WB, 3rd, Steinberg D 1973 Stimulation of insulin secretion by long-chain free fatty acids. A direct pancreatic effect. J Clin Invest 52:1979-84

76. Stein DT, Esser V, Stevenson BE, et al. 1996 Essentiality of circulating fatty acids for glucose-stimulated insulin secretion in the fasted rat. J Clin Invest 97:2728-35

77. Hirose H, Lee YH, Inman LR, Nagasawa Y, Johnson JH, Unger RH 1996 Defective fatty acid-mediated beta-cell compensation in Zucker diabetic fatty rats. Pathogenic implications for obesity-dependent diabetes. J Biol Chem 271:5633-7

78. Carpentier A, Mittelman SD, Bergman RN, Giacca A, Lewis GF 2000 Prolonged elevation of plasma free fatty acids impairs pancreatic beta-cell function in obese nondiabetic humans but not in individuals with type 2 diabetes. Diabetes 49:399-408

79. Dubois M, Kerr-Conte J, Gmyr V, et al. 2004 Non-esterified fatty acids are deleterious for human pancreatic islet function at physiological glucose concentration. Diabetologia 47:463-9

80. Garrison RJ, Kannel WB, Stokes J, 3rd, Castelli WP 1987 Incidence and precursors of hypertension in young adults: the Framingham Offspring Study. Prev Med 16:235-51

81. Tooke JE, Hannemann MM 2000 Adverse endothelial function and the insulin resistance syndrome. J Intern Med 247:425-31

82. Kuroda S, Uzu T, Fujii T, et al. 1999 Role of insulin resistance in the genesis of sodium sensitivity in essential hypertension. J Hum Hypertens 13:257-62

83. Egan BM 2003 Insulin resistance and the sympathetic nervous system. Curr Hypertens Rep 5:247-54

84. Tripathy D, Mohanty P, Dhindsa S, et al. 2003 Elevation of free fatty acids induces inflammation and impairs vascular reactivity in healthy subjects. Diabetes 52:2882-7

85. Grekin RJ, Vollmer AP, Sider RS 1995 Pressor effects of portal venous oleate infusion. A proposed mechanism for obesity hypertension. Hypertension 26:193-8

86. Bernal-Mizrachi C, Weng S, Li B, et al. 2002 Respiratory uncoupling lowers blood pressure through a leptin-dependent mechanism in genetically obese mice. Arterioscler Thromb Vasc Biol 22:961-8

87. Haynes WG, Sivitz WI, Morgan DA, Walsh SA, Mark AL 1997 Sympathetic and cardiorenal actions of leptin. Hypertension 30:619-23

88. Naukkarinen J, Ehnholm C, Peltonen L 2006 Genetics of familial combined hyperlipidemia. Curr Opin Lipidol 17:285-90

89. Hopkins PN, Heiss G, Ellison RC, et al. 2003 Coronary artery disease risk in familial combined hyperlipidemia and familial hypertriglyceridemia: a case-control comparison from the National Heart, Lung, and Blood Institute Family Heart Study. Circulation 108:519-23 
90. Borgman M, McErlean E 2006 What is the metabolic syndrome? Prediabetes and cardiovascular risk. J Cardiovasc Nurs 21:285-90

91. van der Kallen CJ, Voors-Pette C, de Bruin TW 2004 Abdominal obesity and expression of familial combined hyperlipidemia. Obes Res 12:2054-61

92. Purnell JQ, Kahn SE, Schwartz RS, Brunzell JD 2001 Relationship of insulin sensitivity and ApoB levels to intra-abdominal fat in subjects with familial combined hyperlipidemia. Arterioscler Thromb Vasc Biol 21:567-72

93. Meigs JB, Cupples LA, Wilson PW 2000 Parental transmission of type 2 diabetes: the Framingham Offspring Study. Diabetes 49:2201-7

94. Kaprio J, Tuomilehto J, Koskenvuo M, et al. 1992 Concordance for type 1 (insulindependent) and type 2 (non-insulin-dependent) diabetes mellitus in a population-based cohort of twins in Finland. Diabetologia 35:1060-7

95. Barnett AH, Eff C, Leslie RD, Pyke DA 1981 Diabetes in identical twins. A study of 200 pairs. Diabetologia 20:87-93

96. Newman B, Selby JV, King MC, Slemenda C, Fabsitz R, Friedman GD 1987 Concordance for type 2 (non-insulin-dependent) diabetes mellitus in male twins. Diabetologia 30:763-8

97. Poulsen P, Kyvik KO, Vaag A, Beck-Nielsen H 1999 Heritability of type II (non-insulindependent) diabetes mellitus and abnormal glucose tolerance--a population-based twin study. Diabetologia 42:139-45

98. Medici F, Hawa M, Ianari A, Pyke DA, Leslie RD 1999 Concordance rate for type II diabetes mellitus in monozygotic twins: actuarial analysis. Diabetologia 42:146-50

99. King H, Rewers M 1993 Global estimates for prevalence of diabetes mellitus and impaired glucose tolerance in adults. WHO Ad Hoc Diabetes Reporting Group. Diabetes Care 16:157-77

100. Knowler WC, Bennett PH, Hamman RF, Miller M 1978 Diabetes incidence and prevalence in Pima Indians: a 19-fold greater incidence than in Rochester, Minnesota. Am J Epidemiol 108:497-505

101. Serjeantson SW, Owerbach D, Zimmet P, Nerup J, Thoma K 1983 Genetics of diabetes in Nauru: effects of foreign admixture, HLA antigens and the insulin-gene-linked polymorphism. Diabetologia 25:13-7 


\section{Chapter 2}

Genetic Approaches to the Molecular Understanding of Type 2 Diabetes and Familial Combined Hyperlipidemia 


\section{Introduction}

In contrast to other approaches to the dissection of pathophysiological mechanisms, genetic studies have the advantage of establishing chains of causality, since physiological changes are the result of genomic variation, and never the reverse (1).

The genetic dissection of non-mendelian, or so-called "complex diseases", is extremely challenging. Familial combined hyperlipidemia and type 2 diabetes are typical examples of such complex diseases with substantial genetic heterogeneity. At the molecular level they cannot be looked upon as one disease, but in fact include different molecular disorders which are grouped together because they manifest with the same (combination of) phenotype(s). Obviously this leads to a dilution of effects and consequently loss of power in genetic studies. A major task of genetic research includes providing clarity in the different categories of diabetes and hyperlipidemia, and allowing more specific classification and possibly clinical treatment. For diabetes several subgroups with autosomal dominant inheritance (Maturity-onset Diabetes of the Young, reviewed in $(2,3)$ ), or a specific pathway involved (Mitochondrial diabetes (4)) have been successfully identified.

Two main approaches have been employed to unravel the genetic background of complex diseases such as DM2 and FCHL: a candidate gene approach and a positional cloning approach. Valuable complementary approaches to help directing the search for candidate genes include the use of gene expression experiments, and animal models. An overview of the candidate gene approach and positional cloning approach to susceptibility gene identification for DM2 and FCHL, as well as their individual strengths and drawbacks, is described below. It should be noted that the skewed attention in favor of results from the diabetes field reflects the attention given to these disorders by the scientific community, and explain why several DM2 genes have not been tested for their potential role in FCHL, despite the fact that they are attractive biological candidates. 


\section{The candidate gene approach}

\section{Candidate genes selected for their biologic plausibility}

Most association studies have been conducted on genes, identified through their known function in a relevant physiologic pathway. Given the present incomplete knowledge of the pathogenesis of DM2 and FCHL, the list of potentially interesting genes is large. In fact, it includes -without being limited to- all genes whose proteins are involved in, adipocyte-, muscle-, hepatocyteand beta cell-function, insulin signaling pathways and hypothalamic regulation. It can be expected that only a small subset of these candidates will harbor genetic variants that substantially contribute to the population attributive risk. Several tens and hundreds of biological candidate genes have been genetically explored in relation to FCHL and DM2 respectively. Although many of them showed modest associations in single populations, replication studies often failed to confirm the initial results, preventing definitive statements on their involvement. Genes with abundant evidence for conferring genetic risk to DM2, FCHL or both are discussed below.

\section{Box 1. Diagnostic problems in FCHL}

In addition to the genetic complexity in itself, FCHL research is additionally complicated by diagnostic disagreements. Because no single pathognomonic marker is available for the diagnosis of FCHL in an individual, family studies are needed to establish the diagnosis. However in this family based diagnostic process, different research groups applied different criteria to categorize members of FCHL families either as affected, or unaffected. Fixed cut-off values as well as age-and sex-specific 90-95th population percentiles have been used to distinguish normolipidemic relatives from affected family members $(5,6)$. Also the incorporation of apolipoprotein B in the diagnostic criteria has been advocated (7-11), but until now only applied in a limited fashion (12).

The absence of uniform diagnostic criteria for FCHL, like we do have for DM2, impedes the direct comparison of genetic studies from different research groups, and likely contributes to the inconsistencies encountered when aiming to replicate results from linkage and association studies. Obviously, the fact that many studies are actually underpowered, increasing the chance of type 1 and type 2 errors, is the main reason. Some efforts have been made to work towards a uniform diagnostic consensus for FCHL (9), but in analogy to the attempts being made for a uniform diagnosis of the metabolic syndrome, this appears an extremely demanding and diplomatic process.

\section{Peroxisomal Proliferator-Activated Receptor gamma (PPAR $\gamma$ )}

PPAR $\gamma$ is a member of the nuclear hormone receptor superfamily of transcription factors, and a target of thiazolidinediones, a widely used class of insulin sensitizers. PPAR $\gamma$ was initially selected as a candidate gene for DM2 because 
of its key role in adipogenesis and adipocyte function (13). Multiple studies investigated the common Pro[12]Ala variant in the PPAR $\gamma 2$-isoform for association with type 2 diabetes, Familial Combined Hyperlipidemia, the metabolic syndrome and related traits. An initial study reported that the alanine allele reduce DM2 risk with $75 \%$ (13). Subsequent smaller -often underpoweredstudies provided inconclusive results (14-17), but as larger cohorts were examined and results combined, a consistent relative risk of 1.25 could be attributed to carriers of the proline allele $(18,19)$. The potential contribution of Pro[12]Ala on FCHL has been investigated in the Finnish and Dutch population $(20,21)$. In Finns, the [12]Ala allele was associated with less severe manifestations of both insulin resistance and unfavorable lipid- and lipoprotein phenotypes (20). In the Dutch study, significant associations with free fatty acid levels and glycerol were reported (21). Also associations of the Pro[12]Ala-variant and other metabolic syndrome-related traits have been described in populations not ascertained for DM2 or FCHL (22). Finally, other naturally occurring substitutions in the PPAR $\gamma$-gene, Pro[467]Leu and Val[290]Met, cause insulin resistance, hypertension, hypertriglyceridemia, and early-onset diabetes (23). Together, these data have given $\operatorname{PPAR} \gamma$, as one of the first genes in this field of research, the status of generally accepted genetic risk factor for DM2 and the metabolic syndrome. PPAR $\gamma$ is an excellent example to illustrate the potential importance of "common alleles of weak effects": although the Pro[12]Ala substitution has only a modest effect for individuals carrying the risk variant (odds ratio $\approx 1.25$ ), it has dramatic impact at the population level. As much as $85 \%$ of subjects carry the risk allele (proline), which translates in a population attributive risk of $25 \%$ (18). This means, that if the population were monomorphic for the protective alanine allele, the prevalence of type 2 diabetes would be $25 \%$ lower. PPAR $\gamma$ is also particularly appropriate to illustrate the limitations of linkage studies in common diseases. Despite the population impact of the risk allele, its contribution would have never been discovered by linkage analysis. Since the risk allele would typically be transmitted from both parents, a genome scan of approximately 3 million sib pairs would be required to obtain a LOD peak of 3 (18). Admittedly, PPAR $\gamma$ Pro[12]Ala may represent an extreme example, but it illustrates one of the aspects why power to detect linkage for common diseases is generally considerably lower than for rare mendelian diseases (24). 


\section{Peroxisome proliferator activated receptor- $\gamma$ co-activator-1 $\alpha$ (PGC1 $\alpha$ )}

A promising candidate gene for DM2 is PGC1 $\alpha$. PGC1 $\alpha$ is a transcriptional co activator of a series of nuclear receptors, including PPAR $\gamma$. Modest downregulation of PGC1 $\alpha$, was shown to affect the expression of a whole set of genes involved in oxidative phosphorylation, influencing total body aerobic capacity, which can be very important in muscle (25). The gly[482]ser variant was associated with type 2 diabetes and related traits in many (26-30), but not all studies (31). Also significant associations with metabolic syndrome related traits such as hypertension $(32,33)$ and obesity $(34)$ have been reported.

\section{Peroxisomal Proliferator-Activated Receptor alpha (PPAR $\alpha$ )}

PPAR $\alpha$ is a member of the nuclear hormone receptor superfamily of ligandregulated transcription factors, and a master regulator of fatty acid metabolism. Activation of PPAR $\alpha$ causes a dramatic lowering of plasma, hepatic, and intramuscular triglycerides. The fibrate class of lipid-lowering drugs are ligands for PPAR $\alpha$ (35). Although it represents an excellent candidate gene from a biologic point of view, evidence for conferring genetic risk to develop DM2 and FCHL is less abundant than for PPAR $\gamma$. Variation in the PPAR $\alpha$ gene, especially the Leu[162]Val substitution has been subject to genetic research, and was found to influence plasma lipid levels $(36,37)$, and risk of coronary artery disease (38). An association study from our lab demonstrated that PPAR $\alpha$ could act as a modifier gene for FCHL (39). Also PPAR $\alpha$ gene variation may influence onset and progression of type 2 diabetes (40). Nonetheless, results remain equivocal (41) and await meta-analysis for conclusive interpretation.

\section{The apolipoprotein A1/C3/A4/A5 gene cluster}

Apolipoproteins are lipid binding proteins that are involved in the transport of lipids in plasma. Defects in apolipoprotein structure or synthesis may affect lipid metabolism and result in increased susceptibility to cardiovascular disease. The chromosomal region 11q23-q24 harbors 4 tightly clustered apolipoprotein genes, and is a well investigated locus for FCHL.

Strong linkage between the apolipoprotein A1/C3/A4 and FCHL was first reported in 1991 by Wojciechowski and colleagues (42). Apolipoprotein A5, a new member of this gene cluster was only recently identified and shown to modulate plasma triglycerides in mice and humans (43). Meanwhile several research groups have investigated the contribution of the apolipoprotein 
A1/C3/A4/A5 gene cluster in the pathogenesis of FCHL using linkage and/or association analyses. Most, but not all reports (44), confirmed a potential modulating effect of this locus on HDL cholesterol and triglyceride levels, especially for variants in aplolipoprotein C3 and apolipoprotein A5 (45-51). Due to the strong linkage disequilibrium between the genes in this cluster it has proven challenging to identify the true contribution of each separate gene. According to the current thinking, apolipoprotein C3 and apolipoprotein A5 harbor independent risk alleles for HDL cholesterol and triglyceride levels (52).

\section{The $\beta$-cell potassium channel: KCNJ11 and ABCC8}

In pancreatic beta cells, ATP-potassium channels are crucial for the regulation of glucose-induced insulin secretion and are the target for the sulfonylureas, oral hypoglycemic agents widely used in the treatment of noninsulindependent diabetes mellitus. The $\beta$-cell potassium channel comprises two subunits: the channel itself encoded by the KCNJ11-gene (alias kir6.2 or BIR) and a regulatory subunit, encoded by the neighboring gene $A B C C 8$, which binds sulfonylureas and ATP. Most attention has focused on the Gly[23]Lys variant in KCNJ11, which in most studies is consistently associated with a modest odds ratio (approximately 1.2) for DM2 (53-56). Despite accumulating genetic evidence for this polymorphism, it remains to be established whether it is the sole or the best marker of DM2 susceptibility at this locus, as significant LD extends into the neighboring ABCC8 gene. In fact, the Gly[23]Lys variant is almost in complete LD with a serine to alanine change at position 1369 in ABCC8, and thus Gly[23]Lys and Ser[1369]Ala are genetically undistinguishable. Not surprisingly KCNJ11 and ABCC 8 have not been explored in relation to FCHL, lipid metabolism or the metabolic syndrome, as they do not represent the most attractive candidates for modulating these traits.

\section{Candidate genes from monogenic diseases: Same gene, different muta- tions in rare and common forms of disease}

The study of subjects with extreme phenotypes, or exceptional families segregating a disease in a Mendelian fashion, provided significant insight in the molecular pathogenesis of common complex diseases. A recurrent observation is that different variations in the same gene cause rare (often severe) and common (often mild) forms of disease. Typical examples include PPAR $\gamma$ (Pro[115]Gln causes severe obesity, whereas Pro[12]Ala increases susceptibility to DM2) (57), LMNA encoding Lamin A/C (mutations cause lipodystrophy 
whereas common variants are potentially involved in DM2, the metabolic syndrome and dyslipidemia) $(58,59)$. Box 2 describes three additional examples of rare and common variants in the same gene

\section{Box 2}

Maturity-Onset Diabetes of the Young (MODY) is a rare autosomal dominant inherited form of common diabetes, accounting for $1-5 \%$ of diabetes mellitus in western societies (60). It is characterized by early onset, usually before 25 years of age, primary $\beta$-cell defect and lack of association with obesity (2). At present, six genes can functionally be linked to MODY: HNF4 $\alpha, G C K, H N F 1 \alpha, I P F 1, H N F 1 \beta$ and NEUROD1. All these genes are expressed in pancreatic $\beta$-cells, and all except for GCK code for transcription factors with a role in $\beta$-cell development and function (reviewed in $(2,3)$. Since 15-20\% of MODY families are not linked to polymorphisms in known genes, the genetic background of MODY has not yet been fully unraveled. The close clinical and physiological overlap of MODY and common DM2 triggered several research groups to investigate common variants in MODY genes for their contribution to inherited susceptibility to common type 2 diabetes. Preliminary evidence is now emerging that common variants in at least 5 of 6 MODY genes also predispose to common type 2 diabetes (61). However, strong and consistent evidence is currently limited to variants in HNF4 $\alpha$ (62-70). Interestingly, variants and haplotypes in HNF4 $\alpha$ were also associated with increased serum lipid levels and the metabolic syndrome in families with FCHL from Finland and Mexico (71).

Autosomal Dominant Familial Hypercholesterolemia (FH) (prevalence 1:500) is characterized by increased levels of (LDL)-cholesterol levels and early coronary artery disease, typically before the age of 50. FH is associated with mutations in the low density lipoprotein-receptor, apolipoprotein B or proprotein convertase subtilisin/kexin type 9 (PCSK9). PCSK9, which regulates the degradation rate of the LDL-receptor, was only recently identified as a third gene for FH (72). The two identified mutations in PCSK9 causing FH are probably gain-of-function mutations, as over expression of PCSK9 in the liver of mice produces hypercholesterolemia by reducing LDL-receptor number (73). Interestingly, various common polymorphisms and haplotypes in PCSK9 do not cause FH, but modulate

(LDL-)cholesterol levels in the general populations to a various degree (74-78). PCSK9 is a very attractive candidate gene for FCHL, but has not yet been tested for segregation with this disease.

Tangier Disease patients have truncating mutations in both alleles (autosomal recessive) of the ATPbinding cassette transporter A1-gene (ABCA1). The ABCA1 gene product regulates the ratecontrolling step in the efflux of cellular cholesterol and phospholipids to an apolipoprotein acceptor. The phenotypic characteristics Tangier Disease are an almost complete absence of HDL-cholesterol, severe deposition of cholesteryl esters in cells of the reticulo-endothelial system, and increased risk for coronary artery disease (79). Tangier disease is extremely rare, affecting approximately 100 patients worldwide. Interestingly, heterozygote family members also present with decreased HDL-cholesterol levels. This stimulated the hypothesis that variants of ABCA1 and other genes in the same pathway might be associated with plasma HDL-cholesterol levels in the general population. Common variants in ABCA1 were found associated with plasma lipid levels and severity of cardiovascular disease (80). In a sample of 9000 Danes from the general population, a common non-synonimous SNP in ABCA1 was associated with extremes of the HDL-cholesterol distribution (81). These studies suggest that common variants of ABCA1 may indeed contribute to the HDL-cholesterol level in the general population. 


\section{The positional cloning approach:}

\section{linkage and linkage disequilibrium analyses}

Candidate gene studies have one obvious major drawback: they are constrained by our fragmentary knowledge of the pathophysiological mechanisms underlying the disease. To overcome this disadvantage of candidate gene studies, the genome wide linkage scan strategy has been applied. This hypothesis-free, unbiased approach attempts to map susceptibility loci, purely on the basis of chromosomal location (82). The underlying expectation is that genes with similar chromosomal positions will only rarely be separated during meiotic recombination. Computational analyses of transmission patterns through successive generations allow localization of susceptibility variants by detecting chromosomal markers that show significant co-segregation with disease. Typically, families are genotyped using a dense set of highly polymorphic microsatellite markers ( 400), covering the genome.

Identification of genes responsible for mendelian or monogenic disorders such as MODY, using linkage analysis has proven very successful the last decade. Efforts have been made to extend this method to complex diseases, and at this moment about thirty whole genome scans for DM2 (reviewed in (83), and 5 for FCHL $(12,84-87)$, have been completed in a wide range of ethnic groups. The yield of these efforts is by far not as good as for monogenic diseases, and there is no single global linkage signal for DM2 or FCHL similar to that generated by HLA in type 1 diabetes. Apart from differences in study design, analytical approaches, family configuration, and ethnic heterogeneity there are two principal reasons for these somewhat disappointing results. First, the power to detect linkage in complex diseases is considerably lower than in a monogenetic setting. By definition, a multifactorial complex trait is determined by the concerted action of multiple genes, interacting with one another and with the environment. The consequence is that the magnitude of a genetic effect, attributable to a single genetic factor is small, or modest at best, and generally large sample sizes are needed for reasonable power of detection. The second explanation is related to diagnostic problems. DM2 and FCHL are so-called late onset diseases with incomplete penetrance, complicating correct classification of subjects. Some research groups have tried to overcome this problem (in part) by focusing on the intermediate quantitative traits, rather than on type 2 diabetes itself $(88,89)$. A concomitant advantage of this approach is that the power available in the analysis of pedigrees is preserved, which would otherwise be considerably reduced by the dichotomization process. 
Despite the absence of one recurrent region in all populations, several chromosomal locations have been linked to disease at a higher frequency than one would expect by chance. It has been argued by prominent researchers in the field that each linkage region will in fact harbor multiple disease genes of small effect, and that no single variant will fully explain the linkage peak (90). The regions with strongest evidence of replication include 1q21-25, 2q, 3q, $8 p, 10 q, 11 q, 12 q, 18 p, 20 q$ for DM2, and 1q21-23, 11p, 16q24.1 and 20q13 for FCHL. All these regions are currently subject to positional cloning efforts to identify the etiological variants. For some of them an underlying susceptibility gene has been identified.

\section{1q21-25}

The 1q21-25 region is the most replicated chromosomal region for FCHL and DM2 $(5,91-100)$. It was first presented as a region that harbors one or more susceptibility genes for FCHL in 1998 (5). Later, its potential relevance was extended to DM2 through a sub analysis of genome scan data from youngonset Pima Indian families (91). After these initial reports, linkage with FCHL was confirmed in families from Germany, China, the United States and Mexico (92-94) and linkage with DM2 was reported Utah Caucasians, Amish, United Kingdom, US Caucasians and two Chinese populations (95-100). Noteworthy, the 1q21-25 locus has also been linked to the metabolic syndrome and related quantitative traits in various populations (101-103). The 1q21-25 region is characterized by a high gene density including several attractive candidate genes for FCHL and/or DM2 such as C-reactive protein, apolipoprotein A II, LMNA (encoding lamin $\mathrm{A} / \mathrm{C}$ ) and IRR (coding for the insulin receptor-related receptor). Probably multiple genes in this region underlie the linkage signal (104). The first convincing evidence for Linkage and association with a susceptibility gene in this region was again reported in families with Familial Combined Hyperlipidemia. Genetic variation in Upstream Stimulatory Factor 1 (USF1) was associated with FCHL and triglyceride levels in Finnish patients, with an impressive level of statistical significance (105). Association with FCHL and related lipid traits was subsequently confirmed in UK Caucasians, Utah Caucasians, Mexicans, and Dutch Caucasians (106-109). Also linkage and association with the metabolic syndrome in Chinese subjects has been reported (110). No coding variants were identified in the USF1-gene, and the SNPs that yielded the strongest statistical evidence for association are located in an intron and the 3'untranslated region. Nevertheless, a potential functional role 
may be ascribed to the intronic SNPs as it resides in a 20 base-pair sequence that binds nuclear proteins, representing a potential transcriptional regulatory element (111). USF1 is a ubiquitously expressed transcription factor that belongs to the basic helix-loop-helix leucine zipper family, and regulates expression of about 40 genes involved in lipid and glucose metabolism. The convincing results for USF1 in relation to FCHL and lipid metabolism, with accompanying $\mathrm{p}$-values in the order of $10^{-7}$, generated enormous enthusiasm and expectation in the DM2- genetics community, and triggered researchers to investigate its potential contribution as a genetic risk factor for DM2. Initially, positive results were reported $(106,110)$, extending the role of USF1 as a risk factor for DM2. However, two more recent analysis using French Caucasian subjects and several populations with evidence of chromosome 1q linkage respectively, failed to pursue the initial positive line of evidence. Additional studies in large, well-characterized cohorts are required to investigate the contribution of USF1 risk alleles to DM2 in distinct populations, and provide robust assessment of effect size. We evaluated the USF1 gene for its potential involvement in type 2 diabetes in two large Dutch case control samples, comprising more than 2000 individuals (Chapter 6 of this thesis). The 1q region is probably the most intensively studied region for DM2 and FCHL, and an international collaborative effort funded by the NIH has been established, "The international 1q consortium", to map the susceptibility genes responsible for replicated linkage signal on chromosome 1q.

\section{$2 q$}

The first chromosomal locus for DM2 was mapped to 2q33-37 (112). Four years later following dense linkage-disequilibrium mapping efforts, Calpain 10 (CAPN10) was identified as the underlying susceptibility gene (113). The road to widespread acceptance of CAPN10 as risk gene for type 2 diabetes was impeded by several factors: 1) CAPN10 was a gene of unknown function with and the potential biological mechanism through which it could be influencing DM2 risk was at first unclear. 2) Associated SNPs were intronic and of unknown functional significance. 3) The linkage signal was only found in Mexican Americans and replication efforts were with varying success (114-121). However, recent functional studies support a biological role for CAPN10 in insulin secretion (122) and a recent meta-analysis comprising over 7000 subjects calculated an odds ratio of 1.2, comparable to the risk allele of PPAR $\gamma$ and KCNJ11/ABCC8 (123). 
$10 q$

Linkage to 10q has been reported in Icelandic subjects and Mexican Americans $(124,125)$. In a subsequent positional cloning effort, Grant and colleagues genotyped 228 microsatellite markers in Icelandic individuals with type 2 diabetes and controls throughout a $10.5 \mathrm{Mb}$ interval on 10q (126). Microsatellite marker DG10S478 in intron 3 of TCF7L2 was strongly associated with DM2 in Icelandic subjects, a Danish Cohort and a US cohort (p-value combined: $4.7^{*}\left(0^{-18}\right)$. A series of replication studies confirmed this finding shortly after the initial report (127-143). In a very short time span TCF7L2 acquired the status of well-accepted DM2 susceptibility gene, exceeding genome wide significance criteria, and with the largest odds ratio for a DM2 susceptibility gene reported thus far (odds ratio for one risk allele $\approx 1.4$; for two risk alleles $\approx 2.0$ ). The high prevalence of the risk allele again translates into a large effect in the context of the population, with calculated population attributive risks from $10-27 \%$. The biological mechanism by which TCF7L2 variants modulate DM2-risk is unclear. The TCF7L2 gene encodes for a transcription factor with a role in the Wnt signaling pathway, involved in very fundamental processes of cell proliferation and differentiation. Evidence for effects on insulin secretion as well as insulin sensitivity has been reported (128). A potential speculative mechanism how TCF7L2 variants may influence type 2 diabetes susceptibility is through altered transcriptional regulation of the insulinotropic hormone glucagon-like peptide-1 (GLP1), a peptide encoded by GCG and expressed in the brain and gut (126). An alternative hypothesis is that variants in TCF7L2 disrupt adipogenesis and/or adipocyte function by altering transcriptional regulation of PPAR $\gamma$, leading to deposition of triglycerides in peripheral tissues and resulting in insulin resistance (128). Functional studies towards unraveling the exact molecular mechanism are keenly awaited.

\section{0q12-13}

The chromosomal region 20q12-13 was one of the first loci with evidence for linkage to DM2, first reported approximately 10 years ago (144). This result has meanwhile been repeatedly replicated in families with DM2 and FCHL $(85,145-151)$. Two interesting candidate genes underlie this region: HNF4 $\alpha$ and PTPN1. HNF4 $\alpha$ is one of the MODY-genes and PTPN1 codes for protein tyrosine phosphatase $1 \mathrm{~B}$, which negatively regulates insulin signaling via dephosphorylating the phosphotyrosine residues of the insulin receptor kinase activation domain. Although the biological pathway is plausible, and results 
from knockout studies highlight PTPN1 as an excellent candidate gene for DM2 (152), robust evidence from association studies remains missing. Although significant (but modest) associations with common non coding SNPs and haplotypes in PTPN1 have been reported with DM2 and related traits (153-155), a large association study comprising more than 7000 Caucasian subjects failed to replicate these findings (156).

\section{Recent developments}

Most recently, thanks to technological and analytical advances a novel approach became available that combines the power of association studies and the unbiased approach of linkage studies. This technique, genome wide association (GWA) study, has until now been applied in a limited fashion. One of the first GWA-studies reported association between a variant in the insulin induced gene 2 (INSIG2) and obesity (157). This finding was confirmed in some studies, but not in most other replication attempts (158-163). Other genes identified by GWA-studies -most of them in 2007- include the lymphotoxin-alpha gene $(164,165)$ (susceptibility to myocardial infarction), SLC30A8 (140, 141, 166, 167), IDE-KIF11-HHEX (140, 141, 166-168), EXT2-ALX4 (141), CDKAL1, CDKAL2(140, 166-169), CDKN2A, CDKN2B (140, 166-168, 170). IGF2BP2 $(140,166,167)$ (susceptibility to type 2 diabetes), FTO $(140,168,171$, 172) (susceptibility to obesity and type 2 diabetes), and GCKR (166) (serum triglycerides). The INSIG2 story illustrates that replication studies are of critical importance to validate the results from GWA-studies. Nevertheless, GWA-studies represent thé major breakthrough for studying complex genetic diseases. The ultimate goal of the genetics community however, is nothing less than fast, affordable "whole-genome-sequencing". According to the Nature Genetics "Question of the Year 2007" website, reaching this goal is a matter of when, rather than if.

\section{Summary}

In this chapter we discussed the various approaches that can be used to dissect the genetic background of complex diseases, and the contribution of each method to our present understanding of the genetic background of FCHL and 
type 2 diabetes. The approach employed in this thesis is a combination of various techniques and can be described as a candidate gene approach, guided by data from gene expression studies and genome wide linkage analyses.

\section{References}

1. McCarthy MI, Froguel P 2002 Genetic approaches to the molecular understanding of type 2 diabetes. Am J Physiol Endocrinol Metab 283:E217-25

2. Fajans SS, Bell GI, Polonsky KS 2001 Molecular mechanisms and clinical pathophysiology of maturity-onset diabetes of the young. N Engl J Med 345:971-80

3. Stride A, Hattersley AT 2002 Different genes, different diabetes: lessons from maturityonset diabetes of the young. Ann Med 34:207-16

4. van den Ouweland JM, Lemkes HH, Ruitenbeek W, et al. 1992 Mutation in mitochondrial tRNA(Leu)(UUR) gene in a large pedigree with maternally transmitted type II diabetes mellitus and deafness. Nat Genet 1:368-71

5. Pajukanta P, Nuotio I, Terwilliger JD, et al. 1998 Linkage of familial combined hyperlipidaemia to chromosome 1q21-q23. Nat Genet 18:369-73

6. Meex SJ, van der Kallen CJ, van Greevenbroek MM, et al. 2005 Up-regulation of CD36/FAT in preadipocytes in familial combined hyperlipidemia. Faseb J 19:2063-5

7. Sniderman AD 2002 How, when, and why to use apolipoprotein B in clinical practice. Am J Cardiol 90:48i-54i

8. Sniderman AD 2004 Applying apoB to the diagnosis and therapy of the atherogenic dyslipoproteinemias: a clinical diagnostic algorithm. Curr Opin Lipidol 15:433-8

9. Sniderman AD, Castro Cabezas M, Ribalta J, et al. 2002 A proposal to redefine familial combined hyperlipidaemia -- third workshop on FCHL held in Barcelona from 3 to 5 May 2001, during the scientific sessions of the European Society for Clinical Investigation. Eur J Clin Invest 32:71-3

10. Sniderman AD, Ribalta J, Castro Cabezas M 2001 How should FCHL be defined and how should we think about its metabolic bases? Nutr Metab Cardiovasc Dis 11:259-73

11. Veerkamp MJ, de Graaf J, Hendriks JC, Demacker PN, Stalenhoef AF 2004 Nomogram to diagnose familial combined hyperlipidemia on the basis of results of a 5-year follow-up study. Circulation 109:2980-5

12. Aouizerat BE, Allayee H, Cantor RM, et al. 1999 A genome scan for familial combined hyperlipidemia reveals evidence of linkage with a locus on chromosome 11. Am J Hum Genet 65:397-412

13. Deeb SS, Fajas L, Nemoto M, et al. 1998 A Pro12Ala substitution in PPARgamma2 associated with decreased receptor activity, lower body mass index and improved insulin sensitivity. Nat Genet 20:284-7

14. Clement K, Hercberg S, Passinge B, et al. 2000 The Pro115Gln and Pro12Ala PPAR gamma gene mutations in obesity and type 2 diabetes. Int J Obes Relat Metab Disord 24:391-3

15. Hara K, Okada T, Tobe K, et al. 2000 The Pro12Ala polymorphism in PPAR gamma2 may confer resistance to type 2 diabetes. Biochem Biophys Res Commun 271:212-6 
16. Mancini FP, Vaccaro O, Sabatino L, et al. 1999 Pro12Ala substitution in the peroxisome proliferator-activated receptor-gamma2 is not associated with type 2 diabetes. Diabetes 48:1466-8

17. Ringel J, Engeli S, Distler A, Sharma AM 1999 Pro12Ala missense mutation of the peroxisome proliferator activated receptor gamma and diabetes mellitus. Biochem Biophys Res Commun 254:450-3

18. Altshuler D, Hirschhorn JN, Klannemark M, et al. 2000 The common PPARgamma Pro12Ala polymorphism is associated with decreased risk of type 2 diabetes. Nat Genet 26:76-80

19. Memisoglu A, Hu FB, Hankinson SE, et al. 2003 Prospective study of the association between the proline to alanine codon 12 polymorphism in the PPARgamma gene and type 2 diabetes. Diabetes Care 26:2915-7

20. Pihlajamaki J, Miettinen R, Valve R, et al. 2000 The Pro12A1a substitution in the peroxisome proliferator activated receptor gamma 2 is associated with an insulin-sensitive phenotype in families with familial combined hyperlipidemia and in nondiabetic elderly subjects with dyslipidemia. Atherosclerosis 151:567-74

21. Eurlings PM, van der Kallen CJ, Vermeulen VM, de Bruin TW 2003 Variants in the PPARgamma gene affect fatty acid and glycerol metabolism in familial combined hyperlipidemia. Mol Genet Metab 80:296-301

22. Beamer BA, Yen CJ, Andersen RE, et al. 1998 Association of the Pro12Ala variant in the peroxisome proliferator-activated receptor-gamma2 gene with obesity in two Caucasian populations. Diabetes 47:1806-8

23. Barroso I, Gurnell M, Crowley VE, et al. 1999 Dominant negative mutations in human PPARgamma associated with severe insulin resistance, diabetes mellitus and hypertension. Nature 402:880-3

24. Risch N, Merikangas K 1996 The future of genetic studies of complex human diseases. Science 273:1516-7

25. Mootha VK, Lindgren CM, Eriksson KF, et al. 2003 PGC-1alpha-responsive genes involved in oxidative phosphorylation are coordinately downregulated in human diabetes. Nat Genet 34:267-73

26. Ek J, Andersen G, Urhammer SA, et al. 2001 Mutation analysis of peroxisome proliferator-activated receptor-gamma coactivator-1 (PGC-1) and relationships of identified amino acid polymorphisms to Type II diabetes mellitus. Diabetologia 44:2220-6

27. Hara K, Tobe K, Okada T, et al. 2002 A genetic variation in the PGC-1 gene could confer insulin resistance and susceptibility to Type II diabetes. Diabetologia 45:740-3

28. Muller YL, Bogardus C, Pedersen O, Baier L 2003 A Gly482Ser missense mutation in the peroxisome proliferator-activated receptor gamma coactivator-1 is associated with altered lipid oxidation and early insulin secretion in Pima Indians. Diabetes 52:895-8

29. Kunej T, Globocnik Petrovic M, Dovc P, Peterlin B, Petrovic D 2004 A Gly482Ser polymorphism of the peroxisome proliferator-activated receptor-gamma coactivator-1 (PGC1) gene is associated with type 2 diabetes in Caucasians. Folia Biol (Praha) 50:157-8

30. Andrulionyte L, Zacharova J, Chiasson JL, Laakso M 2004 Common polymorphisms of the PPAR-gamma2 (Pro12Ala) and PGC-1alpha (Gly482Ser) genes are associated with the conversion from impaired glucose tolerance to type 2 diabetes in the STOP-NIDDM trial. Diabetologia 47:2176-84

31. Lacquemant C, Chikri M, Boutin P, Samson C, Froguel P 2002 No association between the G482S polymorphism of the proliferator-activated receptor-gamma coactivator-1 
(PGC-1) gene and Type II diabetes in French Caucasians. Diabetologia 45:602-3; author reply 604

32. Cheurfa N, Reis AF, Dubois-Laforgue D, Bellanne-Chantelot C, Timsit J, Velho G 2004 The Gly482Ser polymorphism in the peroxisome proliferator-activated receptor-gamma coactivator-1 gene is associated with hypertension in type 2 diabetic men. Diabetologia 47:1980-3

33. Andersen G, Wegner L, Jensen DP, et al. 2005 PGC-1alpha Gly482Ser polymorphism associates with hypertension among Danish whites. Hypertension 45:565-70

34. Ridderstrale M, Johansson LE, Rastam L, Lindblad U 2006 Increased risk of obesity associated with the variant allele of the PPARGC1A Gly482Ser polymorphism in physically inactive elderly men. Diabetologia 49:496-500

35. Staels B, Dallongeville J, Auwerx J, Schoonjans K, Leitersdorf E, Fruchart JC 1998 Mechanism of action of fibrates on lipid and lipoprotein metabolism. Circulation 98:2088-93

36. Flavell DM, Pineda Torra I, Jamshidi Y, et al. 2000 Variation in the PPARalpha gene is associated with altered function in vitro and plasma lipid concentrations in Type II diabetic subjects. Diabetologia 43:673-80

37. Vohl MC, Lepage P, Gaudet D, et al. 2000 Molecular scanning of the human PPARa gene: association of the L162v mutation with hyperapobetalipoproteinemia. J Lipid Res 41:94552

38. Flavell DM, Jamshidi Y, Hawe E, et al. 2002 Peroxisome proliferator-activated receptor alpha gene variants influence progression of coronary atherosclerosis and risk of coronary artery disease. Circulation 105:1440-5

39. Eurlings PM, van der Kallen CJ, Geurts JM, Flavell DM, de Bruin TW 2002 Identification of the PPARA locus on chromosome 22q13.3 as a modifier gene in familial combined hyperlipidemia. Mol Genet Metab 77:274-81

40. Flavell DM, Ireland H, Stephens JW, et al. 2005 Peroxisome proliferator-activated receptor alpha gene variation influences age of onset and progression of type 2 diabetes. Diabetes 54:582-6

41. Gouni-Berthold I, Giannakidou E, Muller-Wieland D, et al. 2004 Association between the PPARalpha L162V polymorphism, plasma lipoprotein levels, and atherosclerotic disease in patients with diabetes mellitus type 2 and in nondiabetic controls. Am Heart J $147: 1117-24$

42. Wojciechowski AP, Farrall M, Cullen P, et al. 1991 Familial combined hyperlipidaemia linked to the apolipoprotein AI-CII-AIV gene cluster on chromosome 11q23-q24. Nature 349:161-4

43. Pennacchio LA, Olivier M, Hubacek JA, et al. 2001 An apolipoprotein influencing triglycerides in humans and mice revealed by comparative sequencing. Science 294:169-73

44. Wijsman EM, Brunzell JD, Jarvik GP, Austin MA, Motulsky AG, Deeb SS 1998 Evidence against linkage of familial combined hyperlipidemia to the apolipoprotein AI-CIII-AIV gene complex. Arterioscler Thromb Vasc Biol 18:215-26

45. Gagnon F, Jarvik GP, Motulsky AG, Deeb SS, Brunzell JD, Wijsman EM 2003 Evidence of linkage of HDL level variation to APOC3 in two samples with different ascertainment. Hum Genet 113:522-33

46. Eichenbaum-Voline S, Olivier M, Jones EL, et al. 2004 Linkage and association between distinct variants of the APOA1/C3/A4/A5 gene cluster and familial combined hyperlipidemia. Arterioscler Thromb Vasc Biol 24:167-74 
47. Pennacchio LA, Olivier M, Hubacek JA, Krauss RM, Rubin EM, Cohen JC 2002 Two independent apolipoprotein A5 haplotypes influence human plasma triglyceride levels. Hum Mol Genet 11:3031-8

48. Evans D, Buchwald A, Beil FU 2003 The single nucleotide polymorphism $-1131 \mathrm{~T}>\mathrm{C}$ in the apolipoprotein A5 (APOA5) gene is associated with elevated triglycerides in patients with hyperlipidemia. J Mol Med 81:645-54

49. Ribalta J, Figuera L, Fernandez-Ballart J, et al. 2002 Newly identified apolipoprotein AV gene predisposes to high plasma triglycerides in familial combined hyperlipidemia. Clin Chem 48:1597-600

50. Talmud PJ, Martin S, Taskinen MR, et al. 2004 APOA5 gene variants, lipoprotein particle distribution, and progression of coronary heart disease: results from the LOCAT study. J Lipid Res 45:750-6

51. Mar R, Pajukanta P, Allayee H, et al. 2004 Association of the APOLIPOPROTEIN A1/C3/A4/A5 gene cluster with triglyceride levels and LDL particle size in familial combined hyperlipidemia. Circ Res 94:993-9

52. Naukkarinen J, Ehnholm C, Peltonen L 2006 Genetics of familial combined hyperlipidemia. Curr Opin Lipidol 17:285-90

53. Gloyn AL, Weedon MN, Owen KR, et al. 2003 Large-scale association studies of variants in genes encoding the pancreatic beta-cell KATP channel subunits Kir6.2 (KCNJ11) and SUR1 (ABCC8) confirm that the KCNJ11 E23K variant is associated with type 2 diabetes. Diabetes 52:568-72

54. Nielsen EM, Hansen L, Carstensen B, et al. 2003 The E23K variant of Kir6.2 associates with impaired post-OGTT serum insulin response and increased risk of type 2 diabetes. Diabetes 52:573-7

55. Love-Gregory L, Wasson J, Lin J, Skolnick G, Suarez B, Permutt MA 2003 E23K single nucleotide polymorphism in the islet ATP-sensitive potassium channel gene (Kir6.2) contributes as much to the risk of Type II diabetes in Caucasians as the PPARgamma Pro12Ala variant. Diabetologia 46:136-7

56. Florez JC, Burtt N, de Bakker PI, et al. 2004 Haplotype structure and genotypephenotype correlations of the sulfonylurea receptor and the islet ATP-sensitive potassium channel gene region. Diabetes 53:1360-8

57. Ristow M, Muller-Wieland D, Pfeiffer A, Krone W, Kahn CR 1998 Obesity associated with a mutation in a genetic regulator of adipocyte differentiation. N Engl J Med 339:9539

58. Shackleton S, Lloyd DJ, Jackson SN, et al. 2000 LMNA, encoding lamin A/C, is mutated in partial lipodystrophy. Nat Genet 24:153-6

59. Steinle NI, Kazlauskaite R, Imumorin IG, et al. 2004 Variation in the lamin A/C gene: associations with metabolic syndrome. Arterioscler Thromb Vasc Biol 24:1708-13

60. Ledermann HM 1995 Is maturity onset diabetes at young age (MODY) more common in Europe than previously assumed? Lancet 345:648

61. Bonnycastle LL, Willer CJ, Conneely KN, et al. 2006 Common variants in maturity-onset diabetes of the young genes contribute to risk of type 2 diabetes in Finns. Diabetes 55:2534-40

62. Silander K, Mohlke KL, Scott LJ, et al. 2004 Genetic variation near the hepatocyte nuclear factor- 4 alpha gene predicts susceptibility to type 2 diabetes. Diabetes 53:1141-9 
63. Hansen SK, Rose CS, Glumer C, et al. 2005 Variation near the hepatocyte nuclear factor (HNF)-4alpha gene associates with type 2 diabetes in the Danish population. Diabetologia 48:452-8

64. Weedon MN, Owen KR, Shields B, et al. 2004 Common variants of the hepatocyte nuclear factor-4alpha P2 promoter are associated with type 2 diabetes in the U.K. population. Diabetes 53:3002-6

65. Vaxillaire M, Dina C, Lobbens S, et al. 2005 Effect of common polymorphisms in the HNF4alpha promoter on susceptibility to type 2 diabetes in the French Caucasian population. Diabetologia 48:440-4

66. Bagwell AM, Bento JL, Mychaleckyj JC, Freedman BI, Langefeld CD, Bowden DW 2005 Genetic analysis of HNF4A polymorphisms in Caucasian-American type 2 diabetes. Diabetes 54:1185-90

67. Mohlke KL, Boehnke M 2005 The role of HNF4A variants in the risk of type 2 diabetes. Curr Diab Rep 5:149-56

68. Muller YL, Infante AM, Hanson RL, et al. 2005 Variants in hepatocyte nuclear factor 4alpha are modestly associated with type 2 diabetes in Pima Indians. Diabetes 54:3035-9

69. Hara K, Horikoshi M, Kitazato H, et al. 2006 Hepatocyte nuclear factor-4alpha P2 promoter haplotypes are associated with type 2 diabetes in the Japanese population. Diabetes 55:1260-4

70. Andrulionyte L, Laukkanen O, Chiasson JL, Laakso M 2006 Single nucleotide polymorphisms of the HNF4alpha gene are associated with the conversion to type 2 diabetes mellitus: the STOP-NIDDM trial. J Mol Med 84:701-8

71. Weissglas-Volkov D, Huertas-Vazquez A, Suviolahti E, et al. 2006 Common hepatic nuclear factor-4alpha variants are associated with high serum lipid levels and the metabolic syndrome. Diabetes 55:1970-7

72. Abifadel M, Varret M, Rabes JP, et al. 2003 Mutations in PCSK9 cause autosomal dominant hypercholesterolemia. Nat Genet 34:154-6

73. Maxwell KN, Fisher EA, Breslow JL 2005 Overexpression of PCSK9 accelerates the degradation of the LDLR in a post-endoplasmic reticulum compartment. Proc Natl Acad Sci U S A 102:2069-74

74. Cohen JC, Boerwinkle E, Mosley TH, Jr., Hobbs HH 2006 Sequence variations in PCSK9, low LDL, and protection against coronary heart disease. N Engl J Med 354:1264-72

75. Shioji K, Mannami T, Kokubo Y, et al. 2004 Genetic variants in PCSK9 affect the cholesterol level in Japanese. J Hum Genet 49:109-14

76. Chen SN, Ballantyne CM, Gotto AM, Jr., Tan Y, Willerson JT, Marian AJ 2005 A common PCSK9 haplotype, encompassing the E670G coding single nucleotide polymorphism, is a novel genetic marker for plasma low-density lipoprotein cholesterol levels and severity of coronary atherosclerosis. J Am Coll Cardiol 45:1611-9

77. Kotowski IK, Pertsemlidis A, Luke A, et al. 2006 A spectrum of PCSK9 alleles contributes to plasma levels of low-density lipoprotein cholesterol. Am J Hum Genet 78:410-22

78. Yue P, Averna M, Lin X, Schonfeld G 2006 The c.43_44insCTG variation in PCSK9 is associated with low plasma LDL-cholesterol in a Caucasian population. Hum Mutat 27:460-6

79. Brunham LR, Singaraja RR, Hayden MR 2006 Variations on a gene: rare and common variants in ABCA1 and their impact on HDL cholesterol levels and atherosclerosis. Annu Rev Nutr 26:105-29 
80. Clee SM, Zwinderman AH, Engert JC, et al. 2001 Common genetic variation in ABCA1 is associated with altered lipoprotein levels and a modified risk for coronary artery disease. Circulation 103:1198-205

81. Frikke-Schmidt R, Nordestgaard BG, Jensen GB, Tybjaerg-Hansen A 2004 Genetic variation in $\mathrm{ABC}$ transporter A1 contributes to HDL cholesterol in the general population. J Clin Invest 114:1343-53

82. Lander ES, Schork NJ 1994 Genetic dissection of complex traits. Science 265:2037-48

83. McCarthy MI 2003 Growing evidence for diabetes susceptibility genes from genome scan data. Curr Diab Rep 3:159-67

84. Pajukanta P, Terwilliger JD, Perola M, et al. 1999 Genomewide scan for familial combined hyperlipidemia genes in finnish families, suggesting multiple susceptibility loci influencing triglyceride, cholesterol, and apolipoprotein B levels. Am J Hum Genet 64:1453-63

85. Soro A, Pajukanta P, Lilja HE, et al. 2002 Genome scans provide evidence for low-HDL-C loci on chromosomes 8q23, 16q24.1-24.2, and 20q13.11 in Finnish families. Am J Hum Genet 70:1333-40

86. Cantor RM, de Bruin T, Kono N, et al. 2004 Quantitative trait loci for apolipoprotein B, cholesterol, and triglycerides in familial combined hyperlipidemia pedigrees. Arterioscler Thromb Vasc Biol 24:1935-41

87. Pajukanta P, Allayee H, Krass KL, et al. 2003 Combined analysis of genome scans of dutch and finnish families reveals a susceptibility locus for high-density lipoprotein cholesterol on chromosome 16q. Am J Hum Genet 72:903-17

88. Pratley RE, Thompson DB, Prochazka M, et al. 1998 An autosomal genomic scan for loci linked to prediabetic phenotypes in Pima Indians. J Clin Invest 101:1757-64

89. Chiu YF, Chuang LM, Hsiao CF, et al. 2005 An autosomal genome-wide scan for loci linked to pre-diabetic phenotypes in nondiabetic Chinese subjects from the Stanford Asia-Pacific Program of Hypertension and Insulin Resistance Family Study. Diabetes 54:1200-6

90. Das SK, Elbein SC 2006 The Genetic Basis of Type 2 Diabetes. Cellscience 2:100-131

91. Hanson RL, Ehm MG, Pettitt DJ, et al. 1998 An autosomal genomic scan for loci linked to type II diabetes mellitus and body-mass index in Pima Indians. Am J Hum Genet 63:1130-8

92. Pei W, Baron H, Muller-Myhsok B, et al. 2000 Support for linkage of familial combined hyperlipidemia to chromosome 1q21-q23 in Chinese and German families. Clin Genet 57:29-34

93. Coon H, Myers RH, Borecki IB, et al. 2000 Replication of linkage of familial combined hyperlipidemia to chromosome 1q with additional heterogeneous effect of apolipoprotein A-I/C-III/A-IV locus. The NHLBI Family Heart Study. Arterioscler Thromb Vasc Biol 20:2275-80

94. Huertas-Vazquez A, del Rincon JP, Canizales-Quinteros S, et al. 2004 Contribution of chromosome 1q21-q23 to familial combined hyperlipidemia in Mexican families. Ann Hum Genet 68:419-27

95. Elbein SC, Hoffman MD, Teng K, Leppert MF, Hasstedt SJ 1999 A genome-wide search for type 2 diabetes susceptibility genes in Utah Caucasians. Diabetes 48:1175-82

96. Hsueh WC, St Jean PL, Mitchell BD, et al. 2003 Genome-wide and fine-mapping linkage studies of type 2 diabetes and glucose traits in the Old Order Amish: evidence for a new 
diabetes locus on chromosome 14q11 and confirmation of a locus on chromosome 1q21q24. Diabetes 52:550-7

97. Wiltshire S, Hattersley AT, Hitman GA, et al. 2001 A genomewide scan for loci predisposing to type 2 diabetes in a U.K. population (the Diabetes UK Warren 2 Repository): analysis of 573 pedigrees provides independent replication of a susceptibility locus on chromosome 1q. Am J Hum Genet 69:553-69

98. Meigs JB, Panhuysen CI, Myers RH, Wilson PW, Cupples LA 2002 A genome-wide scan for loci linked to plasma levels of glucose and $\mathrm{HbA}(1 \mathrm{c})$ in a community-based sample of Caucasian pedigrees: The Framingham Offspring Study. Diabetes 51:833-40

99. Ng MC, So WY, Cox NJ, et al. 2004 Genome-wide scan for type 2 diabetes loci in Hong Kong Chinese and confirmation of a susceptibility locus on chromosome 1q21-q25. Diabetes 53:1609-13

100. Du W, Sun H, Wang H, et al. 2001 Confirmation of susceptibility gene loci on chromosome 1 in northern China Han families with type 2 diabetes. Chin Med J (Engl) 114:876-8

101. Ng MC, So WY, Lam VK, et al. 2004 Genome-wide scan for metabolic syndrome and related quantitative traits in Hong Kong Chinese and confirmation of a susceptibility locus on chromosome 1q21-q25. Diabetes 53:2676-83

102. Langefeld CD, Wagenknecht LE, Rotter JI, et al. 2004 Linkage of the metabolic syndrome to 1q23-q31 in Hispanic families: the Insulin Resistance Atherosclerosis Study Family Study. Diabetes 53:1170-4

103. Elbein SC, Hasstedt SJ 2002 Quantitative trait linkage analysis of lipid-related traits in familial type 2 diabetes: evidence for linkage of triglyceride levels to chromosome 19q. Diabetes 51:528-35

104. Das SK, Hasstedt SJ, Zhang Z, Elbein SC 2004 Linkage and association mapping of a chromosome 1q21-q24 type 2 diabetes susceptibility locus in northern European Caucasians. Diabetes 53:492-9

105. Pajukanta P, Lilja HE, Sinsheimer JS, et al. 2004 Familial combined hyperlipidemia is associated with upstream transcription factor 1 (USF1). Nat Genet 36:371-6

106. Putt W, Palmen J, Nicaud V, et al. 2004 Variation in USF1 shows haplotype effects, gene : gene and gene : environment associations with glucose and lipid parameters in the European Atherosclerosis Research Study II. Hum Mol Genet 13:1587-97

107. Coon H, Xin Y, Hopkins PN, Cawthon RM, Hasstedt SJ, Hunt SC 2005 Upstream stimulatory factor 1 associated with familial combined hyperlipidemia, LDL cholesterol, and triglycerides. Hum Genet 117:444-51

108. Huertas-Vazquez A, Aguilar-Salinas C, Lusis AJ, et al. 2005 Familial combined hyperlipidemia in Mexicans: association with upstream transcription factor 1 and linkage on chromosome 16q24.1. Arterioscler Thromb Vasc Biol 25:1985-91

109. van der Vleuten GM, Isaacs A, Hijmans A, van Duijn CM, Stalenhoef AF, de Graaf J 2007 The involvement of upstream stimulatory factor 1 in Dutch patients with familial combined hyperlipidemia. J Lipid Res 48:193-200

110. Ng MC, Miyake K, So WY, et al. 2005 The linkage and association of the gene encoding upstream stimulatory factor 1 with type 2 diabetes and metabolic syndrome in the Chinese population. Diabetologia 48:2018-24

111. Naukkarinen J, Gentile M, Soro-Paavonen A, et al. 2005 USF1 and dyslipidemias: converging evidence for a functional intronic variant. Hum Mol Genet 14:2595-605 
112. Hanis CL, Boerwinkle E, Chakraborty R, et al. 1996 A genome-wide search for human non-insulin-dependent (type 2) diabetes genes reveals a major susceptibility locus on chromosome 2. Nat Genet 13:161-6

113. Horikawa Y, Oda N, Cox NJ, et al. 2000 Genetic variation in the gene encoding calpain10 is associated with type 2 diabetes mellitus. Nat Genet 26:163-75

114. Baier LJ, Permana PA, Yang X, et al. 2000 A calpain-10 gene polymorphism is associated with reduced muscle mRNA levels and insulin resistance. J Clin Invest 106:R69-73

115. Hegele RA, Harris SB, Zinman B, Hanley AJ, Cao H 2001 Absence of association of type 2 diabetes with CAPN10 and PC-1 polymorphisms in Oji-Cree. Diabetes Care 24:1498-9

116. Rasmussen SK, Urhammer SA, Berglund L, et al. 2002 Variants within the calpain-10 gene on chromosome 2 q37 (NIDDM1) and relationships to type 2 diabetes, insulin resistance, and impaired acute insulin secretion among Scandinavian Caucasians. Diabetes 51:3561-7

117. Cassell PG, Jackson AE, North BV, et al. 2002 Haplotype combinations of calpain 10 gene polymorphisms associate with increased risk of impaired glucose tolerance and type 2 diabetes in South Indians. Diabetes 51:1622-8

118. Evans JC, Frayling TM, Cassell PG, et al. 2001 Studies of association between the gene for calpain-10 and type 2 diabetes mellitus in the United Kingdom. Am J Hum Genet 69:54452

119. Tsai HJ, Sun G, Weeks DE, et al. 2001 Type 2 diabetes and three calpain-10 gene polymorphisms in Samoans: no evidence of association. Am J Hum Genet 69:1236-44

120. Elbein SC, Chu W, Ren Q, et al. 2002 Role of calpain-10 gene variants in familial type 2 diabetes in Caucasians. J Clin Endocrinol Metab 87:650-4

121. Garant MJ, Kao WH, Brancati F, et al. 2002 SNP43 of CAPN10 and the risk of type 2 Diabetes in African-Americans: the Atherosclerosis Risk in Communities Study. Diabetes 51:231-7

122. Zhou YP, Sreenan S, Pan CY, et al. 2003 A 48-hour exposure of pancreatic islets to calpain inhibitors impairs mitochondrial fuel metabolism and the exocytosis of insulin. Metabolism 52:528-34

123. Weedon MN, Schwarz PE, Horikawa Y, et al. 2003 Meta-analysis and a large association study confirm a role for calpain-10 variation in type 2 diabetes susceptibility. Am J Hum Genet 73:1208-12

124. Reynisdottir I, Thorleifsson G, Benediktsson R, et al. 2003 Localization of a susceptibility gene for type 2 diabetes to chromosome 5q34-q35.2. Am J Hum Genet 73:323-35

125. Duggirala R, Blangero J, Almasy L, et al. 1999 Linkage of type 2 diabetes mellitus and of age at onset to a genetic location on chromosome 10q in Mexican Americans. Am J Hum Genet 64:1127-40

126. Grant SF, Thorleifsson G, Reynisdottir I, et al. 2006 Variant of transcription factor 7-like 2 (TCF7L2) gene confers risk of type 2 diabetes. Nat Genet 38:320-3

127. Florez JC, Jablonski KA, Bayley N, et al. 2006 TCF7L2 polymorphisms and progression to diabetes in the Diabetes Prevention Program. N Engl J Med 355:241-50

128. Damcott CM, Pollin TI, Reinhart LJ, et al. 2006 Polymorphisms in the transcription factor 7-like 2 (TCF7L2) gene are associated with type 2 diabetes in the Amish: replication and evidence for a role in both insulin secretion and insulin resistance. Diabetes 55:2654-9

129. Chandak GR, Janipalli CS, Bhaskar S, et al. 2007 Common variants in the TCF7L2 gene are strongly associated with type 2 diabetes mellitus in the Indian population. Diabetologia 50:63-7 
130. Groves CJ, Zeggini E, Minton J, et al. 2006 Association analysis of 6,736 U.K. subjects provides replication and confirms TCF7L2 as a type 2 diabetes susceptibility gene with a substantial effect on individual risk. Diabetes 55:2640-4

131. Hayashi T, Iwamoto Y, Kaku K, Hirose H, Maeda S 2007 Replication study for the association of TCF7L2 with susceptibility to type 2 diabetes in a Japanese population. Diabetologia

132. Helgason A, Palsson S, Thorleifsson G, et al. 2007 Refining the impact of TCF7L2 gene variants on type 2 diabetes and adaptive evolution. Nat Genet 39:218-25

133. Horikoshi M, Hara K, Ito C, Nagai R, Froguel P, Kadowaki T 2007 A genetic variation of the transcription factor 7-like 2 gene is associated with risk of type 2 diabetes in the Japanese population. Diabetologia 50:747-51

134. Humphries SE, Gable D, Cooper JA, et al. 2006 Common variants in the TCF7L2 gene and predisposition to type 2 diabetes in UK European Whites, Indian Asians and AfroCaribbean men and women. J Mol Med 84:1-10

135. Lehman DM, Hunt KJ, Leach RJ, et al. 2007 Haplotypes of transcription factor 7-like 2 (TCF7L2) gene and its upstream region are associated with type 2 diabetes and age of onset in Mexican Americans. Diabetes 56:389-93

136. Marzi C, Huth C, Kolz M, et al. 2007 Variants of the transcription factor 7-like 2 gene (TCF7L2) are strongly associated with type 2 diabetes but not with the metabolic syndrome in the MONICA/KORA surveys. Horm Metab Res 39:46-52

137. Mayans S, Lackovic K, Lindgren P, et al. 2007 TCF7L2 polymorphisms are associated with type 2 diabetes in northern Sweden. Eur J Hum Genet 15:342-6

138. Saxena R, Gianniny L, Burtt NP, et al. 2006 Common single nucleotide polymorphisms in TCF7L2 are reproducibly associated with type 2 diabetes and reduce the insulin response to glucose in nondiabetic individuals. Diabetes 55:2890-5

139. Scott LJ, Bonnycastle LL, Willer CJ, et al. 2006 Association of transcription factor 7-like 2 (TCF7L2) variants with type 2 diabetes in a Finnish sample. Diabetes 55:2649-53

140. Scott LJ, Mohlke KL, Bonnycastle LL, et al. 2007 A genome-wide association study of type 2 diabetes in Finns detects multiple susceptibility variants. Science 316:1341-5

141. Sladek R, Rocheleau G, Rung J, et al. 2007 A genome-wide association study identifies novel risk loci for type 2 diabetes. Nature 445:881-5

142. van Vliet-Ostaptchouk JV, Shiri-Sverdlov R, Zhernakova A, et al. 2007 Association of variants of transcription factor 7-like 2 (TCF7L2) with susceptibility to type 2 diabetes in the Dutch Breda cohort. Diabetologia 50:59-62

143. Zhang C, Qi L, Hunter DJ, et al. 2006 Variant of transcription factor 7-like 2 (TCF7L2) gene and the risk of type 2 diabetes in large cohorts of U.S. women and men. Diabetes 55:2645-8

144. Hani el H, Zouali H, Philippi A, et al. 1996 Indication for genetic linkage of the phosphoenolpyruvate carboxykinase (PCK1) gene region on chromosome $20 \mathrm{q}$ to non-insulindependent diabetes mellitus. Diabetes Metab 22:451-4

145. Bowden DW, Sale M, Howard TD, et al. 1997 Linkage of genetic markers on human chromosomes 20 and 12 to NIDDM in Caucasian sib pairs with a history of diabetic nephropathy. Diabetes 46:882-6

146. Zouali H, Hani EH, Philippi A, et al. 1997 A susceptibility locus for early-onset noninsulin dependent (type 2) diabetes mellitus maps to chromosome 20q, proximal to the phosphoenolpyruvate carboxykinase gene. Hum Mol Genet 6:1401-8 
147. Ghosh S, Watanabe RM, Hauser ER, et al. 1999 Type 2 diabetes: evidence for linkage on chromosome 20 in 716 Finnish affected sib pairs. Proc Natl Acad Sci U S A 96:2198-203

148. Vionnet N, Hani El H, Dupont S, et al. 2000 Genomewide search for type 2 diabetessusceptibility genes in French whites: evidence for a novel susceptibility locus for earlyonset diabetes on chromosome 3q27-qter and independent replication of a type 2diabetes locus on chromosome 1q21-q24. Am J Hum Genet 67:1470-80

149. Permutt MA, Wasson JC, Suarez BK, et al. 2001 A genome scan for type 2 diabetes susceptibility loci in a genetically isolated population. Diabetes 50:681-5

150. Luo TH, Zhao Y, Li G, et al. 2001 A genome-wide search for type II diabetes susceptibility genes in Chinese Hans. Diabetologia 44:501-6

151. Mori Y, Otabe S, Dina C, et al. 2002 Genome-wide search for type 2 diabetes in Japanese affected sib-pairs confirms susceptibility genes on $3 q, 15 q$, and $20 q$ and identifies two new candidate Loci on 7p and 11p. Diabetes 51:1247-55

152. Bence KK, Delibegovic M, Xue B, et al. 2006 Neuronal PTP1B regulates body weight, adiposity and leptin action. Nat Med 12:917-24

153. Bento JL, Palmer ND, Mychaleckyj JC, et al. 2004 Association of protein tyrosine phosphatase 1B gene polymorphisms with type 2 diabetes. Diabetes 53:3007-12

154. Palmer ND, Bento JL, Mychaleckyj JC, et al. 2004 Association of protein tyrosine phosphatase 1B gene polymorphisms with measures of glucose homeostasis in Hispanic Americans: the insulin resistance atherosclerosis study (IRAS) family study. Diabetes 53:3013-9

155. Cheyssac C, Lecoeur C, Dechaume A, et al. 2006 Analysis of common PTPN1 gene variants in type 2 diabetes, obesity and associated phenotypes in the French population. BMC Med Genet 7:44

156. Florez JC, Agapakis CM, Burtt NP, et al. 2005 Association testing of the protein tyrosine phosphatase 1B gene (PTPN1) with type 2 diabetes in 7,883 people. Diabetes 54:1884-91

157. Herbert A, Gerry NP, McQueen MB, et al. 2006 A common genetic variant is associated with adult and childhood obesity. Science 312:279-83

158. Dina C, Meyre D, Samson C, et al. 2007 Comment on "A common genetic variant is associated with adult and childhood obesity". Science 315:187; author reply 187

159. Rosskopf D, Bornhorst A, Rimmbach C, et al. 2007 Comment on "A common genetic variant is associated with adult and childhood obesity". Science 315:187; author reply 187

160. Loos RJ, Barroso I, O'Rahilly S, Wareham NJ 2007 Comment on "A common genetic variant is associated with adult and childhood obesity". Science 315:187; author reply 187

161. Kumar J, Sunkishala RR, Karthikeyan G, Sengupta S 2007 The common genetic variant upstream of INSIG2 gene is not associated with obesity in Indian population. Clin Genet 71:415-8

162. Smith AJ, Cooper JA, Li LK, Humphries SE 2007 INSIG2 gene polymorphism is not associated with obesity in Caucasian, Afro-Caribbean and Indian subjects. Int J Obes (Lond)

163. Lyon HN, Emilsson V, Hinney A, et al. 2007 The association of a SNP upstream of INSIG2 with body mass index is reproduced in several but not all cohorts. PLoS Genet 3:e61

164. Ozaki K, Ohnishi Y, Iida A, et al. 2002 Functional SNPs in the lymphotoxin-alpha gene that are associated with susceptibility to myocardial infarction. Nat Genet 32:650-4

165. Clarke R, Xu P, Bennett D, et al. 2006 Lymphotoxin-alpha gene and risk of myocardial infarction in 6,928 cases and 2,712 controls in the ISIS case-control study. PLoS Genet 2:e107 
166. Saxena R, Voight BF, Lyssenko V, et al. 2007 Genome-wide association analysis identifies loci for type 2 diabetes and triglyceride levels. Science 316:1331-6

167. Zeggini E, Weedon MN, Lindgren CM, et al. 2007 Replication of genome-wide association signals in UK samples reveals risk loci for type 2 diabetes. Science 316:1336-41

168. 2007 Genome-wide association study of 14,000 cases of seven common diseases and 3,000 shared controls. Nature 447:661-78

169. Steinthorsdottir V, Thorleifsson G, Reynisdottir I, et al. 2007 A variant in CDKAL1 influences insulin response and risk of type 2 diabetes. Nat Genet 39:770-5

170. McPherson R, Pertsemlidis A, Kavaslar N, et al. 2007 A common allele on chromosome 9 associated with coronary heart disease. Science 316:1488-91

171. Frayling TM, Timpson NJ, Weedon MN, et al. 2007 A common variant in the FTO gene is associated with body mass index and predisposes to childhood and adult obesity. Science 316:889-94

172. Dina C, Meyre D, Gallina S, et al. 2007 Variation in FTO contributes to childhood obesity and severe adult obesity. Nat Genet 39:724-6 



\section{Chapter 3}

\section{Up-regulation of CD36/FAT in Pre-adipocytes in Familial Combined Hyperlipidemia}

\section{SUMMARY}

Familial combined hyperlipidemia (FCHL) shows many features of the metabolic syndrome. The strong genetic component makes it an excellent model to study the genetic background of metabolic syndrome and insulin resistance. Adipose tissue is believed to contribute to, or even underlie, the FCHL phenotype and is an interesting target tissue for gene expression studies. However, interpretation of adipose tissue gene expression experiments is complex since expression differences cannot only arise as a direct consequence of a genetic trait, but may also reflect an adaptation to metabolic influences at the cellular level. In the present study, we measured

gene expression levels in cultured primary human preadipocytes from FCHL and control subjects. Since

isolated preadipocytes were allowed to replicate for weeks under standardized conditions, the contribution of previous metabolic influences is rather small whereas

genetic defects are preserved and expressed in vitro. The main finding was up-regulation of CD36/FAT in FCHL preadipocytes, confirmed in two independent groups of subjects, and a concomitant increase in CD36/FAT-mediated fatty acid uptake. CD36/FAT overexpression has previously been shown to be associated with other insulin-resistant states. The present data suggest that CD36/FAT overexpression in FCHL occurs very early in adipocyte differentiation and may be of genetic origin. 


\section{Introduction}

Familial combined hyperlipidemia (FCHL), a familial form of dyslipidemia with typical features of the metabolic syndrome, was delineated three decades ago (1-3) and has been associated with a fivefold increased risk of myocardial infarction before the age of 60 (4). Although substantial insight has been acquired in this common lipid disorder, the complex genetics are not yet fully understood. Genome-wide scans revealed a number of chromosomal loci, among others 1q21, 1p31, 11p, and 16q, which are expected to be involved in the pathogenesis of FCHL (5-8). Recently, association was found in a Finnish FCHL study population with upstream stimulatory factor 1 (USF1) on 1q21 (9), a ubiquitous transcription factor directing a number of genes involved in lipid and glucose metabolism. Several organs, including liver, fat, muscle, and brain, are plausible targets in which genetic alterations may result in the typical FCHL phenotype of insulin resistance and dyslipidemia.

Arrays for gene expression studies are promising tools to identify the underlying genetic defects of complex disorders such as FCHL and diabetes mellitus type 2 (DM2) (10). A recent gene expression study from our laboratory in freshly isolated, subcutaneous adipocytes from matched FCHL and control subjects (11) revealed a number of consistently up- and down-regulated genes in FCHL, involved in lipid- and lipoprotein metabolism, cell growth, apoptosis, matrix remodeling, and fatty acid metabolism. However, an inherent limitation of gene expression analyses in tissue samples, obtained in vivo, is the difficulty to discriminate between primary genetic modifications that cause FCHL, and secondary changes resulting from cellular adaptations to the hyperlipidemia. In the present study, we used a novel approach in an attempt to identify primary genetic alterations, or the direct cellular consequences thereof, in FCHL. We prepared pre-adipocyte cell cultures obtained from subcutaneous fat biopsies from FCHL patients and matched healthy controls. Preadipocytes were repeatedly cultured under the same experimental conditions and studied for differential gene expression by arrays and quantitative RT-PCR (qRT-PCR). As the contribution of previous metabolic influences is rather small, this approach avoided overwhelming noise of adaptational gene expression, whereas genetic defects are preserved and expressed in vitro, thereby increasing - at least in theory - the chance of discovering the genetic defect. 


\section{Materials and methods}

\section{Subjects}

FCHL probands and controls were recruited through the Lipid Clinic of the Maastricht University Hospital. FCHL families were ascertained as described previously (12). The affected FCHL subjects in this study had each been ascertained as an affected relative of a FCHL family that contained at least one other first-degree relative with a total cholesterol (TC) $\geq 6.5 \mathrm{mmol} / \mathrm{l}$ and/or triglyceride (TG) $\geq 2.3 \mathrm{mmol} / \mathrm{l}$, combined with the presence of premature CAD within the family. Control participants were recruited from the spouse group or by an advertisement, and matched for body mass index (BMI) and sex with the FCHL patients. All controls had fasting TC $<5.5 \mathrm{mmol} / \mathrm{l}$, and fasting TG $<1.7$ $\mathrm{mmol} / \mathrm{l}$, and no family history of CAD. The clinical characteristics of the subjects at the time of the fat biopsy are listed in Table 1. The Human Investigation Review Committee of the Academic Hospital Maastricht approved the study protocol, and all subjects gave written informed consent.

Table 1. Clinical characteristics of FCHL-control pairs for macro-array analyses and qRT-PCR.

\begin{tabular}{|c|c|c|c|c|c|c|c|c|c|c|c|c|}
\hline \multicolumn{7}{|c|}{$\begin{array}{l}\text { Familial Combined } \\
\text { Hyperlipidemia }\end{array}$} & \multicolumn{6}{|c|}{ Control } \\
\hline Pair & Sex & Age & BMI & $\mathrm{TC}$ & TG & FFA & Sex & Age & BMI & TC & TG & FFA \\
\hline \multicolumn{13}{|c|}{ Array } \\
\hline 1 & $\mathrm{~F}$ & 45 & 24.5 & 6.4 & 1.1 & 0.05 & $\mathrm{~F}$ & 44 & 23.5 & 3.9 & 1.1 & 0.33 \\
\hline 2 & $\mathrm{~F}$ & 63 & 24.3 & 7.5 & 2.3 & 0.27 & $\mathrm{~F}$ & 55 & 25.7 & 4.9 & 0.9 & 0.18 \\
\hline 3 & $M$ & 55 & 26.8 & 7.2 & 1.3 & 0.05 & $\mathrm{~F}$ & 45 & 27.0 & 4.7 & 1.7 & 0.29 \\
\hline 4 & $M$ & 58 & 26.3 & 4.6 & 3.6 & 0.23 & $M$ & 51 & 26.2 & 4.3 & 1.0 & 0.38 \\
\hline 5 & $M$ & 39 & 24.2 & 6.6 & 3.7 & 0.26 & $M$ & 57 & 25.4 & 5.1 & 1.2 & 0.28 \\
\hline \multicolumn{13}{|c|}{ qRT-PCR } \\
\hline 6 & $M$ & 51 & 27.0 & 5.9 & 7.1 & 0.59 & $M$ & 48 & 26.9 & 5.5 & 1.4 & 0.05 \\
\hline 7 & $\mathrm{~F}$ & 46 & 22.0 & 7.7 & 1.8 & 0.40 & $\mathrm{~F}$ & 48 & 22.2 & 3.3 & 0.7 & 0.43 \\
\hline 8 & $M$ & 53 & 23.5 & 7.2 & 1.8 & 0.49 & $M$ & 61 & 23.4 & 4.3 & 0.5 & 0.50 \\
\hline 9 & $\mathrm{~F}$ & 48 & 25.3 & 7.4 & 2.8 & 0.58 & $\mathrm{~F}$ & 42 & 24.5 & 4.7 & 0.8 & 0.19 \\
\hline 10 & $\mathrm{~F}$ & 54 & 26.4 & 6.7 & 3.9 & 0.47 & $\mathrm{~F}$ & 41 & 25.7 & 3.9 & 0.8 & 0.41 \\
\hline \multirow{2}{*}{\multicolumn{2}{|c|}{$\begin{array}{l}\text { Mean } \\
\text { SD }\end{array}$}} & 51 & 25.0 & 6.7 & 2.9 & 0.32 & & 49 & 25.1 & 4.5 & 1.0 & 0.30 \\
\hline & & 7 & 1.6 & 0.9 & 1.8 & 0.2 & & 7 & 1.6 & 0.7 & 0.4 & 0.13 \\
\hline
\end{tabular}

BMI: Body mass index; TC: Total Cholesterol; TG: Triglycerides; FFA: Free fatty acids.

\section{Blood and adipose tissue sampling}

Plasma TC and TG concentrations were measured after an overnight fast as described previously (12). Subjects had refrained from smoking and did not drink coffee or tea in the morning. To obtain unbiased lipid values, partici- 
pants had abstained from alcohol for at least $72 \mathrm{~h}$ and any lipid-lowering medication had been withdrawn 2 weeks before blood sampling. Blood and liposuction samples were taken as described previously (11).

\section{Sample preparation}

Within minutes after the biopsy, the collagenase-treated cell suspension (11) was filtered through $500 \mu \mathrm{m}$ nylon mesh and spun at $220 \times \mathrm{g}$ for $1 \mathrm{~min}$ to separate pre-adipocytes from mature adipocytes. Pre-adipocytes were suspended in $5 \mathrm{ml}$ DMEM medium containing 10\% fetal calf serum (FCS) and 1\% glutamine/streptomycine/peniciline (GSP) and cultured. At passage 4, RNA was isolated using the TRIzol reagent (GibcoBRL, Grand Island, NY) according to the manufacturer's protocol. The Rneasy kit (Qiagen, Hilden, Germany) was used for total RNA clean up, and quality was assessed following the manufacturer's instructions. Plastic disposables were purchased from Greiner Bio-One (Alphen aan den Rijn, The Netherlands).

\section{Suppression subtractive hybridization}

Human subcutaneous adipose tissue samples obtained from a single FCHL/control pair were used for suppression subtractive hybridization (SSH) (Figure 1). The SMART PCR cDNA Synthesis Kit (Clontech, Palo Alto, CA) was used for preparation and amplification of double stranded cDNA, and subtractive hybridization was carried out using the PCR-Select CDNA Subtraction Kit (Clontech), both according to the manufacturer's instructions. The amplified differentially expressed cDNAs were gel-purified using the QIAEX gel subtraction kit (Qiagen), and cloned into the pGEMT-easy vector before transformation into highly competent Escherichia coli JM109 cells (Promega, Leiden, The Netherlands).

\section{Sequence identification}

All SSH clones were sequenced using the T7 and SP6 primers and the Dye Terminator Sequencing Kit (Applied Biosystems, Nieuwekerk a/d IJssel, The Netherlands) on an ABI310 genetic analyzer (Applied Biosystems).The cleaned sequence reads, that is, SSH clone sequences without adaptor and vector sequences, were assembled into contigs, thus lowering the number of sequences to be evaluated and increasing the average length of the sequences. In this way, the original number of 547 sequences, representing 369 different clones, 


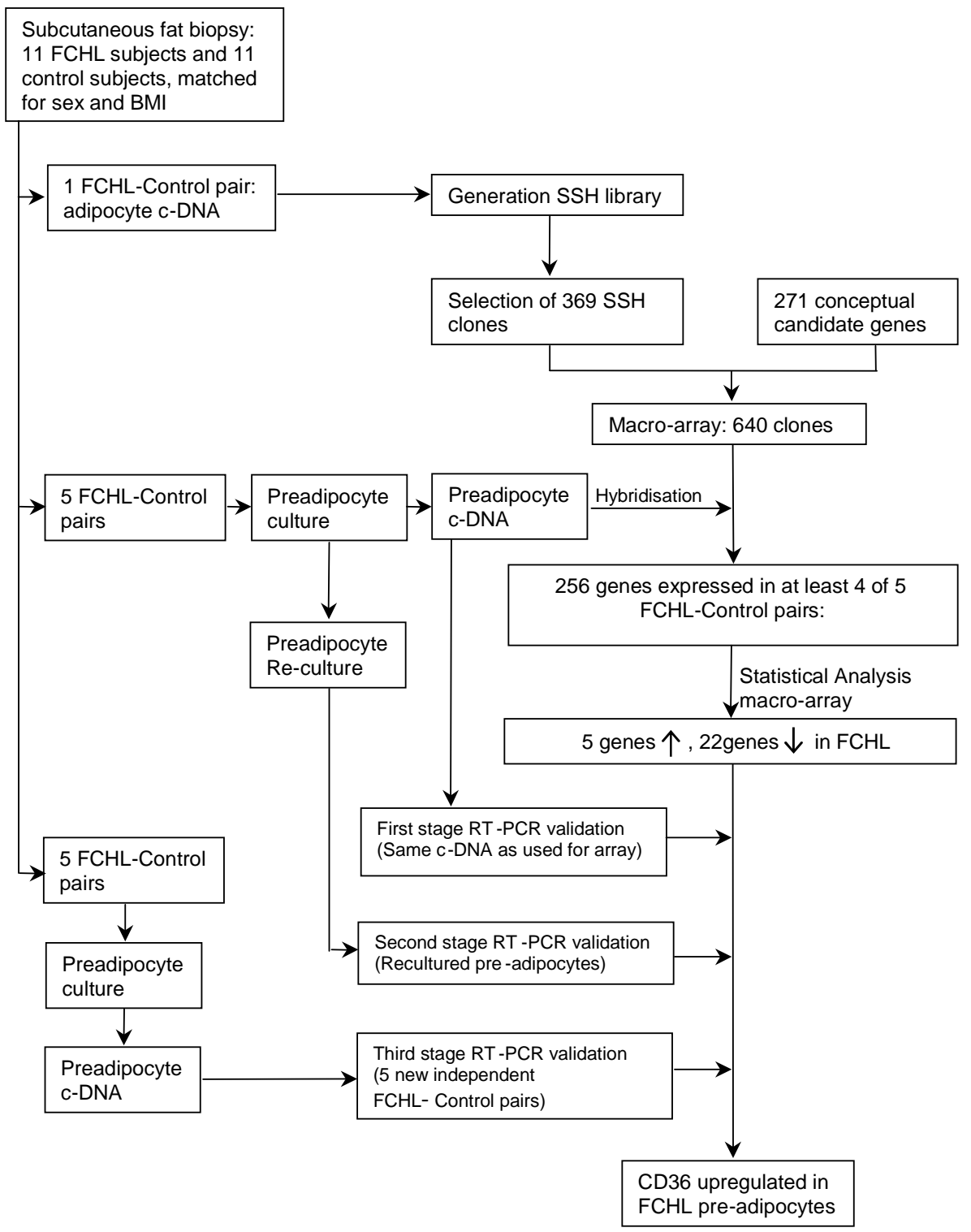

Figure 1. The design of the gene expression experiments is schematically depicted in this flow chart. Subcutaneous fat biopsies were taken from 11 familial combined hyperlipidemia (FCHL) subjects and 11 healthy controls, pair-matched for sex and body mass index (BMI). Suppression subtractive hybridization (SSH) was applied using one FCHL-control pair to generate a library of differentially expressed genes in adipose tissue, leaving 10 pairs for study. A selection of differentially expressed genes generated by SSH combined with conceptual candidate genes were spotted on macro-arrays. Gene expression levels in pre-adipocytes from 5 FCHL-control pairs, cultured and harvested under the same conditions, were measured by macro-array. A three-step validation procedure was applied. First, reliability of the array was tested by measuring gene expression levels in a selection of genes by qRT-PCR with the same RNA as used for the macro-array. Second, a selection of differentially expressed genes was validated by GRT-PCR using RNA from regrown cell lines of the same subjects. Third, genes with consistent differential expression were validated in pre-adipocytes of 5 additional, genetically independent, FCHL-control pairs 
was reduced to 264 contigs. Megablast searches with these 264 contigs against the Unigene database showed that 167 contigs obtained a significant blast hit $\left(\mathrm{E}<10^{-3}\right.$; sequence identity $>95 \%$ ), which represented 73 unique genes and 65 unique ESTs. For 97 contigs, no significant blast hits were obtained. As a quality control check, 32 of the 271 commercially obtained clones were sequenced, using M13 primers, to verify their cDNA content. In all, $15 \%$ of the clones did not contain the insert guaranteed by the supplier. Therefore, all commercial clones discussed in the current study were sequence verified.

\section{Macroarray procedure}

Clones derived by SSH, representing genes differentially expressed between FCHL and control adipocytes, and commercially obtained clones with conceptual candidate genes for FCHL, were used in macroarray analyses. Inserts were amplified by PCR using the T7/Sp6 primer set or the M13 primer set. PCR products were purified using a 96-well PCR filtration system (Millipore,Bedford, MA). Subsequently, the PCR products were spotted in duplicate on nylon filters using a BioRobotics gridder (Eurogentec, Seraing, Belgium), and denatured in $0.66 \mathrm{M} \mathrm{NaCl}$ and $0.5 \mathrm{M} \mathrm{NaOH}$, neutralized in $40 \mathrm{mM}$ phosphate buffer $\mathrm{pH} 7.3$, and subsequently UV cross-linked to the membrane. The macro-arrays were hybridized with an $\alpha^{-32} \mathrm{P}[\mathrm{dATP}]-l a b e l e d$ cDNA probe generated from $10 \mu \mathrm{g}$ of total RNA from either a FCHL or control subject using an oligo(dT) 12-18 $^{-18}$ primer according to standard procedures. Probe purification was done using ProbeQuant G-50 microcolumns (Amersham, Piscataway, NJ). The arrays were pre incubated for $30 \mathrm{~min}$ in $5 \mathrm{ml}$ ExpressHyb hybridization solution (Clontech) with denatured salmon sperm DNA (100 $\mu \mathrm{g} / \mathrm{ml}$,Invitrogen, Merelbeke, Belgium) at $55^{\circ} \mathrm{C}$. Subsequently, denatured probes, and $25 \mu \mathrm{g}$ of CoT-1 DNA (Invitrogen), were hybridized to the arrays for $16 \mathrm{~h}$ at $55^{\circ} \mathrm{C}$. The arrays were washed once with $2 \times$ SSC $/ 1 \%$ SDS and twice with $0.1 \times$ SSC $/ 0.5 \%$ SDS and exposed to an imaging screen (Bio-Rad, Hercules, CA).

\section{Macroarray data analysis}

The array consisted of 369 clones from our cDNA library generated by SSH, 271 commercially acquired conceptual candidates for cardiovascular disease, 4 housekeeping genes in triplicate and 100 blanco spots. All were represented in duplicate on the array. The software package Imagene (Biodiscovery, El Segundo, CA) was used to construct and superimpose a series of grids over the 
blot. Radiation intensities of the spots were quantified, and the numerical output was exported to Microsoft Excel for further analyses. All spots were visually inspected, and only visible spots with a homogeneous round shape were taken into account. Expression in at least 4 of 5 pairs was required for a gene to be included for analyses. As a reference for background correction, the intensities of a number of empty spots in the blot and a complete row of empty spots at the top and the bottom of the blots were averaged. Intensities of the spots were corrected for background and mean intensities of 3 housekeeping genes (23 kD highly basic protein, hypoxanthine phosphoribosyltransferase 1 , and $\beta$-actine) present in sixfold on each array. Akaike information criterion (AIC) $(13,14)$, the likeliness of a model based on the observed data penalized by the complexity of this model, was used to identify differentially expressed genes. The AIC complexity penalization was chosen to be more stringent than usual in order to match a two-sided test with a $95 \%$ significance level. A gene was therefore found to be differentially expressed when the AIC indicated the model, including a group effect, that is, being an FCHL patient or a control subject, was describing better the observed radiation intensities. Differences were expressed as a ratio of normalized spot intensities on the FCHL array and the control array.

\section{qRT-PCR validation procedure}

The accuracy and reproducibility of the macro-array data were verified in a three-stage validation procedure using qRT-PCR (Figure 1). In the first stage of the validation procedure, the reliability of the array itself was tested. To this purpose, expression patterns of a selection of genes were determined in one FCHL/control pair by qRT-PCR, using the same RNA sample as used for the array. Fold expression differences were calculated and correlated with the array results of the same couple. In the second validation stage, the reproducibility of the results was tested. The same cell cultures as used for the macroarray were recultured and qRT-PCR was performed on a selection of genes, using newly extracted RNA. In the third validation phase, we tested whether observed differences in gene expression levels were also present in preadipocyte RNA of another group of five unrelated FCHL/control pairs.

qRT-PCR was carried out using the qPCR for SYBR Green core kit (Eurogentec, Seraing, Belgium) on an ABI PRISM 7700 sequence detection system (Applied Biosystems). The selected genes and primers used are listed in Table 2. Target gene mRNA levels were normalized to $18 \mathrm{~S}$ rRNA and analyzed using a 


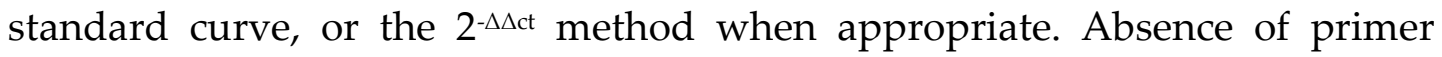
dimers and presence of a single amplification product were verified by a melting curve analysis at the end of each assay.

Table 2. Primers used for $q R T-P C R$ validation

\begin{tabular}{|c|c|}
\hline Gene name & Primers $\left(5^{\prime}-3^{\prime}\right)$ \\
\hline Adipophilin (ADRP) & $\begin{array}{l}\text { Forward: ACCAGTGCTCTGCCCATCA } \\
\text { Reverse: CCCCTTACAGGCATAGGTATTGG }\end{array}$ \\
\hline CD36 antigen (CD36/FAT) & $\begin{array}{l}\text { Forward: AGTCACTGCGACATGATTAATGGT } \\
\text { Reverse: CTGCAATACCTGGCTTTCTCA }\end{array}$ \\
\hline Surfeit 1 (SURF1) & $\begin{array}{l}\text { Forward: CCTATGTGGTCACTCCCTTCCA } \\
\text { Reverse: TGGGAACGAACCСTCTATTTACC }\end{array}$ \\
\hline HSP70 interacting protein (ST13) & $\begin{array}{l}\text { Forward: AGAAGTTCAACCTAGGGCACAGA } \\
\text { Reverse: TTGATCTCTCGCTCTTCACGTTT }\end{array}$ \\
\hline Tumor rejection antigen gp96 (TRA1) & $\begin{array}{l}\text { Forward: AAAAAGAGCGATTACATTAAGCTCTATG } \\
\text { Reverse: CCACACСCTTGACAAAATTGAG }\end{array}$ \\
\hline Collagen, type 1 , alpha 2 (Col1a2) & $\begin{array}{l}\text { Forward: TGAAAACATCCCAGCCAAGAA } \\
\text { Reverse: CAAACTGGCTGCCAGCATT }\end{array}$ \\
\hline Matrix metalloproteinase 2 (MMP2) & $\begin{array}{l}\text { Forward: CATCTTTGCTGGAGACAAATTCTG } \\
\text { Reverse: CTGCGATGAGCTTGGGAAA }\end{array}$ \\
\hline $\begin{array}{l}\text { Tissue inhibitor of metalloproteinase } 3 \\
\text { (TIMP3) }\end{array}$ & $\begin{array}{l}\text { Forward: CTGACAGGTCGCGTCTATGATG } \\
\text { Reverse: TTACAACCCAGGTGATACCGATAGT }\end{array}$ \\
\hline $18 \mathrm{~S}$ ribosomal RNA (18S rRNA) & $\begin{array}{l}\text { Forward: TGCATGGCCGTTCTTTAGTTG } \\
\text { Reverse: AGTTAGCATGCCAGAGTCTCGTT }\end{array}$ \\
\hline
\end{tabular}

\section{Fatty acid uptake and esterification}

CD36/FAT-specific fatty acid uptake and subsequent esterification was studied using sulfo-N-succinimidyl esters (SSO). SSO specifically binds CD36 and arrests the LCFA transport function of this protein (15).

Pre-adipocytes were pre incubated for $45 \mathrm{~min}$ at $37^{\circ} \mathrm{C}$ in the presence of SSO (concentration $0.2 \mathrm{mM}$ ) or DMSO (concentration $0.4 \%$ ). Palmitate uptake was measured by addition of [14C]palmitate $(0.3 \mu \mathrm{Ci}$, final concentration, $0.6 \mathrm{mM})$ in a $2 \% \mathrm{BSA} / \mathrm{MKR}$ solution. The reaction was carried out at $37^{\circ} \mathrm{C}$ for $30 \mathrm{~min}$. Cells were rinsed three times with $1 \mathrm{ml}$ stop solution (MKR $0.2 \%$ BSA $+0.2 \mathrm{mM}$ phloretin) to terminate palmitate uptake. Cells were lysed in $1 \mathrm{ml}$ isopropanolheptane (2:3). Samples were applied to HP-TLC plates to separate triglycerides and phospholipids. Radioactivity was measured after exposure to an imaging screen with the Personal Molecular Imager FX (Bio-Rad). 


\section{RESULTS}

\section{Subjects}

Initial macro-array experiments were done with $5 \mathrm{FCHL} / \mathrm{control}$ pairs, which were also used in the first and second stage of validation by qRT-PCR (Figure 1). In the third stage of validation with qRT-PCR, 5 additional FCHL/control pairs were studied, all unrelated and independent subjects not used in earlier experiments. The clinical characteristics of all subjects are listed in Table 1.

FCHL patients showed higher plasma levels of total cholesterol (TC), TG, FFA, glycerol, and apolipoprotein B, and lower levels of HDL cholesterol, as expected. Age was not different between patients and controls.

\section{Differentially expressed genes}

Subcutaneous fat from a female/female FCHL/control pair was used to create a differential mature adipocyte SSH library. The FCHL subject was 47 years old, BMI $26.8 \mathrm{~kg} / \mathrm{m}^{2}$, with a plasma TC of $7.77 \mathrm{mmol} / \mathrm{l}$, TG $2.26 \mathrm{mmol} / \mathrm{l}$, and HDL cholesterol $1.08 \mathrm{mmol} / \mathrm{l}$. The control subject was 39 years old, BMI $25.0 \mathrm{~kg} / \mathrm{m}^{2}$, and a plasma TC of $5.59 \mathrm{mmol} / \mathrm{l}$, TG $0.69 \mathrm{mmol} / \mathrm{l}$, and HDL cholesterol 1.41 $\mathrm{mmol} / \mathrm{l}$. SSH procedures resulted in a forward and a reverse library containing up-regulated and down-regulated FCHL clones, respectively. In total, 369 clones were selected from both libraries and combined with 271 commercially obtained conceptual cardiovascular candidate gene clones on macro-arrays (Figure 1). Housekeeping genes were used to normalize macro-array expression data. Relative intensities of housekeeping genes were similar on the FCHL and control arrays (Table 3). This low variability in relative expression of housekeeping genes in FCHL and control pre-adipocytes illustrated the suitability of these genes for normalization.

Table 3. Relative housekeeping gene intensities (\%) on FCHL and control macro-arrays

\begin{tabular}{|c|c|c|}
\hline Housekeeping gene & $\mathrm{FCHL}(\%)$ & Control (\%) \\
\hline 23-kDa basic protein & $5.1 \pm 3.3$ & $4.9 \pm 2.0$ \\
\hline HPRT & $1.1 \pm 1.1$ & $0.9 \pm 0.6$ \\
\hline ACTB & $93.8 \pm 4.1$ & $94.3 \pm 2.4$ \\
\hline
\end{tabular}

Macro-array analyses showed that 256 of 640 (40\%) genes reported on the array were expressed in at least 4 of $5 \mathrm{FCHL} / \mathrm{control}$ pairs (Figure 1). Twentyseven $(11 \%)$ of these genes exhibited statistically significant altered expression 
Table 4. FCHL/Control ratios + 95\% confidence intervals of 27 genes found statistically significant $(P<0.05)$ differentially expressed in pre-adipocyte cellines

\begin{tabular}{|c|c|c|c|}
\hline Gene Name & Chromosome & $\begin{array}{l}\text { Ratio } \\
\text { fchl/cont }\end{array}$ & $95 \%$ C.I. \\
\hline \multicolumn{4}{|l|}{ Receptors } \\
\hline CD36 antigen $(\mathrm{CD} 36 / \mathrm{FAT})^{1+2}$ & $7 q 11.2$ & 1.71 & $1.21-2.21$ \\
\hline $\begin{array}{l}\text { Platelet-derived growth factor receptor alpha } \\
\text { polypeptide (PDGFRA) }{ }^{2}\end{array}$ & $4 q 12$ & 0.63 & $0.43-0.82$ \\
\hline Adenosine $A 2$ a receptor $(A D O R A 2 A)^{1}$ & $22 q 11.2$ & 0.47 & $0.18-0.76$ \\
\hline \multicolumn{4}{|l|}{ Mitochondrion } \\
\hline Surfeit $1\left(\right.$ SURF1) ${ }^{1}$ & $9 q 34$ & 0.42 & $0.24-0.60$ \\
\hline $\begin{array}{l}\text { Succinate dehydrogenase complex, subunit C, } \\
\text { integral membrane protein, } 15 \mathrm{kD}(\mathrm{SDHC})^{1}\end{array}$ & $1 q 21$ & 0.58 & $0.31-0.85$ \\
\hline $\begin{array}{l}\text { ATP synthase, } \mathrm{H}+\text { transporting, mitochondrial } \\
\text { F0 complex, subunit F6 (ATP5J) })^{1}\end{array}$ & $19 p 13.2$ & 0.56 & $0.32-0.80$ \\
\hline $\begin{array}{l}\text { Translocase of inner mitochondrial membrane } \\
17 \text { homolog } A \text { yeast (TIMM17A) }{ }^{2}\end{array}$ & $1 q 32$ & 0.46 & $0.32-0.60$ \\
\hline \multicolumn{4}{|l|}{ Matrix turnover } \\
\hline Collagen, type VI, alpha $3\left(\right.$ COL6A3) ${ }^{1}$ & $2 q 37$ & 1.73 & $1.02-2.45$ \\
\hline Collagen, type XVIII, alpha 1 (COL18A1) ${ }^{1}$ & $21 q 22.3$ & 0.60 & $0.43-0.76$ \\
\hline Collagen, type I, alpha $2(\operatorname{COL} 1 \mathrm{~A} 2)^{1}$ & 7q22.1 & 0.55 & $0.09-0.38$ \\
\hline Matrix metalloproteinase $2(\mathrm{MMP} 2)^{1}$ & $16 q 13$ & 0.37 & $0.22-0.52$ \\
\hline Matrix metalloproteinase 9 (MMP9) ${ }^{1}$ & $20 \mathrm{q} 11.2 \mathrm{q} 13.1$ & 0.50 & $0.28-0.73$ \\
\hline $\begin{array}{l}\text { Tissue inhibitor of metalloproteinase } 3 \\
(\text { TIMP3 })^{1}\end{array}$ & $22 q 12.1 q 13.2$ & 0.41 & $0.10-0.73$ \\
\hline \multicolumn{4}{|l|}{ Metabolism and others } \\
\hline $\begin{array}{l}\text { Methylene tetrahydrofolate dehydrogenase } \\
\text { (NAD+ dependent) (MTHFD } 1)^{1}\end{array}$ & $14 q 24$ & 0.45 & $0.21-0.69$ \\
\hline $\begin{array}{l}\text { LIM domain-containing preferred translocation } \\
\text { partner in lipoma (LPP) }\end{array}$ & $3 q 28$ & 0.64 & $0.42-0.86$ \\
\hline $\begin{array}{l}\text { Suppression of tumorigenicity } 13 \text { colon carci- } \\
\text { noma (ST13) (Hsp70 interacting protein })^{1}\end{array}$ & $22 q 13$ & 0.41 & $0.16-0.65$ \\
\hline $\begin{array}{l}\text { 3-hydroxymethyl-3-methylglutaryl-Coenzyme } \\
\text { A lyase (HMGCL) }\end{array}$ & 1pter-p33 & 0.61 & $0.35-0.88$ \\
\hline Glutamyl-prolyl-tRNA synthetase (EPRS) ${ }^{2}$ & $1 q 41-q 42$ & 0.64 & $0.44-0.84$ \\
\hline Vimentin $(\text { VIM })^{2}$ & $10 p 13$ & 1.51 & $1.05-1.97$ \\
\hline Tumor rejection antigen gp96 (TRA1) ${ }^{2}$ & $12 \mathrm{q} 24.2 \mathrm{q} 24.3$ & 0.54 & $0.31-0.78$ \\
\hline $\begin{array}{l}\text { ATPase, } \mathrm{H}+\text { transporting, lysosomal } 42 \mathrm{kDa}, \mathrm{V} 1 \\
\text { subunit } \mathrm{C} \text { isoform } 2(\mathrm{ATP} 6 \mathrm{~V} 1 \mathrm{C} 2)^{2}\end{array}$ & $2 \mathrm{p} 25.1$ & 0.63 & $0.40-0.87$ \\
\hline \multicolumn{4}{|l|}{ ESTs } \\
\hline Est $(B E 621121)^{2}$ & & 1.53 & $1.04-2.02$ \\
\hline Est 4c.12 (AI570255) $)^{2}$ & & 1.66 & $1.05-2.27$ \\
\hline Est/hypothetical protein DC42 (AK025746) ${ }^{2}$ & & 0.37 & $0.06-0.69$ \\
\hline $\begin{array}{l}\text { Est weakly similar to hypothetical protein } \\
\text { FLJ20234 (AI090487) }\end{array}$ & & 0.51 & $0.26-0.77$ \\
\hline Est (NM_002085) $)^{2}$ & & 0.32 & $0.14-0.49$ \\
\hline $\begin{array}{l}\text { Est/hypothetical protein My014 } \\
(\text { NT_032962.5) }\end{array}$ & & 0.66 & $0.44-0.88$ \\
\hline
\end{tabular}


in FCHL. Five genes were up-regulated in FCHL and 22 were down-regulated. These genes, with their chromosomal location, are listed in Table 4 and divided into 4 main groups: receptors (3 genes), mitochondrial function (4 genes), matrix turnover (6 genes), and metabolism and others (8 genes). Six clones were ESTs.

\section{Multistep validation procedure}

Six genes (CD36/FAT, MMP 2, TIMP 3, TRA1, ST13 [mentioned in Table 4], and ADRP [not in Table 4]) were selected for the first stage of validation. Quantitative expression differences were measured by qRT-PCR in the same RNA samples as used for the array (Figure 1). A highly significant correlation coefficient of $0.78(\mathrm{P}<0.001)$ was found between the logarithm of the fold differences obtained by macro-array and qRT-PCR (Figure 2), which demonstrated the accuracy and validity of the array data obtained.

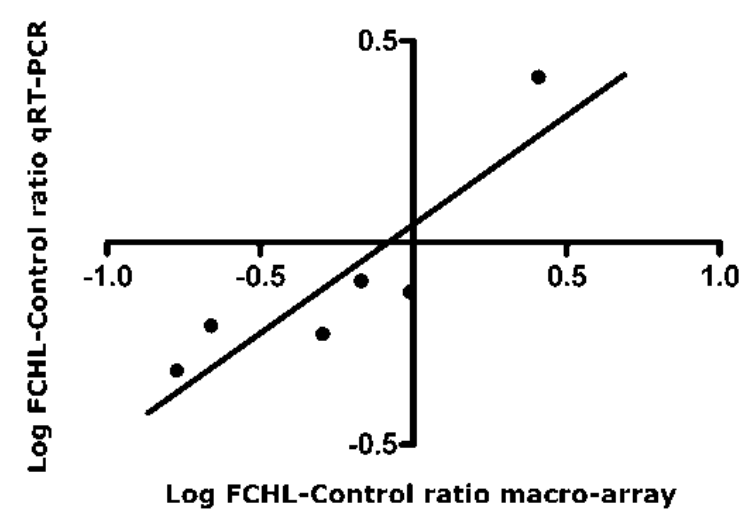

Figure 2. Fold changes of mRNA levels measured by macro-array and GRT-PCR $\left(r^{2}=0.78\right.$, $\mathrm{P}<0.01$ ).

The second stage of the validation procedure tested whether the expression data of a selection of 8 genes was confirmed by qRT-PCR in newly isolated RNA from regrown cell cultures of the same 5 pairs of subjects (Figure 1). The 8 genes were CD36/FAT, COL1A2, MMP2, ST13, SURF1, TIMP3, and TRA1 (mentioned in Table 4), as well as ADRP (not in Table 4). Very similar expression patterns to those observed on the arrays were found with CD36/FAT (5 of 5 pairs, shown in Fig. 3A) as well as TRA1 (4/5 pairs), COL1A2 (4/5 pairs), and 
to a lesser extent with MMP2, TIMP3, ST13, and ADRP (3 of 5 pairs). SURF1, which has low expression levels in pre-adipocytes, showed a similar expression difference as observed on arrays in only 2 of 5 couples. Combined, this second stage of the validation confirmed a true expression difference in CD36/FAT, TRA1, and COL1A2 genes in pre-adipocyte cell lines from the first 5 FCHL patients vs. paired controls.

In the third validation step, we evaluated which gene(s) remained differentially expressed in a new, independent set of 5 pairs of BMI- and sex-matched
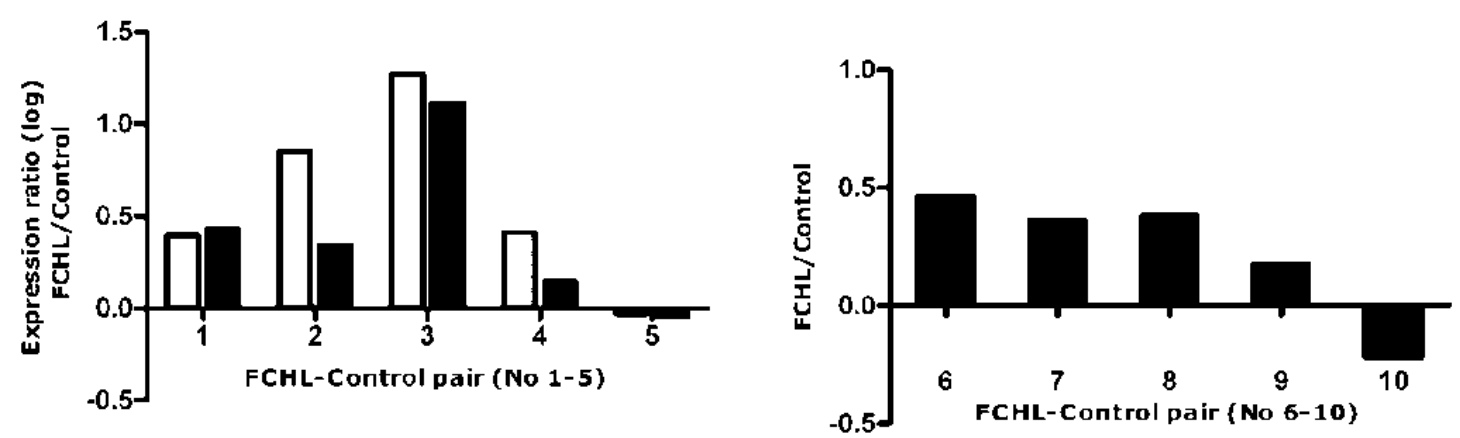

Figure 3. White bars represent expression data of the macro-array. Black bars represent qRT-PCR expression data. Left panel: CD36/FAT was up-regulated in 4 out of 5 FCHL patients on the macro-array. CD36/FAT expression levels measuredby qRT-PCR in re-cultured preadipocytes closely followed expression levels of the macro-array, indicating the reproducibility of the data. Right panel: Up-regulation of CD36/FAT was confirmed by qRT-PCR in a second group of 5 independent FCHL-control pairs.

FCHL and control subjects (pairs 6-10 in Table 1 and Fig. 3), aiming to answer the question of which genes can be regarded as consistently FCHL-specific. Up-regulation of CD36/FAT was confirmed in 4 of 5 new FCHL/control pairs (Fig. 3B). Down-regulation of TRA1 and COL1A2 could not be confirmed in the new pairs. All combined, CD36/FAT showed up-regulation in 8 out of 10 FCHL pre-adipocyte cell cultures compared with pre-adipocytes derived from sex- and BMI-matched controls.

\section{CD36/FAT up-regulation is functional}

To investigate whether CD36/FAT up-regulation was functional, we recultured FCHL and control pre-adipocytes, and measured total and CD36/FATspecific LCFA uptake and incorporation in phospholipids and triglycerides. In 
the combined group (FCHL + control subjects) a significant correlation was found between CD36/FAT expression measured by quantitative PCR and the fraction of fatty acids taken up via CD36/FAT and incorporated into phospholipids and triglycerides (Figure 4).

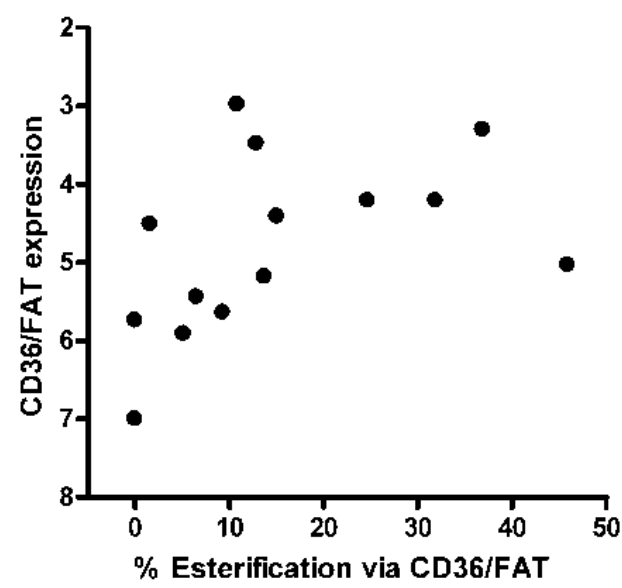

Figure 4. CD36/FAT RNA levels are positively correlated with the CD36/FAT mediated fatty acid esterification fraction (spearman's rho $=0.65, \mathrm{P}=0.01$ ). CD36/FAT expression is depicted as the CD36/FAT Ct value measured by QRT PCR, corrected for housekeeping gene (18srRNA) expression.

\section{Discussion}

In the present study, we investigated gene expression profiles in human preadipocyte cell cultures from human subjects with FCHL and pair-wisematched normolipidemic controls. The main finding was up-regulation of CD36/FAT in FCHL pre-adipocytes, confirmed in two independent groups, and a concomitant increase in CD36/FAT-mediated incorporation of fatty acids into triglycerides and phospholipids. Since gene expression differences in cultured pre-adipocytes reflect the direct expression of a genetic trait, and adaptive expression differences are suppressed, these results indicate that CD36/FAT overexpression in FCHL impacts very early in adipocyte differentiation state and may be of genetic origin.

The application of the SSH library combined with a candidate gene approach offered some substantial advantages. Because a selection was made of genes that are differentially expressed, a limited number of genes needed statistical 
testing, thereby reducing the multiple-testing problem and the number of false-positive results. Given these relative advantages and its known limitations, in combination with a stringent statistical analysis and a rigorous validation procedure, the present results offer an intriguing insight into an FCHL preadipocyte and perhaps general fat tissue functioning in FCHL.

Adipose tissue is an interesting target tissue for gene expression studies in FCHL, since impaired function of adipose tissue is believed to contribute to, or even underlie, the expression of the FCHL phenotype. Previously, the expression profile of mature adipocytes, freshly isolated from fat tissue of FCHL adipose tissue, was investigated by our lab (11). However, an inherent drawback of gene expression studies on in vivo samples is the inability to distinguish between primary genetic defects, or direct cellular consequences thereof, and adaptive responses to, for example, hyperlipidemia. In the present study, we cultured pre-adipocytes of FCHL subjects and BMI- and sex-matched controls. This design is based on the assumption that gene expression differences due to previous metabolic influences are rather small, as isolated preadipocytes were allowed to replicate for weeks in a standardized environment, equal for FCHL and control pre-adipocytes. A similar approach was used by Gaster et al. (16), using cultured myotubes to study genetic effects of reduced lipid oxidation in muscle from type 2 diabetes subjects. This approach ruled out expression differences due to environmental factors, and allowed us to attribute the increased CD36/FAT expression to the underlying genetic background in FCHL (Figure 5).

CD36/FAT is a multiligand class B scavenger receptor that has been implicated in multiple biological processes. Apart from its function as a scavenger receptor, CD36/FAT has been identified as a regulator of angiogenesis and as a fatty acid translocase (FAT) facilitating the transmembrane transport of long-chain fatty acids (LCFAs) (17). CD36/FAT has atherogenic and anti-atherogenic aspects (18). Ligands for CD36/FAT are, among others, oxidized LDL, LCFAs, collagen, thrombospondin-1, and apoptotic cells. CD36/FAT expression is broad but especially abundant in tissues with high LCFA storage capacity, such as adipocytes, or oxidative capacity, such as heart and muscle (18).

The consistent up-regulation of CD36/FAT is remarkable given the metabolic (Fredrickson type IIa, Iib, or IV) and genetic heterogeneity of FCHL $(1,19)$. In pre-adipocytes, CD36/FAT was upregulated in 8 of $10 \mathrm{FCHL}$ patients, equally expressed in one pair, and down-regulated in another FCHL patient. Furthermore, in mature, freshly isolated adipocytes, CD36/FAT expression was also 
FAT BIOPSY

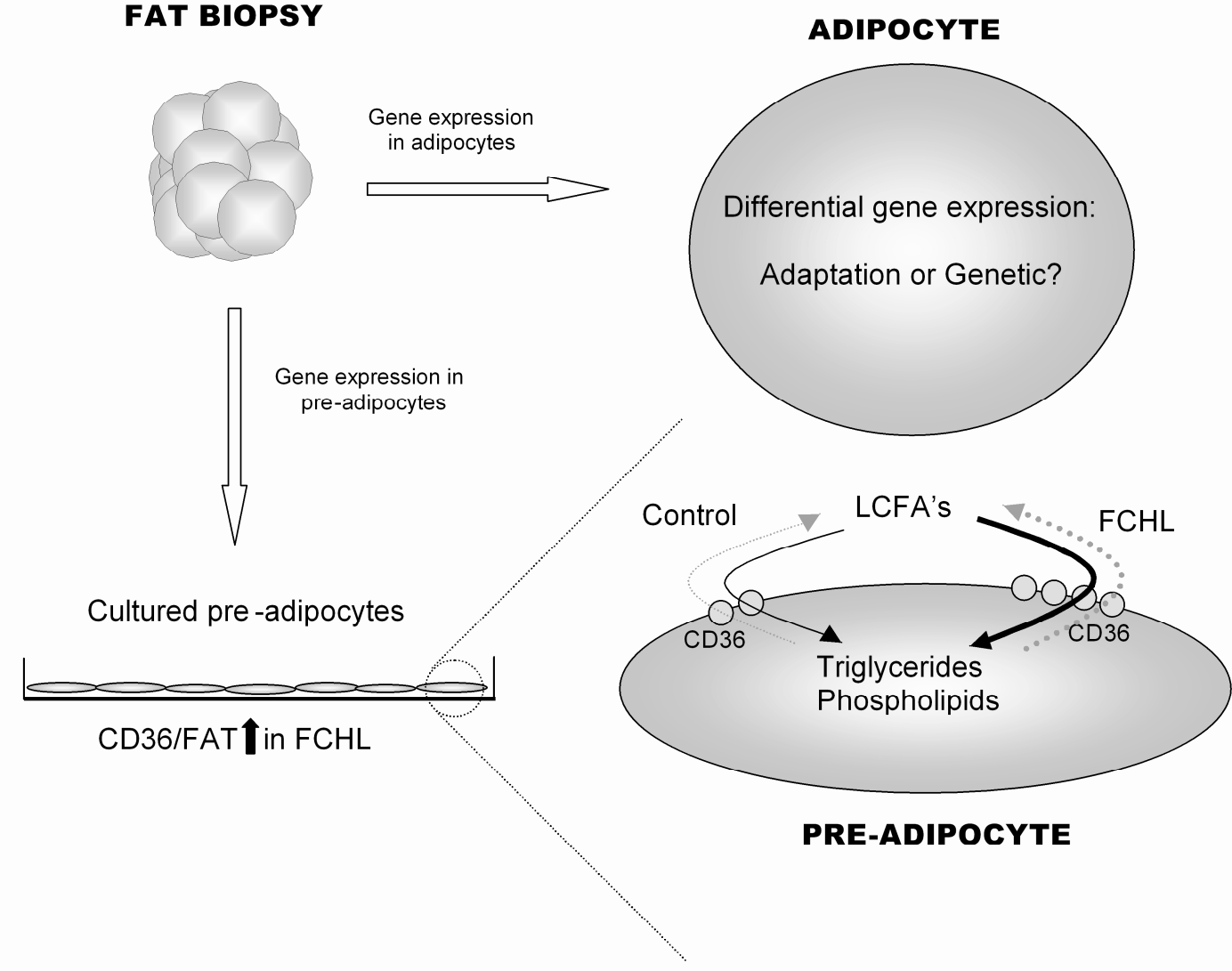

Figure 5. Gene expression experiments in mature freshly isolated adipocytes do not allow to distinguish between adaptations to metabolic influences or expression differences that are a direct result of a genetic trait. In cultured pre-adipocytes, the contribution of previous metabolic traits on gene expression is suppressed, whereas genetic defects, and direct consequences thereof, are preserved and expressed in vitro. CD36/FAT expression was increased in FCHL pre-adipocytes. Up-regulation was confirmed at the functional level, as FCHL preadipocytes demonstrated increased CD36/FAT-mediated uptake and esterification of fatty acids.

$50 \%$ increased in FCHL (unpublished data). Nevertheless, in contrast to the spontaneous hypertensive rat (SHR) in which CD36/FAT has been identified as the causal insulin-resistance gene (20), CD36/FAT is probably not the mutated gene in FCHL. CD36/FAT is located on chromosome 7q11.2, and to our knowledge, no genome-wide scan showed linkage in this region with FCHL or any related trait. Obviously, this may change when more data become available and phenotypes are refined. Furthermore, from a biological point of view, overexpression of CD36/FAT is expected to result in a more favorable plasma lipid spectrum than presently seen in FCHL, due to increased CD36/FATmediated FA uptake. This is supported by observations in transgenic mice 
overexpressing CD36/FAT in muscle. These animals typically exhibit reduced plasma triglycerides and fatty acids but increased plasma glucose and insulin (21). In line with this mechanism, CD36/FAT knockout mice have increased levels of fatty acids, triglycerides, and cholesterol (22). In our opinion, CD36/FAT up-regulation is therefore more likely a manifestation for a genetic alteration in FCHL, rather than the defect itself, in analogy to overexpression of the 3-HMG-CoA-reductase enzyme in fibroblasts from patients with an LDL receptor defect (23).

CD36/FAT overexpression may well reflect insulin resistance (24) or defective insulin signaling in FCHL. Previously, CD36/FAT was found to be increased in other insulin-resistant states. Cardiac myocytes from obese Zucker rats, a commonly used rodent model for obesity and insulin resistance, have increased sarcolemmal CD36/FAT and enhanced extracellular fatty acid uptake (25). Similarly, in skeletal muscle from human subjects with type 2 diabetes, sarcolemmal CD36/FAT was increased and associated with increased LCFA transport (26). CD36/FAT protein was also increased in diabetic macrophages as a response to defective insulin signaling (27). Finally, Griffin et al. (28) showed increased CD36/FAT translation efficiency in diabetic macrophages. These data and ours show that CD36/FAT is increased in insulin resistance.

In the present study, increased CD36 RNA and functional CD36/FAT protein in cultured pre-adipocytes suggests that CD36/FAT up-regulation is the direct consequence of a genetic defect, rather than a metabolic adaptation to, for example, hyperlipidemia, and that the actual defect in FCHL is already metabolically apparent in a very early adipocyte differentiation state. This defect may be increased genetic susceptibility to insulin resistance of FCHL adipose tissue.

In conclusion, CD36/FAT is the first gene found with consistent increased expression in pre-adipocytes of two independent groups of unrelated FCHL subjects. The use of cultured pre-adipocytes suppressed expression differences due to adaptive compensations at the cellular level and allowed us to specifically select for gene expression differences that are a direct consequence of a genetic trait. Increased CD36/FAT RNA and functional CD36/FAT protein in cultured pre-adipocytes implies that a genetic defect in FCHL affects fatty acid metabolism in a very early adipocyte differentiation stage and that FCHL adipocyte dysfunction may be of genetic origin. Future gene expression studies in other candidate tissues such as liver and muscle will further advance our understanding of insulin resistance and altered lipid metabolism in FCHL. 


\section{Acknowledgements}

We thank the patients and controls for their participation in the present study. We thank J. van Lin for recruitment of FCHL patients and control subjects. We thank the Department of Plastic Surgery (head: Prof. Dr. W.D. Boeckx) of the Academic Hospital Maastricht for help with the liposuction fat biopsies. This study was supported by a grant from the Cardiovascular Research Institute Maastricht (CARIM) and the Academic Hospital Maastricht. J.J.F.P. Luiken is the recipient of a VIDI-Innovational Research Grant from the Netherlands Organization for Scientific Research (ZonMw 016.036.305). J.F.C. Glatz is Netherlands Heart Foundation Professor of Cardiac Metabolism.

\section{References}

1. Goldstein JL, Schrott HG, Hazzard WR, Bierman EL, Motulsky AG 1973 Hyperlipidemia in coronary heart disease. II. Genetic analysis of lipid levels in 176 families and delineation of a new inherited disorder, combined hyperlipidemia. J Clin Invest 52:1544-68

2. Nikkila EA, Aro A 1973 Family study of serum lipids and lipoproteins in coronary heartdisease. Lancet 1:954-9

3. Rose HG, Kranz P, Weinstock M, Juliano J, Haft JI 1973 Inheritance of combined hyperlipoproteinemia: evidence for a new lipoprotein phenotype. Am J Med 54:148-60

4. Voors-Pette C, de Bruin TW 2001 Excess coronary heart disease in Familial Combined Hyperlipidemia, in relation to genetic factors and central obesity. Atherosclerosis 157:481-9

5. Pajukanta P, Nuotio I, Terwilliger JD, et al. 1998 Linkage of familial combined hyperlipidaemia to chromosome 1q21-q23. Nat Genet 18:369-73

6. Allayee H, Krass KL, Pajukanta P, et al. 2002 Locus for elevated apolipoprotein B levels on chromosome 1p31 in families with familial combined hyperlipidemia. Circ Res 90:926-31

7. Aouizerat BE, Allayee H, Cantor RM, et al. 1999 A genome scan for familial combined hyperlipidemia reveals evidence of linkage with a locus on chromosome 11. Am J Hum Genet 65:397-412

8. Pajukanta P, Allayee H, Krass KL, et al. 2003 Combined analysis of genome scans of dutch and finnish families reveals a susceptibility locus for high-density lipoprotein cholesterol on chromosome 16q. Am J Hum Genet 72:903-17

9. Pajukanta P, Lilja HE, Sinsheimer JS, et al. 2004 Familial combined hyperlipidemia is associated with upstream transcription factor 1 (USF1). Nat Genet 36:371-6

10. Mootha VK, Lindgren CM, Eriksson KF, et al. 2003 PGC-1alpha-responsive genes involved in oxidative phosphorylation are coordinately downregulated in human diabetes. Nat Genet 34:267-73 
11. Eurlings PM, Van Der Kallen CJ, Geurts JM, Kouwenberg P, Boeckx WD, De Bruin TW 2002 Identification of differentially expressed genes in subcutaneous adipose tissue from subjects with familial combined hyperlipidemia. J Lipid Res 43:930-5

12. Keulen ET, Voors-Pette C, de Bruin TW 2001 Familial dyslipidemic hypertension syndrome: familial combined hyperlipidemia, and the role of abdominal fat mass. Am J Hypertens 14:357-63

13. Lindsey JK, Jones B 1998 Choosing among generalized linear models applied to medical data. Stat Med 17:59-68

14. Akaike H 1973 Information theory and an extension of the maximum likelihood principle. 2nd Inter. Symp. on Information Theory. In: Petrov BN, Csaki F (eds). Akademiai Kiado, Budapest, pp 267-281

15. Coort SL, Willems J, Coumans WA, et al. 2002 Sulfo-N-succinimidyl esters of long chain fatty acids specifically inhibit fatty acid translocase (FAT/CD36)-mediated cellular fatty acid uptake. Mol Cell Biochem 239:213-9

16. Gaster M, Rustan AC, Aas V, Beck-Nielsen H 2004 Reduced lipid oxidation in skeletal muscle from type 2 diabetic subjects may be of genetic origin: evidence from cultured myotubes. Diabetes 53:542-8

17. Abumrad NA, el-Maghrabi MR, Amri EZ, Lopez E, Grimaldi PA 1993 Cloning of a rat adipocyte membrane protein implicated in binding or transport of long-chain fatty acids that is induced during preadipocyte differentiation. Homology with human CD36. J Biol Chem 268:17665-8

18. Hirano K, Kuwasako T, Nakagawa-Toyama Y, Janabi M, Yamashita S, Matsuzawa Y 2003 Pathophysiology of human genetic CD36 deficiency. Trends Cardiovasc Med 13:136-41

19. Georgieva AM, van Greevenbroek MM, Krauss RM, et al. 2004 Subclasses of low-density lipoprotein and very low-density lipoprotein in familial combined hyperlipidemia: relationship to multiple lipoprotein phenotype. Arterioscler Thromb Vasc Biol 24:744-9

20. Aitman TJ, Glazier AM, Wallace CA, et al. 1999 Identification of Cd36 (Fat) as an insulinresistance gene causing defective fatty acid and glucose metabolism in hypertensive rats. Nat Genet 21:76-83

21. Ibrahimi A, Bonen A, Blinn WD, et al. 1999 Muscle-specific overexpression of FAT/CD36 enhances fatty acid oxidation by contracting muscle, reduces plasma triglycerides and fatty acids, and increases plasma glucose and insulin. J Biol Chem 274:26761-6

22. Coburn CT, Knapp FF, Jr., Febbraio M, Beets AL, Silverstein RL, Abumrad NA 2000 Defective uptake and utilization of long chain fatty acids in muscle and adipose tissues of CD36 knockout mice. J Biol Chem 275:32523-9

23. Brown MS, Goldstein JL 1974 Familial hypercholesterolemia: defective binding of lipoproteins to cultured fibroblasts associated with impaired regulation of 3-hydroxy-3methylglutaryl coenzyme A reductase activity. Proc Natl Acad Sci U S A 71:788-92

24. van der Kallen CJ, Voors-Pette C, Bouwman FG, et al. 2002 Evidence of insulin resistant lipid metabolism in adipose tissue in familial combined hyperlipidemia, but not type 2 diabetes mellitus. Atherosclerosis 164:337-46

25. Coort SL, Hasselbaink DM, Koonen DP, et al. 2004 Enhanced sarcolemmal FAT/CD36 content and triacylglycerol storage in cardiac myocytes from obese zucker rats. Diabetes 53:1655-63 
26. Bonen A, Parolin ML, Steinberg GR, et al. 2004 Triacylglycerol accumulation in human obesity and type 2 diabetes is associated with increased rates of skeletal muscle fatty acid transport and increased sarcolemmal FAT/CD36. Faseb J

27. Liang CP, Han S, Okamoto H, et al. 2004 Increased CD36 protein as a response to defective insulin signaling in macrophages. J Clin Invest 113:764-73

28. Griffin E, Re A, Hamel N, et al. 2001 A link between diabetes and atherosclerosis: Glucose regulates expression of CD36 at the level of translation. Nat Med 7:840-6 



\section{Chapter 4}

\section{Activating Transcription Factor 6 Polymorphisms and Haplotypes Are Associated with Impaired Glucose Homeostasis and Type 2 Diabetes in Dutch Caucasians.}

\begin{abstract}
SUMMARY
An association between genetic variation in ATF6 and type 2 diabetes was recently reported in Pima Indians. To investigate the broader significance of this association for type 2 diabetes, replication studies in distinct ethic populations are required. We investi-

gated ATF6 for its association with type 2 diabetes in Dutch Caucasians.Two independent Dutch cohorts, comprising a total of

952 subjects, were used to investigate the genetic association between polymorphisms in the ATF6 gene and disturbed glucose homeostasis / type 2 diabetes. Cohort $1(N=154)$ was used to eva-

luate genetic variation in the ATF6-gene in relation to glucose homeostasis in the general population. Cohort $2(N=798)$ consisted of patients with type 2 diabetes, impaired glucose tolerance, impaired fasting glucose, and normoglycaemic control subjects and was used to investigate ATF6 polymorphisms for their contribution to disturbed glucose homeostasis and type 2 diabetes. Sixteen

tag-SNPs, including three nonsynonymous coding variants, captured all common allelic variants of ATF6, and were genotyped in all subjects of both cohorts. Our data show that common ATF6 variants are associated with elevated glucose levels in the general population (Cohort 1, P=0.009-0.04). Furthermore, the majority of these variants, and haplotypes thereof, were significantly associated with impaired fasting glucose, impaired glucose tolerance and type 2 diabetes. (Cohort 2, p=0.006-0.05). Associated variants differ from those identified in Pima Indians. This study extensively investigated the ATF6-gene in Dutch Caucasians. Our results strengthen the evidence that one or more variants in ATF6 are associated with dissturbed glucose homeostasis and type 2 diabetes.
\end{abstract}

\author{
Steven J.R. Meex \\ Marleen M.J. van Greevenbroek \\ Torik A. Ayoubi \\ Robert Vlietinck \\ Jana V. van Vliet-Ostaptchouk \\ Marten H. Hofker \\ Vicky M. M-J Vermeulen \\ Casper G. Schalkwijk \\ Edith J.M. Feskens \\ Jolanda M.A. Boer \\ Coen D.A. Stehouwer \\ Carla J.H. van der Kallen \\ Tjerk W.A. de Bruin \\ The Journal of Clinical \\ Endocrinology \& Metabolism \\ 2007, 92(7):2720-2725
}




\section{Introduction}

Evidence is emerging in literature that the endoplasmic reticulum (ER) may represent a major link between obesity, insulin resistance, beta cell function and type 2 diabetes (DM2) (1-5). Obesity generates stress conditions that increase the demand on the ER. To cope with this stress, cells initiate a signal transduction pathway called the ER-stress response, or unfolded protein response (UPR). Activation of the UPR is regulated by three ER stress sensors: PERK (PKR-like endoplasmic reticulum kinase), IRE1 (inositol requiring 1) and ATF6 (activating transcription factor 6) (6). Activation of PERK, IRE1 and ATF6 is under control of a master UPR regulator, the ER chaperone protein BiP/Grp78. The PERK and IRE1 initiated pathways of the unfolded protein response play an important role in DM2 through effects on beta cell function and peripheral insulin signaling respectively $(1,3)$.

Within the framework of a previous gene expression study (7) we found a positive significant correlation between in vitro mRNA levels of BiP/Grp78 in cultured EBV-transformed lymphoblasts, and the fasting plasma glucose levels that had been measured in the corresponding subjects, in vivo. Therefore, we hypothesized that the intrinsic cellular UPR capacity may partially determine a subject's plasma glucose level, and moreover that genetic variation in UPR genes may contribute to DM2. An excellent candidate gene to link UPR capacity to DM2 is ATF6. First, ATF6 is essential for full activation of the UPR and considered as a critical UPR-initiator in mammalian cells (8). Second, ATF6 induces expression of $\mathrm{BiP} / \mathrm{Grp} 78$ both directly and indirectly via activation of XBP1. Third, ATF6 maps to chromosome 1q23.3, the most replicated chromosomal locus for DM2 (9). While preparing this manuscript, Thameem et al reported an association of ATF6 with DM2 in Pima Indians (10). To investigate the broader significance of this association for DM2, replication studies in additional populations are required. In the present study, we investigated ATF6 as a positional and functional candidate gene for disturbed glucose homeostasis and DM2. 


\section{Materials and Methods}

\section{Study populations}

Two independent Dutch cohorts, comprising a total of 952 Caucasian subjects, were used to investigate the genetic association between polymorphisms in the ATF6 gene, disturbed glucose homeostasis, and DM2. The first cohort $(\mathrm{N}=154)$ was recruited as spouses of hyperlipidemic patients, collected within the framework of a family study on the genetics of Familial Combined Hyperlipidemia. These subjects, not selected in any way, represent the general population and exhibited the following clinical characteristics: $42 \%$ males, age $51 \pm$ 11 years, body mass index $25.4 \pm 3.9 \mathrm{~kg} / \mathrm{m} 2$, fasting blood glucose $4.9 \pm 0.7$ $\mathrm{mmol} / \mathrm{L}$, fasting plasma insulin $6.1 \pm 5.4 \mu \mathrm{U} / \mathrm{mL}$ and HOMA IR $1.4 \pm 1.5$. In this cohort, 137 subjects $(89 \%)$ had normal fasting glucose levels, 16 subjects $(10.5 \%)$ had impaired fasting glucose levels, and one subject $(<1 \%)$ had DM2. No DNA was available for three subjects, leaving 151 subjects available for analyses. This cohort was used to explore the genetic variation in the ATF6 gene in relation to glucose homeostasis in the general population.

A second independent Dutch cohort ( $\mathrm{N}=798)$ that consisted of 211 DM2 patients, 208 IFG/IGT subjects and 379 normoglycemic controls was used to investigate ATF6 polymorphisms for their contribution to disturbed glucose homeostasis and type 2 diabetes. This case control cohort was collected as described previously $(11,12)$. Briefly, more than 2700 subjects with one or more cardiovascular risk factors, including hypertension, BMI $>25 \mathrm{~kg} / \mathrm{m} 2$, a positive family history for DM2, or a history of gestational diabetes, were screened for DM2. Exclusion criteria were the use of medication that affects glucose metabolism and non-Caucasian ethnicity. All newly diagnosed subjects with impaired fasting glucose, impaired glucose tolerance or type 2 diabetes, and a random selection of 379 normoglycemic control subjects were included in the present study. Characteristics of this cohort are provided in table 1. The Human Investigation Review Committee of the Academic Hospital Maastricht approved the study protocol, and all subjects gave written informed consent.

\section{SNP selection and genotyping}

SNP selection was designed to achieve a $100 \%$ coverage of the common genetic variation (Minor allele frequency MAF $>10 \%$ ) of the ATF6-gene including 
$3 \mathrm{~kb}$ upstream and downstream this locus. Using the HAPMAP database, 13 tag-SNPs were selected for genotyping. One tag-SNP (SNP 4) was located in an exon and caused an amino acid substitution. In addition to the selection of 13 SNPs by the tagging process, 3 additional SNPs were selected for their potential direct functional effect: SNP3 and SNP5 for their location in exons, causing an amino acid substitution, and SNP15 for its location in the 3' UTR. In total, 16 SNPs were genotyped in 952 subjects. Genotyping was done using the TaqMan 7900HT (Applied Biosystems).

Table 1. Characteristics of sample 2.

\begin{tabular}{l|ccc|}
\multicolumn{1}{c}{ Trait } & NGT & IFG/IGT & DM2 \\
\hline N (male/female) & $379(222 / 157)$ & $208(125 / 83)$ & $211(144 / 67)$ \\
\hline Age (years) & $58 \pm 7$ & $58 \pm 7$ & $60 \pm 7$ \\
\hline BMI $\left(\mathrm{kg} / \mathrm{m}^{2}\right)$ & $27.4 \pm 3.8$ & $29.3 \pm 4.2$ & $30.7 \pm 4.4$ \\
\hline $\begin{array}{l}\text { Data are mean } \pm \text { SD, } \\
\text { paired fasting glucose, IGT impaired glucose e tolerance, DM2 type 2 diabetes. }\end{array}$
\end{tabular}

\section{Statistical Analyses}

Power calculations were performed using the genetic power calculator of Purcell et al (13) (available at http://pngu.mgh.harvard.edu/ purcell/gpc/). Assuming a disease prevalence of 0.1 , a genotype relative risk of 1.1 and 2.3 (the calculated relative risks of Aa and AA respectively in a previous study (10)), and an allele frequency of 0.2 (the frequency of the ATF6 risk allele, previously associated with DM2 (10)), the case control sample afforded an estimated power of $71 \%$ at $p<0.05$. Linkage disequilibrium statistics were analyzed by Haploview software (14). Haplotypes were constructed using the program SNPHAP. Analyses of variance and Student's t-tests were used to test polymorphisms in the ATF6 gene for association with plasma glucose levels. Odds ratios and P-values for case control analyses were calculated using logistic regression analyses in which "allele" was parameterized in the model as a dichotomous variable. Adjustments for age, gender and body mass index were done by including these variables in the logistic regression model. 


\section{Results}

\section{The intrinsic capacity of the unfolded protein response may influence fasting plasma glucose levels}

In a previous gene expression experiment, designed to study the genetic background of combined hyperlipidemia, we cultured EBV-transformed lymphoblast cells from 12 hyperlipidemic patients and 12 normolipidemic controls (7). To further explore this dataset in relation to glucose homeostasis, we measured plasma glucose levels in these subjects and re-analyzed transcript levels in relation to this previously unstudied trait. One subject with a fasting plasma glucose $>3$ standard-deviations of the mean was excluded, leaving 23 subjects for analyses. Subjects exhibited the following characteristics: age $50 \pm 9$ years, 11 males / 12 females, and fasting plasma glucose levels: $5.3 \pm 0.8 \mathrm{mmol} / \mathrm{L}$. A complete clinical characterization of these subjects has been provided in an article by Morello et al (7). We observed a strong positive correlation $(\mathrm{r}=0.57$, $\mathrm{p}=0.004)$ between in vitro mRNA levels of BiP/Grp78 and the fasting plasma glucose levels in the corresponding subjects, in vivo (Figure 1).

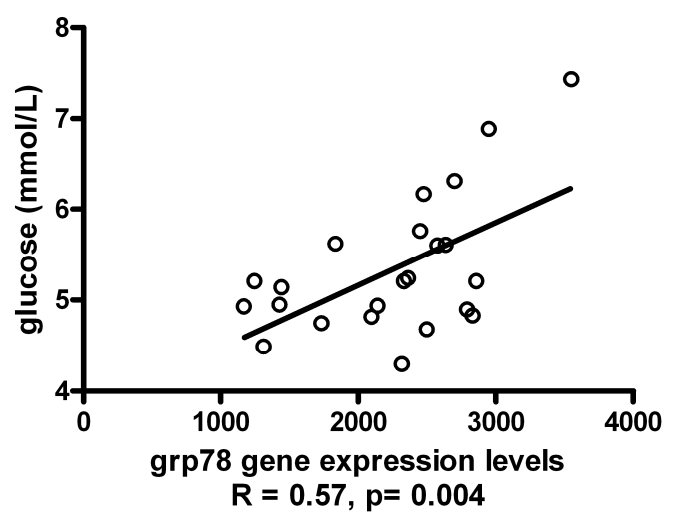

Figure 1 Grp78 gene expression levels in immortalized cultured lymphoblasts versus corresponding fasting plasma glucose levels in each of the 23 subjects studied. Mean fasting plasma glucose level at the time of B-cell isolation was $5.3 \pm 0.76 \mathrm{mmol} / \mathrm{L}$. Other clinical and anthropometric characteristics of the subjects are described in (7)

This correlation is very unlikely the result of the well-known response of Bip/Grp78 expression to glucose (15), since all cells had been cultured for several weeks under isoglycaemic and standardized conditions. This observation led to the hypothesis that the intrinsic UPR capacity may partially determine fasting plasma glucose levels, and that UPR genes may be involved in glucose 
homeostasis. We therefore performed a genetic association study with ATF6, a key gene of the unfolded protein response, and transcriptional regulator of Bip/Grp78.

\section{Genetic variation in the ATF6 gene}

The ATF6 gene consists of 16 exons that span approximately $193 \mathrm{~kb}$ of genomic DNA. The gene structure of ATF6, the frequencies of the minor alleles for each SNP, and the pairwise correlation of alleles between various SNPs are depicted in Figure 2 (data for cohort 2, N=798). Genotype success rate was $>97 \%$ for all 16 genotyped SNPs. All SNPs were in Hardy Weinberg equilibrium.

\section{ATF6}

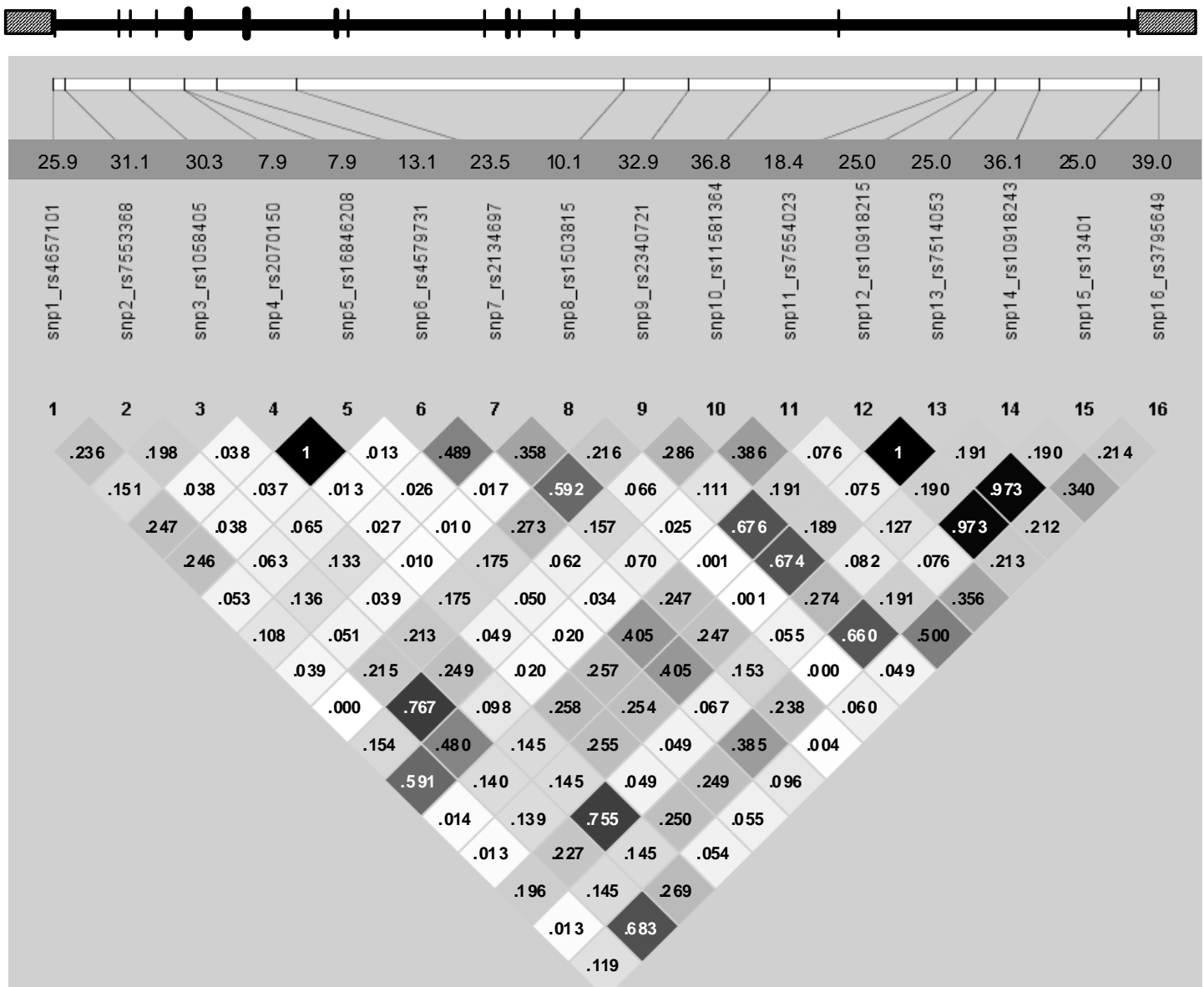

Figure 2. Genetic structure of the ATF6 gene, including the 16 genotyped SNPs and minor allele frequencies (MAF). Dashed boxes represent the promoter region and the 3'untranslated region. Exons are represented by vertical lines. Minor allele frequencies of the genotyped SNPS are shown in the gray horizontal bar. The shade of the diamonds represents the pairwise $r^{2}$ between the two SNPs defined by the top left and the top right sides of the diamond. Shading represents the magnitude of pairwise $r^{2}$, with at the extremes white reflecting very low $r^{2}(<0.20)$ and black reflecting very high $r^{2}(>0.80)$ 


\section{ATF6 polymorphisms are associated with fasting plasma glucose levels in the general population (Cohort 1)}

First, we investigated whether genetic variation in the ATF6-gene was associated with fasting glucose levels in the first cohort from the general population (Table 2). Analyses of variance revealed a significant association of SNP 9 , SNP 12, SNP 13 and SNP 15 with fasting glucose levels in this cohort $(\mathrm{p}=0.018$ 0.053). Further analyses under a dominant genetic model strengthened the evidence for association with these SNPs ( $\mathrm{p}=0.005-0.015)$. In addition, SNP3 and SNP6 were borderline significant under a dominant genetic model. These data suggest that ATF6 polymorphisms modulate plasma glucose levels in the general population.

\section{ATF6 polymorphisms are associated with disturbed glucose homeostasis and type 2 diabetes (Cohort 2)}

Next, to test the hypothesis that variation in ATF6 contributes to disturbed glucose metabolism and DM2, we genotyped all selected SNPs in the second cohort ( $\mathrm{n}=798)$, comprising 211 patients with type 2 diabetes, 208 subjects with IFG/IGT, and 379 normoglycemic controls (Table 3). In line with results from the first cohort, prevalence of the minor allele of SNP 12, SNP 13 and SNP 15 was significantly increased in cases compared to control subjects $(p=0.033$ 0.051). Furthermore SNP 6, which showed a trend for association in cohort 1 , was significantly different in cases and controls of cohort 2 (unadjusted $\mathrm{p}=0.027$ ). For SNP 3 and SNP 9 we were not able to confirm the significant association of cohort 1 . Statistical analyses using alternative genetic models (genotype, dominant, recessive) support these findings ( $\mathrm{p}=0.01-0.05$; Table 4)

\section{Haplotype analysis}

Haplotype analysis provided similar results. Statistical reconstruction of haplotypes comprising the four significantly associated SNPs (SNP 6, 12, 13 and 15), identified three common haplotypes which together account for $99 \%$ of observed haplotypes in cases and controls (Table 5). We identified an "at risk" haplotype (GGAG), with higher prevalence in subjects with type 2 diabetes, impaired glucose tolerance and impaired fasting glucose compared to controls ( $14.4 \%$ versus $9.9 \%$, odds ratio $=1.54 ; 95 \%$ C.I. $1.13-2.09 ; \mathrm{p}=0.006)$. The opposite AAGA-haplotype showed a trend for higher prevalence in control subjects 
Table 2. Associations (genotype effects) of ATF6 polymorphisms with fasting plasma glucose levels in the general population. (Sample 1)

\begin{tabular}{|c|c|c|c|c|c|c|}
\hline $\begin{array}{l}\text { SNP } \\
\text { (rs) }\end{array}$ & Genotype & $\mathrm{N}$ & $\begin{array}{l}\text { Glucose } \pm \text { sd } \\
(\mathrm{mmol} / \mathrm{L})\end{array}$ & $\begin{array}{l}\text { p-value } \\
\text { gen. }\end{array}$ & $\begin{array}{l}\text { p-value } \\
\text { rec. }\end{array}$ & $\begin{array}{l}\mathrm{p} \text {-value } \\
\text { dom. }\end{array}$ \\
\hline $\begin{array}{l}\text { SNP } 1 \\
\text { rs } 4657101\end{array}$ & $\begin{array}{l}A / A \\
A / C \\
C / C\end{array}$ & $\begin{array}{l}94 \\
34 \\
12\end{array}$ & $\begin{array}{l}4.85 \pm 0.54 \\
5.00 \pm 0.89 \\
4.90 \pm 0.51\end{array}$ & 0.501 & 0.938 & 0.276 \\
\hline $\begin{array}{l}\text { SNP } 2 \\
\text { rs7553368 }\end{array}$ & $\begin{array}{l}\mathrm{T} / \mathrm{T} \\
\mathrm{T} / \mathrm{C} \\
\mathrm{C} / \mathrm{C}\end{array}$ & $\begin{array}{l}70 \\
56 \\
16\end{array}$ & $\begin{array}{l}4.95 \pm 0.68 \\
4.90 \pm 0.73 \\
4.82 \pm 0.61\end{array}$ & 0.789 & 0.559 & 0.584 \\
\hline $\begin{array}{l}\text { SNP 3 } \\
\text { rs1058405 }\end{array}$ & $\begin{array}{l}A / A \\
A / G \\
G / G\end{array}$ & $\begin{array}{l}78 \\
53 \\
13\end{array}$ & $\begin{array}{l}5.00 \pm 0.79 \\
4.78 \pm 0.57 \\
4.72 \pm 0.45\end{array}$ & 0.123 & 0.331 & 0.043 \\
\hline $\begin{array}{l}\text { SNP } 4 \\
\text { rs2070150 }\end{array}$ & $\begin{array}{l}\mathrm{G} / \mathrm{G} \\
\mathrm{G} / \mathrm{C} \\
\mathrm{C} / \mathrm{C}\end{array}$ & $\begin{array}{c}125 \\
17 \\
1\end{array}$ & $\begin{array}{c}4.88 \pm 0.65 \\
5.05 \pm 0.81 \\
5.60\end{array}$ & 0.357 & 0.297 & 0.232 \\
\hline $\begin{array}{l}\text { SNP 5 } \\
\text { rs16846208 }\end{array}$ & $\begin{array}{l}\mathrm{C} / \mathrm{C} \\
\mathrm{C} / \mathrm{T} \\
\mathrm{T} / \mathrm{T}\end{array}$ & $\begin{array}{c}124 \\
16 \\
1\end{array}$ & $\begin{array}{c}4.89 \pm 0.67 \\
5.08 \pm 0.83 \\
5.6\end{array}$ & 0.356 & 0.323 & 0.214 \\
\hline $\begin{array}{l}\text { SNP } 6 \\
\text { rs4579731 }\end{array}$ & $\begin{array}{l}A / A \\
A / G \\
G / G\end{array}$ & $\begin{array}{c}102 \\
38 \\
1\end{array}$ & $\begin{array}{c}4.84 \pm 0.58 \\
5.10 \pm 0.91 \\
4.60\end{array}$ & 0.127 & 0.657 & 0.057 \\
\hline $\begin{array}{c}\text { SNP } 7 \\
\text { rs2134697 }\end{array}$ & $\begin{array}{l}\mathrm{T} / \mathrm{T} \\
\mathrm{T} / \mathrm{C} \\
\mathrm{C} / \mathrm{C}\end{array}$ & $\begin{array}{c}76 \\
63 \\
6\end{array}$ & $\begin{array}{l}4.81 \pm 0.58 \\
4.99 \pm 0.83 \\
5.03 \pm 0.45\end{array}$ & 0.306 & 0.625 & 0.125 \\
\hline $\begin{array}{l}\text { SNP 8 } \\
\text { rs1503815 }\end{array}$ & $\begin{array}{l}\mathrm{C} / \mathrm{C} \\
\mathrm{C} / \mathrm{T} \\
\mathrm{T} / \mathrm{T}\end{array}$ & $\begin{array}{c}115 \\
31 \\
1\end{array}$ & $\begin{array}{c}4.89 \pm 0.72 \\
4.89 \pm 0.50 \\
5.3\end{array}$ & 0.838 & 0.552 & 0.912 \\
\hline $\begin{array}{l}\text { SNP 9 } \\
\text { rs2340721 }\end{array}$ & $\begin{array}{l}A A \\
C / A \\
C / C\end{array}$ & $\begin{array}{l}61 \\
73 \\
14\end{array}$ & $\begin{array}{l}4.73 \pm 0.51 \\
5.03 \pm 0.77 \\
5.01 \pm 0.75\end{array}$ & 0.033 & 0.567 & 0.009 \\
\hline $\begin{array}{l}\text { SNP } 10 \\
\text { rs11581364 }\end{array}$ & $\begin{array}{l}\mathrm{G} / \mathrm{G} \\
\mathrm{G} / \mathrm{T} \\
\mathrm{T} / \mathrm{T}\end{array}$ & $\begin{array}{l}53 \\
66 \\
22\end{array}$ & $\begin{array}{l}4.93 \pm 0.59 \\
4.89 \pm 0.69 \\
4.84 \pm 0.54\end{array}$ & 0.857 & 0.664 & 0.636 \\
\hline $\begin{array}{l}\text { SNP } 11 \\
\text { rs7554023 }\end{array}$ & $\begin{array}{l}A / A \\
A / G \\
G / G\end{array}$ & $\begin{array}{c}107 \\
28 \\
8\end{array}$ & $\begin{array}{l}4.94 \pm 0.65 \\
4.87 \pm 0.88 \\
4.71 \pm 0.29\end{array}$ & 0.630 & 0.397 & 0.441 \\
\hline $\begin{array}{l}\text { SNP } 12 \\
\text { rs10918215 }\end{array}$ & $\begin{array}{l}A / A \\
A / G \\
G / G\end{array}$ & $\begin{array}{l}80 \\
56 \\
10\end{array}$ & $\begin{array}{l}4.77 \pm 0.53 \\
5.08 \pm 0.81 \\
5.09 \pm 0.83\end{array}$ & 0.025 & 0.390 & 0.006 \\
\hline $\begin{array}{l}\text { SNP } 13 \\
\text { rs7514053 }\end{array}$ & $\begin{array}{l}G / G \\
G / A \\
A / A\end{array}$ & $\begin{array}{l}78 \\
56 \\
10\end{array}$ & $\begin{array}{l}4.76 \pm 0.53 \\
5.08 \pm 0.81 \\
5.09 \pm 0.83\end{array}$ & 0.018 & 0.376 & 0.005 \\
\hline $\begin{array}{c}\text { SNP } 14 \\
\text { rs10918243 }\end{array}$ & $\begin{array}{l}\mathrm{T} / \mathrm{T} \\
\mathrm{T} / \mathrm{C} \\
\mathrm{C} / \mathrm{C}\end{array}$ & $\begin{array}{l}64 \\
61 \\
18\end{array}$ & $\begin{array}{l}4.98 \pm 0.76 \\
4.91 \pm 0.65 \\
4.68 \pm 0.48\end{array}$ & 0.260 & 0.120 & 0.304 \\
\hline $\begin{array}{l}\text { SNP } 15 \\
\text { rs13401 }\end{array}$ & $\begin{array}{l}A / A \\
A / G \\
G / G\end{array}$ & $\begin{array}{l}82 \\
57 \\
12\end{array}$ & $\begin{array}{l}4.77 \pm 0.53 \\
5.05 \pm 0.82 \\
5.00 \pm 0.79\end{array}$ & 0.053 & 0.577 & 0.015 \\
\hline $\begin{array}{l}\text { SNP } 16 \\
\text { rs3795649 }\end{array}$ & $\begin{array}{l}\mathrm{C} / \mathrm{C} \\
\mathrm{C} / \mathrm{T} \\
\mathrm{T} / \mathrm{T}\end{array}$ & $\begin{array}{l}57 \\
62 \\
26\end{array}$ & $\begin{array}{l}4.94 \pm 0.73 \\
4.91 \pm 0.66 \\
4.85 \pm 0.67\end{array}$ & 0.849 & 0.616 & 0.657 \\
\hline
\end{tabular}


Table 3. ATF6 SNP allele frequencies in cases (DM2. IFG, and IGT) and normoglycemic control subjects. (Sample 2)

\begin{tabular}{|c|c|c|c|c|c|c|}
\hline $\begin{array}{l}\text { SNP } \\
\text { rs no }\end{array}$ & $\begin{array}{l}\text { No. of } \\
\text { alleles }\end{array}$ & $\begin{array}{l}\text { Affected } \\
\text { status }\end{array}$ & $\begin{array}{l}\text { No. of } \\
\text { allele } 1 \\
(\%)\end{array}$ & $\begin{array}{l}\text { No. of } \\
\text { allele } 2 \\
(\%)\end{array}$ & p-value & $\begin{array}{l}\text { p-value } \\
\text { adjusted* }\end{array}$ \\
\hline $\begin{array}{l}\text { SNP 1 } \\
\text { rs4657101 }\end{array}$ & 1570 & $\begin{array}{c}\text { Controls } \\
\text { Cases }\end{array}$ & $\begin{array}{l}551(0.74) \\
613(0.75)\end{array}$ & $\begin{array}{l}197(0.26) \\
209(0.25)\end{array}$ & 0.680 & 0.805 \\
\hline $\begin{array}{l}\text { SNP 2 } \\
\text { rs7553368 }\end{array}$ & 1570 & $\begin{array}{c}\text { Controls } \\
\text { Cases }\end{array}$ & $\begin{array}{l}506(0.68) \\
576(0.70)\end{array}$ & $\begin{array}{l}244(0.32) \\
244(0.30)\end{array}$ & 0.235 & 0.237 \\
\hline $\begin{array}{l}\text { SNP } 3 \\
\text { rs1058405 }\end{array}$ & 1582 & $\begin{array}{c}\text { Controls } \\
\text { Cases }\end{array}$ & $\begin{array}{l}527(0.70) \\
576(0.70)\end{array}$ & $\begin{array}{l}227(0.30) \\
252(0.30)\end{array}$ & 0.887 & 0.855 \\
\hline $\begin{array}{l}\text { SNP } 4 \\
\text { rs2070150 }\end{array}$ & 1578 & $\begin{array}{c}\text { Controls } \\
\text { Cases }\end{array}$ & $\begin{array}{l}693(0.92) \\
760(0.92)\end{array}$ & $\begin{array}{l}61(0.08) \\
64(0.08)\end{array}$ & 0.812 & 0.974 \\
\hline $\begin{array}{l}\text { SNP 5 } \\
\text { rs } 16846208\end{array}$ & 1584 & $\begin{array}{c}\text { Controls } \\
\text { Cases }\end{array}$ & $\begin{array}{l}693(0.92) \\
766(0.92)\end{array}$ & $\begin{array}{l}61(0.08) \\
64(0.08)\end{array}$ & 0.780 & 0.992 \\
\hline $\begin{array}{l}\text { SNP } 6 \\
\text { rs4579731 }\end{array}$ & 1564 & $\begin{array}{c}\text { Controls } \\
\text { Cases }\end{array}$ & $\begin{array}{l}656(0.89) \\
703(0.85)\end{array}$ & $\begin{array}{c}82(0.11) \\
123(0.15)\end{array}$ & 0.027 & 0.037 \\
\hline $\begin{array}{l}\text { SNP } 7 \\
\text { rs2134697 }\end{array}$ & 1576 & $\begin{array}{c}\text { Controls } \\
\text { Cases }\end{array}$ & $\begin{array}{l}590(0.79) \\
615(0.75)\end{array}$ & $\begin{array}{l}162(0.21) \\
209(0.25)\end{array}$ & 0.074 & 0.082 \\
\hline $\begin{array}{l}\text { SNP 8 } \\
\text { rs1503815 }\end{array}$ & 1566 & $\begin{array}{c}\text { Controls } \\
\text { Cases }\end{array}$ & $\begin{array}{l}672(0.90) \\
736(0.90)\end{array}$ & $\begin{array}{l}76(0.10) \\
82(0.10)\end{array}$ & 0.929 & 0.985 \\
\hline $\begin{array}{l}\text { SNP 9 } \\
\text { rs2340721 }\end{array}$ & 1584 & $\begin{array}{c}\text { Controls } \\
\text { Cases }\end{array}$ & $\begin{array}{l}519(0.69) \\
545(0.66)\end{array}$ & $\begin{array}{l}235(0.31) \\
285(0.34)\end{array}$ & 0.180 & 0.136 \\
\hline $\begin{array}{l}\text { SNP } 10 \\
\text { rs11581364 }\end{array}$ & 1574 & $\begin{array}{c}\text { Controls } \\
\text { Cases }\end{array}$ & $\begin{array}{l}458(0.61) \\
536(0.65)\end{array}$ & $\begin{array}{l}290(0.39) \\
290(0.35)\end{array}$ & 0.133 & 0.165 \\
\hline $\begin{array}{l}\text { SNP } 11 \\
\text { rs7554023 }\end{array}$ & 1574 & $\begin{array}{c}\text { Controls } \\
\text { Cases }\end{array}$ & $\begin{array}{l}608(0.81) \\
677(0.82)\end{array}$ & $\begin{array}{l}140(0.19) \\
149(0.18)\end{array}$ & 0.729 & 0.730 \\
\hline $\begin{array}{l}\text { SNP } 12 \\
\text { rs10918215 }\end{array}$ & 1578 & $\begin{array}{c}\text { Controls } \\
\text { Cases }\end{array}$ & $\begin{array}{l}580(0.77) \\
603(0.73)\end{array}$ & $\begin{array}{l}170(0.23) \\
225(0.27)\end{array}$ & 0.039 & 0.043 \\
\hline $\begin{array}{l}\text { SNP } 13 \\
\text { rs7514053 }\end{array}$ & 1592 & $\begin{array}{c}\text { Controls } \\
\text { Cases }\end{array}$ & $\begin{array}{l}575(0.77) \\
606(0.73)\end{array}$ & $\begin{array}{l}169(0.23) \\
242(0.27)\end{array}$ & 0.051 & 0.058 \\
\hline $\begin{array}{l}\text { SNP } 14 \\
\text { rs10918243 }\end{array}$ & 1576 & $\begin{array}{c}\text { Controls } \\
\text { Cases }\end{array}$ & $\begin{array}{l}481(0.64) \\
526(0.64)\end{array}$ & $\begin{array}{l}273(0.36) \\
296(0.36)\end{array}$ & 0.935 & 0.758 \\
\hline $\begin{array}{l}\text { SNP } 15 \\
\text { rs13401 }\end{array}$ & 1596 & $\begin{array}{c}\text { Controls } \\
\text { Cases }\end{array}$ & $\begin{array}{l}586(0.77) \\
609(0.73)\end{array}$ & $\begin{array}{l}172(0.23) \\
229(0.27)\end{array}$ & 0.033 & 0.042 \\
\hline $\begin{array}{l}\text { SNP } 16 \\
\text { rs3795649 }\end{array}$ & 1570 & $\begin{array}{c}\text { Controls } \\
\text { Cases }\end{array}$ & $\begin{array}{l}439(0.59) \\
520(0.63)\end{array}$ & $\begin{array}{l}307(0.41) \\
304(0.37)\end{array}$ & 0.084 & 0.143 \\
\hline
\end{tabular}


Table 4. ATF6 genotype frequencies in cases (DM2, IFG and IGT) and normoglycemic control subjects. (Sample 2)

\begin{tabular}{|c|c|c|c|c|c|c|}
\hline $\begin{array}{l}\text { SNP } \\
\text { (rs) }\end{array}$ & Genotype & $\begin{array}{l}\text { Controls } \\
\text { N (\%) }\end{array}$ & $\begin{array}{l}\text { Cases } \\
\mathrm{N}(\%)\end{array}$ & $\begin{array}{l}\text { p-value } \\
\text { gen. }\end{array}$ & $\begin{array}{l}\text { p-value } \\
\text { rec. }\end{array}$ & $\begin{array}{c}\text { p-value } \\
\text { dom. }\end{array}$ \\
\hline $\begin{array}{l}\text { SNP } 2 \\
\text { rs } 4657101\end{array}$ & $\begin{array}{l}A / A \\
A / C \\
C / C\end{array}$ & $\begin{array}{c}206(55) \\
139(37) \\
29(8)\end{array}$ & $\begin{array}{c}222(54) \\
169(41) \\
20(5)\end{array}$ & 0.179 & 0.095 & 0.765 \\
\hline $\begin{array}{l}\text { SNP 2 } \\
\text { rs7553368 }\end{array}$ & $\begin{array}{l}T / T \\
T / C \\
C / C\end{array}$ & $\begin{array}{c}167(44) \\
172(46) \\
36(10)\end{array}$ & $\begin{array}{c}195(48) \\
186(45) \\
29(7)\end{array}$ & 0.385 & 0.199 & 0.395 \\
\hline $\begin{array}{l}\text { SNP 3 } \\
\text { rs1058405 }\end{array}$ & $\begin{array}{l}A / A \\
A / G \\
G / G\end{array}$ & $\begin{array}{c}179(47) \\
169(45) \\
29(8)\end{array}$ & $\begin{array}{c}200(48) \\
176(43) \\
38(9)\end{array}$ & 0.675 & 0.453 & 0.816 \\
\hline $\begin{array}{l}\text { SNP } 4 \\
\text { rs2070150 }\end{array}$ & $\begin{array}{l}\text { G/G } \\
\text { G/C } \\
C / C\end{array}$ & $\begin{array}{c}319(85) \\
55(14) \\
3(1)\end{array}$ & $\begin{array}{c}351(85) \\
58(14) \\
3(1)\end{array}$ & 0.973 & 0.913 & 0.820 \\
\hline $\begin{array}{c}\text { SNP } 5 \\
\text { rs16846208 }\end{array}$ & $\begin{array}{l}C / C \\
C / T \\
T / T\end{array}$ & $\begin{array}{c}319(85) \\
55(14) \\
3(1)\end{array}$ & $\begin{array}{c}354(85) \\
58(14) \\
3(1)\end{array}$ & 0.962 & 0.906 & 0.787 \\
\hline $\begin{array}{l}\text { SNP } 6 \\
\text { rs4579731 }\end{array}$ & $\begin{array}{l}A / A \\
A / G \\
G / G\end{array}$ & $\begin{array}{c}293(79) \\
70(19) \\
6(2)\end{array}$ & $\begin{array}{c}295(71) \\
113(28) \\
5(1)\end{array}$ & 0.021 & 0.622 & 0.010 \\
\hline $\begin{array}{c}\text { SNP } 7 \\
\text { rs2134697 }\end{array}$ & $\begin{array}{l}\mathrm{T} / \mathrm{T} \\
\mathrm{T} / \mathrm{C} \\
\mathrm{C} / \mathrm{C}\end{array}$ & $\begin{array}{c}233(62) \\
124(33) \\
19(5)\end{array}$ & $\begin{array}{c}228(55) \\
159(39) \\
25(6)\end{array}$ & 0.168 & 0.535 & 0.059 \\
\hline $\begin{array}{l}\text { SNP 8 } \\
\text { rs1503815 }\end{array}$ & $\begin{array}{l}\mathrm{C} / \mathrm{C} \\
\mathrm{C} / \mathrm{T} \\
\mathrm{T} / \mathrm{T}\end{array}$ & $\begin{array}{c}305(81) \\
62(17) \\
7(2)\end{array}$ & $\begin{array}{c}333(81) \\
70(17) \\
6(2)\end{array}$ & 0.893 & 0.658 & 0.962 \\
\hline $\begin{array}{l}\text { SNP 9 } \\
\text { rs2340721 }\end{array}$ & $\begin{array}{l}A A \\
C / A \\
C / C\end{array}$ & $\begin{array}{c}179(47) \\
161(43) \\
37(9)\end{array}$ & $\begin{array}{c}174(42) \\
197(47) \\
44(11)\end{array}$ & 0.290 & 0.715 & 0.116 \\
\hline $\begin{array}{c}\text { SNP } 10 \\
\text { rs } 11581364\end{array}$ & $\begin{array}{l}\mathrm{G} / \mathrm{G} \\
\mathrm{G} / \mathrm{T} \\
\mathrm{T} / \mathrm{T}\end{array}$ & $\begin{array}{c}139(37) \\
180(48) \\
55(15)\end{array}$ & $\begin{array}{c}173(42) \\
190(46) \\
50(12)\end{array}$ & 0.319 & 0.284 & 0.176 \\
\hline $\begin{array}{l}\text { SNP } 11 \\
\text { rs7554023 }\end{array}$ & $\begin{array}{l}A / A \\
A / G \\
G / G\end{array}$ & $\begin{array}{c}246(66) \\
116(31) \\
12(3)\end{array}$ & $\begin{array}{c}270(65) \\
137(33) \\
6(2)\end{array}$ & 0.231 & 0.100 & 0.906 \\
\hline $\begin{array}{l}\text { SNP } 12 \\
\text { rs10918215 }\end{array}$ & $\begin{array}{l}A / A \\
A / G \\
G / G\end{array}$ & $\begin{array}{c}227(60) \\
126(34) \\
22(6)\end{array}$ & $\begin{array}{c}214(52) \\
175(42) \\
25(6)\end{array}$ & 0.036 & 0.919 & 0.012 \\
\hline $\begin{array}{l}\text { SNP } 13 \\
\text { rs7514053 }\end{array}$ & $\begin{array}{l}G / G \\
G / A \\
A / A\end{array}$ & $\begin{array}{c}225(60) \\
125(34) \\
22(6)\end{array}$ & $\begin{array}{c}216(52) \\
174(42) \\
25(6)\end{array}$ & 0.048 & 0.948 & 0.017 \\
\hline $\begin{array}{l}\text { SNP } 14 \\
\text { rs10918243 }\end{array}$ & $\begin{array}{l}\mathrm{T} / \mathrm{T} \\
\mathrm{T} / \mathrm{C} \\
\mathrm{C} / \mathrm{C}\end{array}$ & $\begin{array}{c}149(39) \\
183(49) \\
45(12)\end{array}$ & $\begin{array}{c}167(40) \\
192(47) \\
52(13)\end{array}$ & 0.869 & 0.760 & 0.751 \\
\hline $\begin{array}{l}\text { SNP } 15 \\
\text { rs13401 }\end{array}$ & $\begin{array}{l}A / A \\
A / G \\
G / G\end{array}$ & $\begin{array}{c}228(60) \\
130(34) \\
21(6)\end{array}$ & $\begin{array}{c}215(51) \\
179(43) \\
25(6)\end{array}$ & 0.039 & 0.797 & 0.012 \\
\hline $\begin{array}{l}\text { SNP } 16 \\
\text { rs3795649 }\end{array}$ & $\begin{array}{l}C / C \\
C / T \\
T / T\end{array}$ & $\begin{array}{c}129(35) \\
181(48) \\
63(17)\end{array}$ & $\begin{array}{c}152(37) \\
216(52) \\
44(11)\end{array}$ & 0.040 & 0.011 & 0.500 \\
\hline
\end{tabular}


Table 5. ATF6 haplotype distribution in cases (DM2+IFG+IGT) and normoglycemic controls

\begin{tabular}{|c|c|c|c|}
\hline Haplotype & Controls (\%) & Cases (\%) & p-value \\
\hline AAGA & 76.4 & 72.2 & 0.056 \\
\hline AGAG & 12.5 & 12.6 & 0.944 \\
\hline GGAG & 9.9 & 14.4 & 0.006 \\
\hline Rare & 1.2 & 0.7 & 0.330 \\
\hline Total & 100 & 100 & \\
\hline
\end{tabular}

compared to subjects with disturbed glucose homeostasis $(76.4 \%$ versus $72.2 \%$, odds ratio 0.80; 95\% C.I. 0.64-1.01; $\mathrm{p}=0.056$ ). Noteworthy, stratified analyses showed that the prevalence of the GGAG-risk haplotype was significantly increased in both subjects with impaired fasting glucose or impaired glucose tolerance (odds ratio $=1.59, \mathrm{p}=0.011$ ) as well as in patients with fully developed type 2 diabetes (odds ratio $=1.48, \mathrm{p}=0.036$ ).

\section{Discussion}

ATF6 is essential for full activation of the UPR and considered a critical UPR initiator in mammalian cells (8). In the present study we show that ATF6 polymorphisms and haplotypes are associated with disturbed glucose homeostasis and DM2 in Dutch Caucasians. While this work was in progress, a genetic association between amino acid variants in ATF6 and type 2 diabetes was reported in Pima Indians (10). Additional replication studies are strongly required to validate these findings, and evaluate their broader significance for predisposition to type 2 diabetes in different ethnic populations.

In the present study, we identified polymorphisms in the ATF6 gene, significantly associated with fasting glucose levels in a cohort representative for the general population, and with disturbed glucose homeostasis/DM2 in a second cohort, ascertained for IFG, IGT and DM2. Allele frequencies from associated SNPs 12, 13 and 15 were slightly higher in subjects from the general population in cohort $1(\sim 26 \%)$ than in normoglycemic control subjects in cohort 2 (23\%). Different recruitment criteria and statistical variance may account for this difference: control subjects in cohort 2 are non-diabetic, verified by an oral glucose tolerance test, whereas subjects from the general population in cohort 1 may include some undetected type 2 diabetes patients. 
The associated SNPs in this study were all located in non-coding regions of the ATF6 gene. SNP6, SNP12 and SNP 13 map to introns, whereas SNP15 locates to the 3' untranslated region. Noteworthy, SNP15 is in the direct vicinity (11 basepairs in $5^{\prime}$ direction) of an AATAAA-poly-adenylation sequence in the $3^{\prime} \mathrm{UTR}$. This recognition site is involved in polyadenosine (poly-A) tail formation, which protects the mRNA molecule from exonucleases, and is important for transcription termination, for export of the mRNA from the nucleus, and for translation.

Three known exonic variants have been described in ATF6: Pro[145]Ala, Ser[157]Pro, and Met[67]Val. In Pima Indians, the amino acid variants Pro[145]Ala and Ser[157]Pro polymorphism showed an association ( $\mathrm{p}=0.05)$ with DM2 (10). These amino acid substitutions (SNP-4 and SNP-5 respectively in our study) were not significantly associated with fasting glucose levels in our first cohort, or with disturbed glucose homeostasis and DM2 in the second cohort. The negative result is very unlikely to be due to a lack of statistical power, since allele frequencies were identical in cases and controls, not even revealing a trend towards significance (SNP 4 adjusted $p=0.97$, SNP 5 adjusted $\mathrm{p}=0.99$ ). The third known ATF6 amino acid variant, Met[67]Val (SNP-3), which was not previously found associated with type 2 diabetes in Pima Indians (10), was associated with fasting plasma glucose levels in cohort 1, but again allele frequencies were not significantly different between cases and controls in cohort 2. Further genetic research and functional studies are needed to establish which SNP(s) in the ATF6-gene are functionally responsible for the observed associations in both populations. Although we do not provide a formal replication of the genetic association in Pima Indians - in which replication is defined by same allele, same genetic model and same phenotype- our data do however confirm and extend the nature of their observations, and emphasize that the ATF6-gene is also relevant for susceptibility to disturbed glucose homeostasis and DM2 in Dutch Caucasians.

\section{Acknowledgements.}

We thank the participants for their cooperation in this study. Collection of the type 2 diabetes patients was supported by grants of the Netherlands Organisation for Scientific Research (940-35-034) and the Dutch Diabetes Foundation 
(DFN98.901). We thank dr. Christopher Glembotski for critically reading the manuscript.

\section{Disclosure information}

S.M, M.vG, T.A, R.V, C.vdK and T.dB are inventors on patent WO2006125513: "Genetic associations of polymorphisms in the ATF6-alpha gene with insulin resistance phenotypes". T.dB is employed by GlaxoSmithKline (GSK), a company that manufactures and markets pharmaceuticals related to the treatment of diabetes and its complications. GSK did not provide financial support for this study. J.vV, M.H, V.V, C.G.S, E.F, J.B and C.D.S have nothing to disclose.

\section{References}

1. Ozcan U, Cao Q, Yilmaz E, et al. 2004 Endoplasmic reticulum stress links obesity, insulin action, and type 2 diabetes. Science 306:457-61

2. Nakatani Y, Kaneto H, Kawamori D, et al. 2005 Involvement of endoplasmic reticulum stress in insulin resistance and diabetes. J Biol Chem 280:847-51

3. Scheuner D, Mierde DV, Song B, et al. 2005 Control of mRNA translation preserves endoplasmic reticulum function in beta cells and maintains glucose homeostasis. Nat Med 11:757-64

4. Hotamisligil GS 2005 Role of Endoplasmic Reticulum Stress and c-Jun NH2-Terminal Kinase Pathways in Inflammation and Origin of Obesity and Diabetes. Diabetes 54 Suppl 2:S73-8

5. Ozcan U, Yilmaz E, Ozcan L, et al. 2006 Chemical chaperones reduce ER stress and restore glucose homeostasis in a mouse model of type 2 diabetes. Science 313:1137-40

6. Schroder M, Kaufman RJ 2005 ER stress and the unfolded protein response. Mutat Res 569:29-63

7. Morello F, de Bruin TW, Rotter JI, et al. 2004 Differential gene expression of bloodderived cell lines in familial combined hyperlipidemia. Arterioscler Thromb Vasc Biol 24:2149-54

8. Yoshida H, Matsui T, Yamamoto A, Okada T, Mori K 2001 XBP1 mRNA is induced by ATF6 and spliced by IRE1 in response to ER stress to produce a highly active transcription factor. Cell 107:881-91

9. Hansen L, Pedersen O 2005 Genetics of type 2 diabetes mellitus: status and perspectives. Diabetes Obes Metab 7:122-35

10. Thameem F, Farook VS, Bogardus C, Prochazka M 2006 Association of Amino Acid Variants in the Activating Transcription Factor 6 Gene (ATF6) on 1q21-q23 With Type 2 Diabetes in Pima Indians. Diabetes 55:839-42

11. van Dam RM, Hoebee B, Seidell JC, Schaap MM, de Bruin TW, Feskens EJ 2005 Common variants in the ATP-sensitive $\mathrm{K}+$ channel genes KCNJ11 (Kir6.2) and ABCC8 (SUR1) in 
relation to glucose intolerance: population-based studies and meta-analyses. Diabet Med 22:590-8

12. Kruijshoop M, Feskens EJ, Blaak EE, de Bruin TW 2004 Validation of capillary glucose measurements to detect glucose intolerance or type 2 diabetes mellitus in the general population. Clin Chim Acta 341:33-40

13. Purcell S, Cherny SS, Sham PC 2003 Genetic Power Calculator: design of linkage and association genetic mapping studies of complex traits. Bioinformatics 19:149-50

14. Barrett JC, Fry B, Maller J, Daly MJ 2005 Haploview: analysis and visualization of LD and haplotype maps. Bioinformatics 21:263-5

15. Shiu RP, Pouyssegur J, Pastan I 1977 Glucose depletion accounts for the induction of two transformation-sensitive membrane proteinsin Rous sarcoma virus-transformed chick embryo fibroblasts. Proc Natl Acad Sci U S A 74:3840-4 


\section{Chapter 5}

\section{The ATF6-Met[67]Val Substitution is Associated with Increased Apolipoprotein B Levels and Plasma Cholesterol}

\section{SUMMARY}

Activating Transcription Factor 6 (ATF6) is a proximal sensor of the endoplasmic reticulum (ER) stress response.

Besides playing a critical role by inducing ER stress response genes involved in the unfolded protein response,

ATF6 has also been shown to regulate expression of several key genes involved in lipogenesis. Using a tagging SNP approach we identified an amino acid substitu-

tion (methionine[67]valine) in ATF6, associated with elevated apolipoprotein $B$ (apoB) levels and hypercholesterolemia. The association was initially identified in two independent Dutch samples with increased cardiovascular risk and Familial Combined Hyperlipidemia (FCHL), respectively (Apolipoprotein B $p=0.00004$, Total Cholesterol $p=0.001$, LDL cholesterol $p=0.001)$. The association was replicated in 715 individuals from 61 extended Finnish FCHL families (apoB $p=0.01, L D L$-cholesterol $p=0.04$,). We functionally characterized the amino acid substitution, and found that a valine at position 67 augments ATF6 protein levels, as well as its downstream transcriptional targets Grp78 and Grp94. In parallel, potency to induce luciferase expression through the Grp78 promoter was increased. This study provides the first evidence that the methionine[67]valine substitution in ATF6 can modulate apoB and cholesterol levels in humans, and highlights ATF6 as a new susceptibility gene for hypercholesterolemia.

\author{
Steven J.R. Meex \\ Carla J.H. van der Kallen \\ Daphna Weissglas-Volkov \\ Donna J. Thuerauf \\ Marleen M.J. van Greevenbroek \\ Casper G. Schalkwijk \\ Coen D.A. Stehouwer \\ Lonneke Heldens \\ Torik A. Ayoubi \\ Marten H. Hofker \\ Bradly G. Wouters \\ Robert Vlietinck \\ Marja-Riita Taskinen \\ Tjerk W.A. de Bruin \\ Païvi Pajukanta \\ Christopher C. Glembotski \\ Submitted for publication
}




\section{Introduction}

The concept that elevated plasma levels of (LDL-) cholesterol are a primary causal factor in the pathogenesis of coronary heart disease is well established (1-3). Cholesterol synthesis and uptake are tightly regulated through a feedback pathway from the endoplasmic reticulum (ER) to the nucleus (4). Sterol regulatory element binding protein 2 (SREBP2), an ER resident transcription factor, has a central role in the cellular cholesterol homeostasis (5). When cellular cholesterol levels are normal, SREBP2 is anchored to the ER membrane. In response to cellular demand for cholesterol SREBP is escorted to the Golgi compartment where it undergoes sequential cleavage by site 1 protease (S1P) and site 2 protease (S2P) (8). The transcriptionally active amino terminal domain of SREBP2 is released in the cytoplasm and migrates to the nucleus where it binds sterol response element (SRE) sequences in the promoter region of target genes, including cholesterogenic enzymes and the LDL receptor (9). Recent studies have identified an Activating Transcription Factor 6 (ATF6) dependent mechanism for the subtle regulation of these processes (10).

ATF6 is also an ER membrane-bound transcription factor and a major regulator of the unfolded protein response (UPR) (11). The UPR is an evolutionary conserved stress-signaling pathway from the endoplasmic reticulum to the nucleus. Various stressful conditions, e.g. nutrient deprivation, oxidative stress, viral infections, obesity, and increased synthesis of secretory proteins, lead to documented accumulation of unfolded proteins in the ER lumen and trigger the UPR $(12,13)$. Activation of the UPR is regulated by ATF6 and two other proximal stress sensors in the ER membrane: inositol requiring 1(IRE1) and PKR-like endoplasmic reticulum kinase (PERK). Together, these three branches coordinate a complex network of physiological responses oriented towards relieve of ER stress. Besides a critical role for ATF6 in initiation and full activation of the UPR (11), lipogenic properties have been ascribed to ATF6, and cross talk with the SREBP2 pathway has been demonstrated (10). Although ATF6 and SREBP2 in the ER membrane are activated by distinct cellular triggers - endoplasmic reticulum stress and sterol deprivation respectively- an intriguing convergence exists in their mechanistic activation. In analogy to SREPB2, ATF6 is transported from the ER to the Golgi where it undergoes sequential cleavage by S1P and S2P. Subsequent release of its transcriptionally active amino terminal domain in the cytoplasm and migration to the nucleus allow binding to Endoplasmic Reticulum Stress Element (ERSE) 
sequences in the promoter region of target genes, including the molecular chaperones Grp78 (BiP) and Grp94. Thus, ATF6 activation by ER stress, and SREBP activation by sterol deprivation may have evolved from a common ancestral pathway, and there is growing evidence that ATF6 mediated attenuation of SREBP2 fine tunes the cholesterol biosynthetic pathway in cells under conditions of ER stress (10). Parallel pathways may exist through which ATF6 could modulate cholesterol homeostasis, suggested by the presence of ATF6binding elements in the promoter of the apoB gene (14).

In the present study, we investigated the hypothesis that genetic variation in the ATF6 gene is associated with increased plasma (LDL-)cholesterol levels, and that it contributes to the complex genetic background of hypercholesterolemia. Our data indicate that a common metionine[67]valine amino acid substitution in ATF6 is associated with (LDL-)cholesterol and apoB in Dutch and Finnish individuals. Moreover, we show that this variant is functional, which augments ATF6 protein levels and its downstream transcriptional targets.

\section{Methods}

\section{Genetic association studies}

\section{Subjects}

The genetic association between common polymorphisms in the ATF6-gene and cholesterol levels was first investigated in two Dutch independent samples and the implicated SNP was further tested in a Finnish sample, comprising a total of 1,310 subjects. All subjects were either at increased risk to develop cardiovascular disease (CVD) (sample 1), or identified as member of families ascertained for Familial Combined Hyperlipidemia (FCHL) (sample 2+3). The study design was approved by the ethics committees of the participating centers and all subjects gave written informed consent.

Sample 1, Dutch CVR (cardiovascular risk). The first Dutch sample consisted of 393 unrelated subjects at increased risk for CVD, i.e. with at least one of the following risk factors: hypertension, body mass index $>25 \mathrm{~kg} / \mathrm{m} 2$, or a family history of type 2 diabetes. Subjects were member of The Cohort study of Diabetes and Atherosclerosis Maastricht (CoDAM). Collection of this cohort has been extensively described previously (15). To exclude a possible interaction of polymorphisms in the ATF6 gene with type 2 diabetes (16), all individuals 
were subjected to an oral glucose tolerance test, and those with a positive diagnosis for type 2 diabetes were excluded in the present study. Lipid lowering drug treatments were withheld for 2 weeks prior to phenotypic data measurements. Clinical characteristics of subjects from sample 1 are listed in Table 1.

Sample 2, Dutch FCHL. The second sample consisted of 202 Dutch unrelated members from families with an established diagnosis of FCHL. Clinical characteristics of Dutch probands and spouses are presented in Table 1. Dutch FCHL families were recruited through the Lipid Clinic of the Utrecht University Hospital (until 1997) and Maastricht University Hospital (1997-2004). The criteria to establish the diagnosis of FCHL in a Dutch family were extensively described previously (17). To obtain unbiased lipid values, participants had abstained from alcohol for at least $72 \mathrm{~h}$ and any lipid-lowering medication had been withdrawn 2 weeks before blood sampling. Also subjects had refrained from smoking and did not drink coffee or tea on the morning of their visit to the lipid clinic.

Sample 3 (Finnish FCHL, replication sample). A total of 61 Finnish FCHL families (715 individuals genotyped) were recruited in the Helsinki and Turku University Central Hospital, as described in detail previously (18). The inclusion criteria for probands were premature CVD and abnormal lipid profile with totalcholesterol (TC) and/or triglyceride levels (TG) $\geq$ the age-sex-specific 90th Finnish population percentiles. Exclusion criteria were type 1 diabetes, hypothyreosis or renal disease. Lipid phenotypes were measured as described previously (18). Lipid lowering drug treatments were withheld for 4 weeks prior to phenotypic data measurements. Clinical characteristics of Finnish FCHL families are provided in Table 1.

\section{SNP selection and genotyping}

SNP selection was designed to cover $100 \%$ of the common genetic variation of the ATF6-gene including the region $3 \mathrm{~kb}$ upstream and downstream this locus using a minor allele frequency (MAF) $>10 \%$. We selected 13 tag-SNPs for genotyping using the HAPMAP database. One tag-SNP (SNP4, rs2070150) was located in an exon and caused a Pro[145]Ala amino acid substitution. In addition to the selection of 13 SNPs by the tagging process, 3 additional SNPs were selected for their potential direct functional effect: SNP3 (rs1058405) and SNP5 (rs16846208) for their location in exons, inducing amino acid substitution Met[67]Val and Pro[157]Ser respectively, and SNP13 (rs13401) for its location 
in the $3^{\prime}$ untranslated region. According to the NCBI SNP database rs1058405 is possibly tri-allelic (Met-Val- Leu), but no leucine variant was detected in a subset of 200 subjects, using an allele-specific primer for this variant. In total, 16 SNPs were genotyped in all subjects of the 2 Dutch samples (sample 1 and 2), using the TaqMan 7900HT (Applied Biosystems). Two SNPs (rs10918215 and rs7514053) were in complete LD with rs13401, and therefore not separately presented in Tables 2 and 3. The implicated exonic variant (SNP3, rs1058405) was further genotyped in a replication sample of 61 Finnish FCHL families (Sample 3), with 715 genotyped individuals. Genotyping in the Finnish sample was done using the pyrosequencing technique on the PSQ HS96A platform. The genotype call rate was $>97 \%$ for all SNPs in the Dutch samples and $98 \%$ in the Finnish FCHL families. For quality control, we replicated $7 \%$ of genotyped samples. The percentage agreement between samples was over $98 \%$. The genotypes of the individuals with Mendelian errors were called as zeroes in the analyses of the Finnish families. All SNPs were in Hardy-Weinberg equilibrium in the total study sample 1, as well as in the Dutch and Finnish FCHL spouses.

\section{Statistical Analyses}

All selected SNPs were first tested in two independent Dutch samples using the SPSS software (version 11.0, SPSS, Inc.). Two factor ANOVA was used to assess the effects on plasma (LDL)-cholesterol levels. The rs1058405 SNP implicated in both samples was further analyzed in the 2 Dutch samples separately and combined using the PLINK package (v0.99r, http://pngu.mgh.harvard.edu/purcell/plink/) (19) and was also tested for association in a replication sample of 61 Finnish FCHL families. A recessive model of inheritance was used, as the cholesterol traits distribution in the three genotype groups clearly suggests a recessive mode of action. In the two Dutch samples, multivariate linear regression was used to assess the effects of rs1058405 on continuous traits (TC, LDL-C and apoB) including age and sex as covariates, as well as "center" in the combined analyses of both samples. Since the Dutch FCHL sample is relatively small and was selected in part on the basis of elevated TC, we also tested rs1058405 for association with qualitative TC using a Fisher exact test to avoid false positive results due to violation of normality assumptions of continuous phenotypes. The Lipid Clinic Research age-sex specific $90^{\text {th }}$ percentile of TC was used to classify the Dutch FCHL sample (20). Subjects with TC levels greater than the age-sex specific $90^{\text {th }}$ per- 
centiles were classified as TC affected. Accordingly, 58 of the probands were classified as affected. Classification according to the age-sex specific $90^{\text {th }}$ Finnish population percentiles (18) was also applied to illustrate that the obtained association is robust under different classification procedures. In the Finnish families, the quantitative association analyses of age and sex adjusted residual values of TC, LDL-C, apoB and TG were performed using the empirical variance option -e of the family based association test (FBAT). The FBAT -e option is a test of association given linkage and the test statistics takes thus the linkage information into account in extended families. Log transformations were performed for traits with non-normal distributions. To control for possible substructure, violation of normality assumptions of continuous traits and small sample size, an empirical p-value was calculated by a permutation procedure using 10000 permutations. Linkage disequilibrium statistics were analyzed by the Haploview software (21). The PedCheck program (22) was used to detect Mendelian errors in the Finnish FCHL families.

\section{Cell studies and functional experiments}

\section{Isolation and culture of pre-adipocytes}

Adipose tissue was collected as described previously (23). Following the fat biopsy and collagenase treatment, the cell suspension was filtered through 500 $\mu \mathrm{m}$ nylon mesh and spun at 220×g for $1 \mathrm{~min}$ to separate pre-adipocytes from mature adipocytes. Pre-adipocytes were suspended in $5 \mathrm{ml}$ DMEM medium containing $10 \%$ fetal calf serum (FCS) and 1\% glutamine / streptomycine / peniciline (GSP) and cultured during 4 passages under standardized conditions. ATF6 protein levels were measured by western blot in lysates of cultured primary pre-adipocytes, derived from 11 subjects. Clinical characteristics of these subjects at the time of the fat biopsy were as follows: 6 women $/ 5$ men, age $50 \pm 12$ years, BMI $26.8 \pm 2.2 \mathrm{~kg} / \mathrm{m} 2$, TC $5.7 \pm 1.5 \mathrm{mmol} / \mathrm{L}$, LDL-C $4.1 \pm 1.7$ $\mathrm{mmol} / \mathrm{L}$, apoB $1.12 \pm 0.33 \mathrm{~g} / \mathrm{L}, \mathrm{TG} 2.1 \pm 1.8 \mathrm{mmol} / \mathrm{L}$.

\section{HeLa cell culture and transfection}

HeLa cells were maintained in DMEM containing 10\% fetal calf serum. HeLa cells were resuspended at $2.5^{*} 10^{6}$ cells per $400 \mu \mathrm{l}$ of cold Dulbecco's phosphatebuffered saline and electroporated in a 0.4- $\mathrm{cm}$ gap electroporation cuvette at $250 \mathrm{~V}$ and 950 microfarads using a GenePulser II Electroporator (Bio-Rad). 
Cells were then plated at a density of $0.5^{*} 10^{6}$ per $24-\mathrm{mm}$ well for luciferase and galactosidase assays, or $1.5^{*} 10^{6}$ per 35 -mm well for Western blot experiments.

\section{Plasmids}

- Cytomegalovirus-Galactosidase

Cytomegalovirus-galactosidase, which codes for a galactosidase reporter driven by the cytomegalovirus promoter, was used to normalize for transfection efficiency.

- Flag-ATF6-(1 $\rightarrow 373[67]-M e t h i o n i n e) ; ~ F l a g-A T F 6-(1 \rightarrow 373[67]-V a l i n e)$ and FlagATF6-(1 $\rightarrow 373[67]$-Leucine).

These constructs encode amino acid 1-373 of the ATF6 protein and confer strong constitutive transcriptional activity, mimicking all aspects of cleaved endogenous ATF6. All three constructs contain a 3xFLAG-epitope and only differ by their amino acid at position 67. Construction of Flag-ATF6$(1 \rightarrow 373[67]$-Leucine) has been described previously (24). This parent vector was used as a template to create Flag-ATF6-(1 $\rightarrow$ 373[67]-Methionine) and FlagATF6- $(1 \rightarrow 373[67]-$ Valine) by site-directed mutagenesis (QuickChange kit, Stratagene, Inc.). The following primers were used:

[67]-Methionine-sense GATTTGGATTTGATGCCTTGGGAGTCAGAC; [67]-Methionine-antisense GTCTGACTCCCAAGGCATCAAATCCAAATC; [67]-Valine-sense GATTTGGATTTGGTGCCTTGGGAGTCAGAC; [67]-Valine-antisense GTCTGACTCCCAAGGCACCAAATCCAAATC.

Nucleotides in bold were responsible for the desired amino acid substitutions.

-Grp78 promoter(-284 $\rightarrow+221)$-Luciferase

This construct encodes the GRP78 promoter from -284 to +221 driving luciferase. It was created by PCR using HeLa genomic DNA as a template and a sense primer that begins at base -284 and includes a Kpn1 restriction site and an antisense primer at +221 and includes an Xho1 restriction site. The resulting PCR product was digested with Kpn1 and Xho1, creating the GRP78-promoter $(-284$ to +221$)$, which was ligated into the vector pGL2 (Promega).

- $p G L 2 p$

pGL2 promoter (catalog number E1631; Promega) is a vector containing an SV40 promoter inserted into the pGL2-Basic vector upstream of a luciferase reporter gene. 


\section{Reporter assays}

- $\beta$-galactosidase

48 hours after transfection, cells were lysed in $500 \mu \mathrm{l}$ of ice-cold lysis buffer (25 mM Gly-Gly, pH 7.8, 15 mM MgSO4, 4 mM EDTA, 0.25\% Triton X-100, and 1 $\mathrm{mM}$ dithiothreitol). After centrifugation of the cell lysate, $100 \mu \mathrm{l}$ of supernatant was combined with $500 \mu \mathrm{l}$ of galactosidase buffer (60 mM Na2HPO4, $40 \mathrm{mM}$ $\mathrm{NaH} 2 \mathrm{PO} 4,10 \mathrm{mM} \mathrm{KCl}, 1 \mathrm{mM} \mathrm{MgSO} 4,1 \mathrm{mg} / \mathrm{ml}$ chlorophenol red-Dgalactopyranoside, and $50 \mathrm{mM}$ 2-mercaptoethanol). After incubation for $1 \mathrm{~h}$, the absorbance was measured at $570 \mathrm{~nm}$.

\section{-Luciferase}

Following cell lysis and centrifugation as described above, $100 \mu$ cell lysate was combined with $100 \mu \mathrm{l}$ of luciferase buffer (the above described lysis buffer containing $45 \mathrm{mM} \mathrm{MgSO} 4,0.3 \mathrm{mM}$ D-luciferin, and $3 \mathrm{mM}$ ATP). An Optocompt II luminometer (MGM Instruments, Inc) was used to measure light emission of each sample for 10 seconds. Relative luciferase activities were determined by dividing luciferase values by $\beta$-galactosidase values.

\section{Western Blotting}

Cell cultures were extracted in lysis buffer composed of $20 \mathrm{mM}$ Tris- $\mathrm{HCl}, \mathrm{pH}$ 7.5, $150 \mathrm{mM} \mathrm{NaCl}, 1 \%$ Triton X-100, 0.1\% SDS, $1 \mathrm{mM}$ phenylmethylsulfonyl fluoride, $10 \mathrm{mg} / \mathrm{ml}$ leupeptin, and $10 \mathrm{mg} / \mathrm{ml}$ aprotinin. After clearing by centrifugation, the protein concentration of the lysate was determined, and after dilution with the appropriate amount of $2 x$ Laemmli buffer, equal amounts of protein from each sample were fractionated by 10\% SDS-PAGE and then transferred to a polyvinylidene difluoride membrane. Membranes were then probed with ATF6-alpha antiserum (Santa Cruz Biotechnology, California), beta-actin antiserum (Biolegend, San Diego), FLAG antiserum (F-3165, Sigma), KDEL antiserum (SPA-827,Stessgen Biotechnologies Inc, San Diego, CA), or GAPDH (RDI-TRK 5G4-65C; Research Diagnostics Inc, Flanders, NJ). 


\section{Results}

\section{ATF6 protein levels in cultured pre-adipocytes correlate with plasma (LDL-)cholesterol levels and apolipoprotein B.}

To obtain additional support for our rationale to study the ATF6-gene in relation to hypercholesterolemia, we first evaluated the relation between basal ATF6 levels and plasma (LDL) cholesterol. ATF6 protein was measured in extracts prepared from cultured human primary pre-adipocytes. A positive relation between ATF6 levels in vitro, and plasma (LDL-) cholesterol levels of the corresponding subjects in vivo was observed (Figure 1). The relation between ATF6 and apoB levels was identical, and equally significant, to that observed with total cholesterol (figure not shown). The advantage of cultured pre-adipocytes instead of freshly isolated mature adipocytes lies in the assumption that cellular effects due to previous metabolic influences are largely repressed by standardized cell-culture, and that remaining variation in the expression of proteins can be ascribed to (epi)genetic factors.

To study whether we could find evidence of a genetic variant within the ATF6-gene associated with cholesterol traits, 16 single nucleotide polymorphisms (SNPs), selected to capture the common genetic variation in the ATF6-
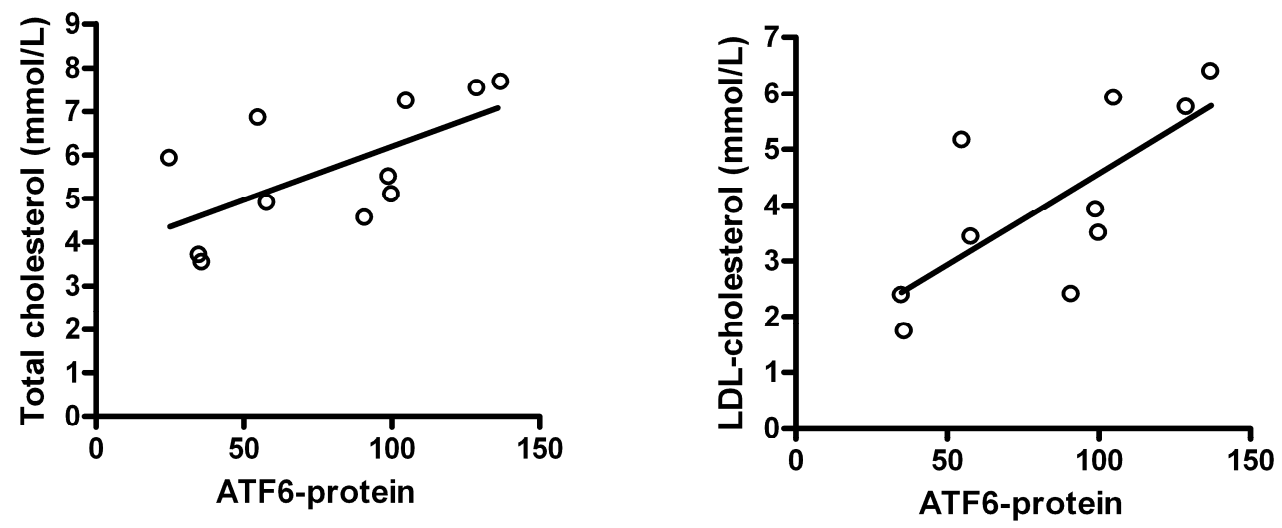

Figure 1. ATF6 protein levels in cultured human pre-adipocytes, normalized to beta-actin, were positively correlated with plasma total cholesterol and LDL-cholesterol concentrations (Pearson correlations 0.645 and $0.724, p=0.032$ and 0.018 respectively). Plasma LDLcholesterol levels were determined according to the Friedewald formula, and not calculated for one subject with a plasma triglyceride concentration $>4.5 \mathrm{mmol} / \mathrm{L}$. 
gene, were first tested for association in two independent samples: 393 Dutch individuals with increased cardiovascular risk (CVR) (Sample 1), and 202 unrelated probands and their spouses from Dutch FCHL families (Sample 2). The variant implicated in both of the Dutch samples was further tested for association in a replication sample of 61 Finnish FCHL families with 715 genotyped individuals (Sample 3). Clinical characteristics of the three study samples are shown in Table 1

Table 1. Clinical characteristics of study samples 1-2-3

\begin{tabular}{|c|c|c|c|c|c|}
\hline \multirow{2}{*}{ Trait } & \multirow{2}{*}{$\begin{array}{c}\text { Sample } 1 \\
\text { (Dutch) } \\
\text { CVR }\end{array}$} & \multicolumn{2}{|c|}{$\begin{array}{l}\text { Sample } 2 \\
\text { (Dutch) }\end{array}$} & \multicolumn{2}{|c|}{$\begin{array}{l}\text { Sample } 3 \\
\text { (Finnish) }\end{array}$} \\
\hline & & Spouses & $\begin{array}{c}\mathrm{FCHL} \\
\text { probands }\end{array}$ & Non FCHL & FCHL \\
\hline Male/Female (N) & $236 / 157$ & $50 / 75$ & $45 / 32$ & $224 / 224$ & $144 / 176$ \\
\hline Age (years) & $59 \pm 7$ & $51 \pm 11$ & $51 \pm 11$ & $38 \pm 18$ & $44 \pm 16$ \\
\hline BMI $\left(\mathrm{kg} / \mathrm{m}^{2}\right)$ & $28 \pm 4$ & $25 \pm 4$ & $27 \pm 3$ & $24 \pm 4$ & $27 \pm 4$ \\
\hline TC (mmol/L) & $5.2 \pm 0.9$ & $5.57 \pm 1.02$ & $6.96 \pm 1.46$ & $5.34 \pm 0.98$ & $7.26 \pm 1.26$ \\
\hline LDL-C (mmol/L) & $3.4 \pm 0.8$ & $3.8 \pm 0.9$ & $4.5 \pm 1.5$ & $3.4 \pm 0.9$ & $4.7 \pm 1.2$ \\
\hline аров (g/L) & $1.12 \pm 0.24$ & $1.00 \pm 0.25$ & $1.42 \pm 0.34$ & $0.91 \pm 0.24$ & $1.41 \pm 0.35$ \\
\hline TG (mmol/L) & $1.44 \pm 0.68$ & $1.33 \pm 0.58$ & $3.30 \pm 2.51$ & $1.28 \pm 0.68$ & $3.18 \pm 2.27$ \\
\hline Gluc (mmol/L) & $5.2 \pm 0.9$ & $4.9 \pm 0.7$ & $5.4 \pm 0.8$ & $4.8 \pm 1.0$ & $5.4 \pm 1.9$ \\
\hline
\end{tabular}

\section{Association analyses in Dutch subjects at increased cardiovascular risk (Sample 1)}

First, genotypic associations for all 16 SNPs in the ATF6-gene with cholesterol and LDL-cholesterol levels were explored in sample 1. All SNPs were in Har$\mathrm{dy}$-Weinberg equilibrium in this sample. We found evidence of association for SNP3 (rs1058405) with apoB (0.011) and LDL-cholesterol ( $\mathrm{p}=0.026)$ (Table 2). SNP3 is a coding variant that translates into the methionine[67]valine amino acid substitution. Total cholesterol and LDL-cholesterol and apoB distributions in the three genotype groups suggest a recessive mode of action with highest levels in homozygous carriers of the rare G-allele. Table 4 shows age and sex adjusted p-values, which are statistically significant for apoB, total cholesterol, and LDL-cholesterol under a recessive genetic model. 
Table 2. Analyses per genotype of ATF6 polymorphisms: total cholesterol levels, LDLcholesterol levels and apolipoprotein B (Sample 1)

\begin{tabular}{|c|c|c|c|c|c|c|c|c|c|}
\hline $\begin{array}{l}\text { SNP } \\
\text { (rs) }\end{array}$ & Gen. & MAF & $\mathrm{N}$ & $\begin{array}{c}\mathrm{TC} \\
\mathrm{mmol} / \mathrm{L}\end{array}$ & $P$ & $\begin{array}{c}\mathrm{LDL}-\mathrm{C} \\
\mathrm{mmol} / \mathrm{L}\end{array}$ & $P$ & $\begin{array}{c}\text { apoB } \\
\mathrm{g} / \mathrm{L}\end{array}$ & $P$ \\
\hline $\begin{array}{l}\text { SNP1 } \\
4657101\end{array}$ & $\begin{array}{l}C / C \\
A / C \\
A / A\end{array}$ & 0.26 & $\begin{array}{c}27 \\
146 \\
205\end{array}$ & $\begin{array}{l}5.2 \pm 0.6 \\
5.3 \pm 0.9 \\
5.2 \pm 0.9\end{array}$ & 0.833 & $\begin{array}{l}3.4 \pm 0.6 \\
3.4 \pm 0.8 \\
3.3 \pm 0.9\end{array}$ & 0.894 & $\begin{array}{l}1.15 \pm 0.2 \\
1.12 \pm 0.2 \\
1.15 \pm 0.2\end{array}$ & 0.833 \\
\hline $\begin{array}{c}\text { SNP2 } \\
7553368\end{array}$ & $\begin{array}{l}\mathrm{C} / \mathrm{C} \\
\mathrm{T} / \mathrm{C} \\
\mathrm{T} / \mathrm{T}\end{array}$ & 0.31 & $\begin{array}{c}32 \\
165 \\
178\end{array}$ & $\begin{array}{l}5.1 \pm 0.9 \\
5.3 \pm 0.9 \\
5.2 \pm 0.9\end{array}$ & 0.636 & $\begin{array}{l}3.3 \pm 0.7 \\
3.4 \pm 0.9 \\
3.3 \pm 0.8\end{array}$ & 0.948 & $\begin{array}{l}1.10 \pm 0.2 \\
1.13 \pm 0.2 \\
1.11 \pm 0.2\end{array}$ & 0.654 \\
\hline $\begin{array}{c}\text { SNP3 } \\
1058405\end{array}$ & $\begin{array}{l}G / G \\
A / G \\
A / A\end{array}$ & 0.30 & $\begin{array}{c}33 \\
168 \\
183\end{array}$ & $\begin{array}{l}5.5 \pm 0.8 \\
5.2 \pm 0.9 \\
5.2 \pm 0.9\end{array}$ & 0.140 & $\begin{array}{l}3.7 \pm 0.8 \\
3.3 \pm 0.8 \\
3.3 \pm 0.9\end{array}$ & 0.026 & $\begin{array}{l}1.23 \pm 0.2 \\
1.10 \pm 0.2 \\
1.12 \pm 0.2\end{array}$ & 0.011 \\
\hline $\begin{array}{l}\text { SNP4 } \\
2070150\end{array}$ & $\begin{array}{l}\mathrm{C} / \mathrm{C} \\
\mathrm{G} / \mathrm{C} \\
\mathrm{G} / \mathrm{G}\end{array}$ & 0.08 & $\begin{array}{c}4 \\
54 \\
322\end{array}$ & $\begin{array}{l}5.1 \pm 0.6 \\
5.2 \pm 0.8 \\
5.3 \pm 0.9\end{array}$ & 0.706 & $\begin{array}{l}3.2 \pm 0.4 \\
3.3 \pm 0.8 \\
3.4 \pm 0.8\end{array}$ & 0.567 & $\begin{array}{l}1.09 \pm 0.2 \\
1.08 \pm 0.2 \\
1.13 \pm 0.2\end{array}$ & 0.410 \\
\hline $\begin{array}{c}\text { SNP5 } \\
16846208\end{array}$ & $\begin{array}{l}T / T \\
C / T \\
C / C\end{array}$ & 0.08 & $\begin{array}{c}4 \\
53 \\
324\end{array}$ & $\begin{array}{l}5.1 \pm 0.6 \\
5.2 \pm 0.8 \\
5.3 \pm 0.9\end{array}$ & 0.724 & $\begin{array}{l}3.2 \pm 0.4 \\
3.3 \pm 0.8 \\
3.4 \pm 0.9\end{array}$ & 0.634 & $\begin{array}{l}1.09 \pm 0.2 \\
1.09 \pm 0.2 \\
1.13 \pm 0.2\end{array}$ & 0.456 \\
\hline $\begin{array}{l}\text { SNP6 } \\
4579731\end{array}$ & $\begin{array}{l}G / G \\
A / G \\
A / A\end{array}$ & 0.14 & $\begin{array}{c}8 \\
86 \\
280\end{array}$ & $\begin{array}{l}5.2 \pm 0.7 \\
5.3 \pm 0.8 \\
5.3 \pm 0.9\end{array}$ & 0.994 & $\begin{array}{l}3.5 \pm 0.9 \\
3.3 \pm 0.8 \\
3.4 \pm 0.8\end{array}$ & 0.790 & $\begin{array}{l}1.08 \pm 0.2 \\
1.12 \pm 0.2 \\
1.13 \pm 0.2\end{array}$ & 0.826 \\
\hline $\begin{array}{c}\text { SNP7 } \\
2134697\end{array}$ & $\begin{array}{l}\mathrm{C} / \mathrm{C} \\
\mathrm{T} / \mathrm{C} \\
\mathrm{T} / \mathrm{T}\end{array}$ & 0.25 & $\begin{array}{c}24 \\
139 \\
216\end{array}$ & $\begin{array}{l}5.0 \pm 1.0 \\
5.2 \pm 0.8 \\
5.3 \pm 0.9\end{array}$ & 0.374 & $\begin{array}{l}3.2 \pm 0.9 \\
3.3 \pm 0.8 \\
3.4 \pm 0.9\end{array}$ & 0.418 & $\begin{array}{l}1.05 \pm 0.2 \\
1.11 \pm 0.2 \\
1.14 \pm 0.2\end{array}$ & 0.206 \\
\hline $\begin{array}{c}\text { SNP8 } \\
1503815\end{array}$ & $\begin{array}{l}T / T \\
C / T \\
C / C\end{array}$ & 0.11 & $\begin{array}{c}6 \\
70 \\
302\end{array}$ & $\begin{array}{l}4.4 \pm 1.2 \\
5.3 \pm 0.8 \\
5.3 \pm 0.9\end{array}$ & 0.057 & $\begin{array}{l}2.7 \pm 1.1 \\
3.4 \pm 0.7 \\
3.4 \pm 0.8\end{array}$ & 0.145 & $\begin{array}{l}0.95 \pm 0.3 \\
1.12 \pm 0.2 \\
1.13 \pm 0.2\end{array}$ & 0.184 \\
\hline $\begin{array}{c}\text { SNP9 } \\
2340721\end{array}$ & $\begin{array}{l}C / C \\
C / A \\
A / A\end{array}$ & 0.34 & $\begin{array}{c}44 \\
171 \\
167\end{array}$ & $\begin{array}{l}5.0 \pm 0.9 \\
5.2 \pm 0.9 \\
5.3 \pm 0.9\end{array}$ & 0.159 & $\begin{array}{l}3.1 \pm 0.8 \\
3.4 \pm 0.8 \\
3.4 \pm 0.9\end{array}$ & 0.104 & $\begin{array}{l}1.04 \pm 0.2 \\
1.12 \pm 0.2 \\
1.14 \pm 0.2\end{array}$ & 0.036 \\
\hline $\begin{array}{c}\text { SNP10 } \\
11581364\end{array}$ & $\begin{array}{l}T / T \\
G / T \\
G / G\end{array}$ & 0.37 & $\begin{array}{c}53 \\
171 \\
155\end{array}$ & $\begin{array}{l}5.2 \pm 1.0 \\
5.2 \pm 0.9 \\
5.2 \pm 0.9\end{array}$ & 0.952 & $\begin{array}{l}3.4 \pm 0.9 \\
3.3 \pm 0.8 \\
3.3 \pm 0.8\end{array}$ & 0.851 & $\begin{array}{l}1.13 \pm 0.2 \\
1.12 \pm 0.2 \\
1.11 \pm 0.2\end{array}$ & 0.765 \\
\hline $\begin{array}{l}\text { SNP11 } \\
7554023\end{array}$ & $\begin{array}{l}G / G \\
A / G \\
A / A\end{array}$ & 0.19 & $\begin{array}{c}10 \\
120 \\
246\end{array}$ & $\begin{array}{l}5.0 \pm 0.6 \\
5.3 \pm 0.9 \\
5.2 \pm 0.9\end{array}$ & 0.378 & $\begin{array}{l}3.2 \pm 0.4 \\
3.5 \pm 0.8 \\
3.3 \pm 0.9\end{array}$ & 0.167 & $\begin{array}{l}1.12 \pm 0.1 \\
1.15 \pm 0.2 \\
1.11 \pm 0.2\end{array}$ & 0.310 \\
\hline $\begin{array}{c}\text { SNP14 } \\
10918243\end{array}$ & $\begin{array}{l}C / C \\
T / C \\
T / T\end{array}$ & 0.35 & $\begin{array}{c}42 \\
183 \\
153\end{array}$ & $\begin{array}{l}5.4 \pm 0.8 \\
5.3 \pm 0.9 \\
5.2 \pm 0.9\end{array}$ & 0.199 & $\begin{array}{l}3.6 \pm 0.8 \\
3.4 \pm 0.8 \\
3.3 \pm 0.8\end{array}$ & 0.154 & $\begin{array}{l}1.20 \pm 0.2 \\
1.12 \pm 0.2 \\
1.10 \pm 0.2\end{array}$ & 0.045 \\
\hline $\begin{array}{c}\text { SNP15 } \\
13401\end{array}$ & $\begin{array}{l}G / G \\
A / G \\
A / A\end{array}$ & 0.25 & $\begin{array}{c}21 \\
144 \\
210\end{array}$ & $\begin{array}{l}5.1 \pm 0.8 \\
5.2 \pm 0.9 \\
5.3 \pm 0.9\end{array}$ & 0.417 & $\begin{array}{l}3.2 \pm 0.9 \\
3.3 \pm 0.8 \\
3.4 \pm 0.8\end{array}$ & 0.177 & $\begin{array}{l}1.07 \pm 0.2 \\
1.10 \pm 0.2 \\
1.14 \pm 0.2\end{array}$ & 0.106 \\
\hline $\begin{array}{l}\text { SNP16 } \\
3795649\end{array}$ & $\begin{array}{l}\mathrm{T} / \mathrm{T} \\
\mathrm{C} / \mathrm{T} \\
\mathrm{C} / \mathrm{C}\end{array}$ & 0.40 & $\begin{array}{c}57 \\
186 \\
134\end{array}$ & $\begin{array}{l}5.2 \pm 0.9 \\
5.2 \pm 0.9 \\
5.3 \pm 0.9\end{array}$ & 0.922 & $\begin{array}{l}3.4 \pm 0.8 \\
3.3 \pm 0.9 \\
3.4 \pm 0.8\end{array}$ & 0.680 & $\begin{array}{l}1.13 \pm 0.2 \\
1.12 \pm 0.2 \\
1.12 \pm 0.2\end{array}$ & 0.881 \\
\hline
\end{tabular}


Table 3. Analyses per genotype of ATF6 polymorphisms: total cholesterol levels, LDLcholesterol levels and apolipoprotein B (Sample 2)

\begin{tabular}{|c|c|c|c|c|c|c|c|c|c|}
\hline $\begin{array}{l}\text { SNP } \\
\text { (rs) }\end{array}$ & Gen. & MAF & $\mathrm{N}$ & $\begin{array}{c}\mathrm{TC} \\
\mathrm{mmol} / \mathrm{L}\end{array}$ & $P$ & $\begin{array}{l}\mathrm{LDL}-\mathrm{C} \\
\mathrm{mmol} / \mathrm{L}\end{array}$ & $P$ & $\begin{array}{c}\text { apoB } \\
\text { g/L }\end{array}$ & $P$ \\
\hline $\begin{array}{l}\text { SNP1 } \\
4657101\end{array}$ & $\begin{array}{l}C / C \\
A / C \\
A / A\end{array}$ & 0.23 & $\begin{array}{c}12 \\
57 \\
106\end{array}$ & $\begin{array}{l}6.0 \pm 1.4 \\
6.3 \pm 1.5 \\
5.9 \pm 1.3\end{array}$ & 0.333 & $\begin{array}{l}4.2 \pm 1.2 \\
4.1 \pm 1.4 \\
3.9 \pm 1.1\end{array}$ & 0.655 & $\begin{array}{l}1.2 \pm 0.3 \\
1.2 \pm 0.4 \\
1.1 \pm 0.3\end{array}$ & 0.680 \\
\hline $\begin{array}{c}\text { SNP2 } \\
7553368\end{array}$ & $\begin{array}{l}\mathrm{C} / \mathrm{C} \\
\mathrm{T} / \mathrm{C} \\
\mathrm{T} / \mathrm{T}\end{array}$ & 0.30 & $\begin{array}{l}19 \\
72 \\
87\end{array}$ & $\begin{array}{l}6.2 \pm 1.4 \\
6.0 \pm 1.3 \\
6.1 \pm 1.4\end{array}$ & 0.838 & $\begin{array}{l}4.0 \pm 0.9 \\
4.0 \pm 1.2 \\
4.0 \pm 1.2\end{array}$ & 0.952 & $\begin{array}{l}1.2 \pm 0.3 \\
1.1 \pm 0.3 \\
1.1 \pm 0.4\end{array}$ & 0.903 \\
\hline $\begin{array}{c}\text { SNP3 } \\
1058405\end{array}$ & $\begin{array}{l}G / G \\
A / G \\
A / A\end{array}$ & 0.27 & $\begin{array}{c}20 \\
58 \\
103\end{array}$ & $\begin{array}{l}6.7 \pm 1.6 \\
5.9 \pm 1.3 \\
6.0 \pm 1.2\end{array}$ & 0.040 & $\begin{array}{l}4.4 \pm 1.6 \\
3.9 \pm 1.2 \\
3.9 \pm 1.0\end{array}$ & 0.182 & $\begin{array}{l}1.3 \pm 0.4 \\
1.1 \pm 0.4 \\
1.1 \pm 0.3\end{array}$ & 0.052 \\
\hline $\begin{array}{c}\text { SNP4 } \\
2070150\end{array}$ & $\begin{array}{l}\mathrm{C} / \mathrm{C} \\
\mathrm{G} / \mathrm{C} \\
\mathrm{G} / \mathrm{G}\end{array}$ & 0.08 & $\begin{array}{c}1 \\
25 \\
152\end{array}$ & $\begin{array}{c}6.8 \\
6.3 \pm 1.8 \\
6.0 \pm 1.3\end{array}$ & 0.583 & $\begin{array}{c}5.0 \\
4.0 \pm 1.6 \\
4.0 \pm 1.1\end{array}$ & 0.695 & $\begin{array}{c}1.4 \\
1.1 \pm 0.4 \\
1.1 \pm 0.3\end{array}$ & 0.757 \\
\hline $\begin{array}{c}\text { SNP5 } \\
16846208\end{array}$ & $\begin{array}{l}\mathrm{T} / \mathrm{T} \\
\mathrm{C} / \mathrm{T} \\
\mathrm{C} / \mathrm{C}\end{array}$ & 0.07 & $\begin{array}{c}1 \\
23 \\
155\end{array}$ & $\begin{array}{c}6.8 \\
6.2 \pm 1.7 \\
6.0 \pm 1.3\end{array}$ & 0.674 & $\begin{array}{c}5.0 \\
3.9 \pm 1.5 \\
4.0 \pm 1.1\end{array}$ & 0.646 & $\begin{array}{c}1.4 \\
1.1 \pm 0.3 \\
1.1 \pm 0.3\end{array}$ & 0.715 \\
\hline $\begin{array}{c}\text { SNP6 } \\
4579731\end{array}$ & $\begin{array}{l}G / G \\
A / G \\
A / A\end{array}$ & 0.12 & $\begin{array}{c}2 \\
39 \\
135\end{array}$ & $\begin{array}{l}6.2 \pm 1.3 \\
5.9 \pm 1.3 \\
6.1 \pm 1.3\end{array}$ & 0.866 & $\begin{array}{l}4.3 \pm 1.2 \\
3.8 \pm 1.1 \\
4.0 \pm 1.2\end{array}$ & 0.583 & $\begin{array}{l}1.4 \pm 0.4 \\
1.1 \pm 0.3 \\
1.1 \pm 0.4\end{array}$ & 0.522 \\
\hline $\begin{array}{c}\text { SNP7 } \\
2134697\end{array}$ & $\begin{array}{l}\mathrm{C} / \mathrm{C} \\
\mathrm{T} / \mathrm{C} \\
\mathrm{T} / \mathrm{T}\end{array}$ & 0.25 & $\begin{array}{c}8 \\
75 \\
100\end{array}$ & $\begin{array}{l}6.1 \pm 0.8 \\
5.8 \pm 1.2 \\
6.3 \pm 1.5\end{array}$ & 0.087 & $\begin{array}{l}4.1 \pm 0.6 \\
3.8 \pm 1.0 \\
4.2 \pm 1.4\end{array}$ & 0.205 & $\begin{array}{l}1.1 \pm 0.3 \\
1.1 \pm 0.3 \\
1.2 \pm 0.4\end{array}$ & 0.758 \\
\hline $\begin{array}{c}\text { SNP8 } \\
1503815\end{array}$ & $\begin{array}{l}\mathrm{T} / \mathrm{T} \\
\mathrm{C} / \mathrm{T} \\
\mathrm{C} / \mathrm{C}\end{array}$ & 0.13 & $\begin{array}{c}3 \\
40 \\
139\end{array}$ & $\begin{array}{l}6.4 \pm 0.7 \\
5.7 \pm 1.0 \\
6.1 \pm 1.4\end{array}$ & 0.239 & $\begin{array}{l}4.0 \pm 0.4 \\
3.9 \pm 0.8 \\
4.0 \pm 1.3\end{array}$ & 0.823 & $\begin{array}{l}1.2 \pm 0.1 \\
1.1 \pm 0.4 \\
1.1 \pm 0.3\end{array}$ & 0.956 \\
\hline $\begin{array}{c}\text { SNP9 } \\
2340721\end{array}$ & $\begin{array}{l}C / C \\
C / A \\
A / A\end{array}$ & 0.34 & $\begin{array}{l}19 \\
86 \\
80\end{array}$ & $\begin{array}{l}5.8 \pm 1.0 \\
6.0 \pm 1.4 \\
6.2 \pm 1.4\end{array}$ & 0.360 & $\begin{array}{l}3.9 \pm 1.0 \\
3.9 \pm 1.1 \\
4.1 \pm 1.3\end{array}$ & 0.629 & $\begin{array}{l}1.1 \pm 0.3 \\
1.1 \pm 0.3 \\
1.2 \pm 0.4\end{array}$ & 0.563 \\
\hline $\begin{array}{c}\text { SNP10 } \\
11581364\end{array}$ & $\begin{array}{l}T / T \\
G / T \\
G / G\end{array}$ & 0.39 & $\begin{array}{l}32 \\
75 \\
70\end{array}$ & $\begin{array}{l}6.1 \pm 1.1 \\
6.0 \pm 1.4 \\
6.1 \pm 1.4\end{array}$ & 0.738 & $\begin{array}{l}4.0 \pm 0.8 \\
3.9 \pm 1.3 \\
4.1 \pm 1.3\end{array}$ & 0.692 & $\begin{array}{l}1.1 \pm 0.3 \\
1.1 \pm 0.3 \\
1.2 \pm 0.4\end{array}$ & 0.168 \\
\hline $\begin{array}{l}\text { SNP11 } \\
7554023\end{array}$ & $\begin{array}{l}G / G \\
A / G \\
A / A\end{array}$ & 0.17 & $\begin{array}{c}7 \\
47 \\
123\end{array}$ & $\begin{array}{l}6.1 \pm 1.9 \\
6.1 \pm 1.3 \\
6.0 \pm 1.3\end{array}$ & 0.861 & $\begin{array}{l}4.5 \pm 1.8 \\
4.0 \pm 1.1 \\
3.9 \pm 1.2\end{array}$ & 0.472 & $\begin{array}{l}1.2 \pm 0.4 \\
1.2 \pm 0.3 \\
1.1 \pm 0.3\end{array}$ & 0.827 \\
\hline $\begin{array}{c}\text { SNP14 } \\
10918243\end{array}$ & $\begin{array}{l}C / C \\
T / C \\
T / T\end{array}$ & 0.35 & $\begin{array}{l}24 \\
75 \\
80\end{array}$ & $\begin{array}{l}6.6 \pm 1.5 \\
5.9 \pm 1.3 \\
6.0 \pm 1.3\end{array}$ & 0.127 & $\begin{array}{l}4.3 \pm 1.5 \\
3.9 \pm 1.1 \\
4.0 \pm 1.2\end{array}$ & 0.304 & $\begin{array}{l}1.2 \pm 0.4 \\
1.1 \pm 0.4 \\
1.1 \pm 0.3\end{array}$ & 0.402 \\
\hline $\begin{array}{c}\text { SNP15 } \\
13401\end{array}$ & $\begin{array}{l}G / G \\
A / G \\
A / A\end{array}$ & 0.25 & $\begin{array}{c}14 \\
65 \\
110\end{array}$ & $\begin{array}{l}5.8 \pm 1.1 \\
6.0 \pm 1.5 \\
6.1 \pm 1.3\end{array}$ & 0.641 & $\begin{array}{l}3.9 \pm 1.1 \\
3.9 \pm 1.3 \\
4.1 \pm 1.2\end{array}$ & 0.695 & $\begin{array}{l}1.1 \pm 0.3 \\
1.1 \pm 0.4 \\
1.1 \pm 0.3\end{array}$ & 0.737 \\
\hline $\begin{array}{l}\text { SNP16 } \\
3795649\end{array}$ & $\begin{array}{l}T / T \\
C / T \\
C / C\end{array}$ & 0.40 & $\begin{array}{l}33 \\
81 \\
65\end{array}$ & $\begin{array}{l}6.1 \pm 1.3 \\
5.9 \pm 1.3 \\
6.1 \pm 1.5\end{array}$ & 0.578 & $\begin{array}{l}4.1 \pm 1.1 \\
4.0 \pm 1.1 \\
4.0 \pm 1.3\end{array}$ & 0.949 & $\begin{array}{l}1.2 \pm 0.3 \\
1.1 \pm 0.3 \\
1.2 \pm 0.4\end{array}$ & 0.589 \\
\hline
\end{tabular}




\section{Association analyses in Dutch FCHL relatives (Sample 2)}

Next, we tested the same set of 16 ATF6-SNPs for association with apoB and plasma cholesterol levels in a second Dutch sample, comprising unrelated members from families with an established diagnosis of FCHL. All SNPs were in Hardy-Weinberg equilibrium in spouses. Again, SNP3 was associated with increased apoB and total plasma cholesterol levels (Table 3), and, identical to sample 1, the highest signals were obtained under a recessive genetic model (Table 4, Total Cholesterol, LDL-cholesterol and apoB). A combined analysis of sample 1 and 2 strengthened the evidence for association with these traits (Table 4, $\mathrm{p}=0.00004-0.001$ ).

We also investigated the direct effect of SNP3 on hypercholesterolemia in a case control setting. Irrespective of whether hypercholesterolemia was defined by the Lipid Clinic Research age-sex specific 90th percentile ( $\mathrm{p}=0.002, \mathrm{OR}=2.11$, 95\% C.I. 1.31-3.39) or by the age-sex specific 90th Finnish population percentile $(\mathrm{p}=0.001, \mathrm{OR}=2.45,95 \%$ C.I. $1.44-4.19)$, the qualitative analyses strongly supported the results of the quantitative analyses.

Table 4. Genetic association analyses of SNP3 (rs1058405, Met[67]Val): recessive model of inheritance, all study samples

\begin{tabular}{|c|c|c|c|c|c|c|}
\hline \multirow{2}{*}{ Sample } & \multicolumn{2}{|c|}{ TC } & \multicolumn{2}{|c|}{ LDL-C } & \multicolumn{2}{|c|}{ apoB } \\
\hline & $p$ & $E-p$ & $p$ & $E-p$ & $p$ & $E-p$ \\
\hline$\frac{\text { Sample } 1}{\text { Dutch CVR }}$ & 0.034 & 0.033 & 0.007 & 0.007 & 0.003 & 0.003 \\
\hline$\frac{\text { Sample } 2}{\text { Dutch FCHL }}$ & 0.011 & 0.012 & 0.061 & 0.06 & 0.007 & 0.007 \\
\hline $\begin{array}{l}\text { Sample } 1+2 \\
\text { Dutch CVR+FCHL }\end{array}$ & 0.001 & 0.001 & 0.001 & 0.001 & 0.00004 & 0.0002 \\
\hline $\begin{array}{l}\text { Sample } 3 \\
\text { Finnish FCHL }\end{array}$ & 0.068 & 0.065 & 0.045 & 0.041 & 0.013 & 0.025 \\
\hline \multicolumn{7}{|c|}{$\begin{array}{l}\text { Quantitative analyses of TC, LDL-C and apoB under a recessive genetic model. P-values } \\
\text { represent the results of multivariate linear regression analyses in the Dutch cohorts, and } \\
\text { the FBAT-e test in the Finnish FCHL families. } \\
\text { "E-p" Empirical p-values using } 10.000 \text { permutations }\end{array}$} \\
\hline
\end{tabular}

\section{Association analyses in Finnish FCHL families (Sample 3)}

To validate and generalize the associations observed in the two Dutch samples, we examined SNP3 in 715 individuals from 61 Finnish FCHL families. For this purpose we used the FBAT -e option, which is a test of association given linkage, and the test statistics takes thus the linkage information into account in extended families. SNP3 was in Hardy-Weinberg equilibrium in spouses. Consistent with the results obtained in the two Dutch samples, the 
highest signal was obtained under a recessive genetic model. Family based association tests under a recessive genetic model showed that the minor allele of SNP3 was significantly associated with LDL-C, $(\mathrm{p}=0.04)$ and apoB $(\mathrm{p}=0.01)$ in Finnish FCHL families (Table 4). The signal for total cholesterol did not exceed the threshold for statistical significance in this sample $(\mathrm{p}=0.07)$.

\section{Secondary association analyses of triglyceride levels and FCHL.}

The lipid core of apoB containing lipoproteins consists of both cholesterol and triglycerides, and elevated plasma triglyceride levels represent the second core phenotypic component of the FCHL definition. We therefore performed secondary analyses and explored the possibility that SNP3 is also associated with triglyceride levels and the binary FCHL-trait itself. No evidence for a significant effect on triglyceride levels was found in sample 1. In the Dutch and Finnish FCHL family members (Sample 2 and 3), association analyses with triglycerides showed a non-significant trend $(\mathrm{p}=0.08)$, and a borderline significant association $(\mathrm{p}=0.05)$ respectively. The trend with triglycerides in FCHL family members only, may thus be driven mainly by the high correlation between cholesterol and triglyceride levels in these subjects. Associations with the binary FCHL trait were not significant in the Dutch and Finnish FCHL samples separately. A combined analysis of Dutch and Finnish FCHL probands and spouses resulted in a p-value of 0.04 for FCHL. It is plausible that the profound effect of SNP3 on (LDL-)cholesterol levels and apoB explains the modest association with FCHL. Taken together our results show a consistent genetic association of SNP3 with (LDL-) cholesterol and apoB levels in the independent samples under a recessive mode of action, whereas evidence for an effect of on plasma triglyceride levels and the complex FCHL trait is modest at best.

\section{Genetic association data from a publicly available genome wide study}

To obtain independent support for the genetic associations above, we also mined the publicly available database from a recent genome wide association study comprising Scandinavian subjects with type 2 diabetes and unrelated population controls. (www.broad.mit.edu/diabetes) (25). In this previous study, subjects were neither genotyped for SNP3, nor for markers that exhibit high LD with SNP3. Also, data on possible associations with total cholesterol were not available. However, five polymorphisms within the ATF6-locus were significantly associated with apoB levels (strongest signals $\mathrm{p}=0.003-0.004$; 
rs10918029 and rs1875762), but not LDL-cholesterol. This unexpected disparity could be due to the combined presence of healthy subjects and patients with type 2 diabetes. In the diabetic state, VLDL is preferably catabolized to small dense LDL, rather than LDL (26), which could have disrupted the linear relationship between apoB and LDL-cholesterol in this study sample. For completeness, two other SNPs in the ATF6-gene (rs1027700 and rs3767635) showed a marginal association with triglyceride levels in this sample ( $p=0.04)$.

\section{Functional characterization of the methionine-67-valine variant.}

The implicated SNP3 is a coding SNP that translates to the met[67]val substitution in the ATF6 protein. This amino acid locates to the transcription activation domain (TAD) of ATF6, more specifically the VN8-like region (amino acid 6168) (Figure 2).

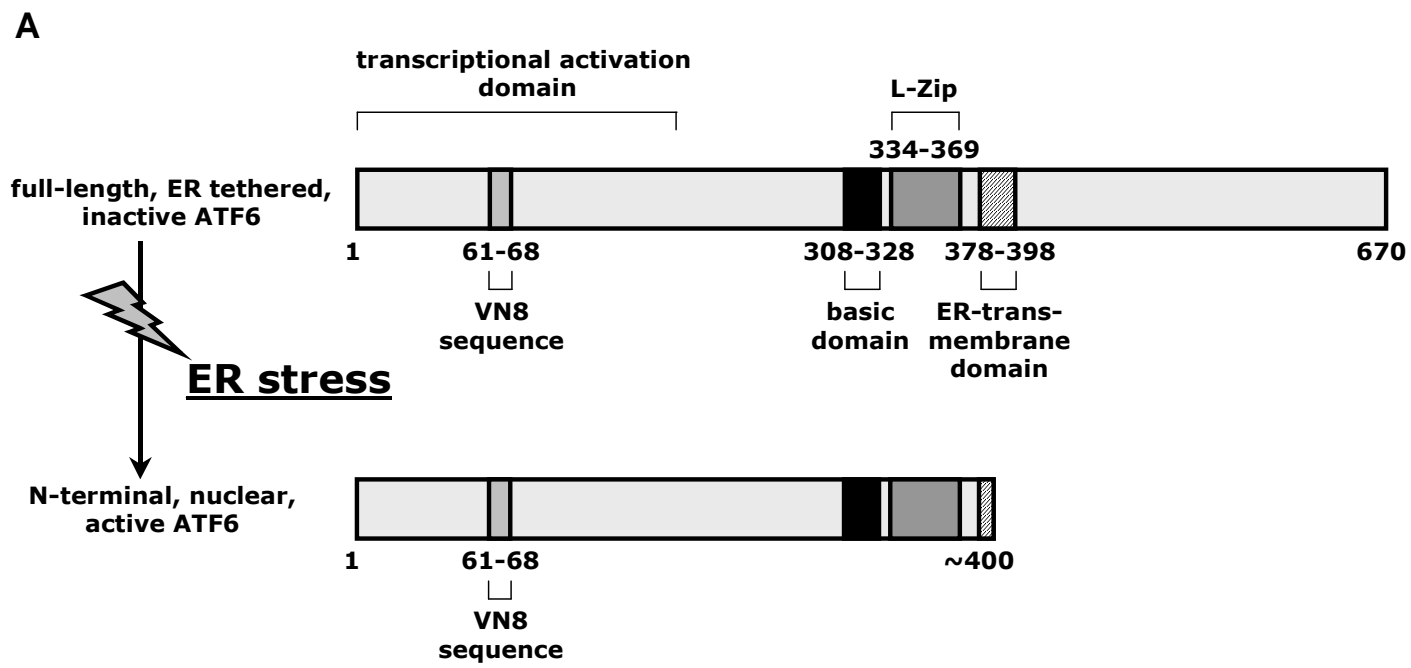

B

VN8 sequence

\begin{tabular}{|c|c|c|c|c|c|c|c|}
\hline $\mathrm{G} A \mathrm{~A}$ & $\mathrm{~T} \quad \mathrm{~T} \quad \mathrm{~T}$ & $G A T$ & $\mathrm{~T} T \mathrm{~T}$ & $\mathrm{G} A \mathrm{~A}$ & $\mathrm{~T} T \mathrm{~T}$ & $\begin{array}{ll}\mathbf{A} / \mathbf{G} & T\end{array}$ & C C T \\
\hline Asp & Phe & Asp & Leu & Asp & Leu & Met/Val & Pro \\
\hline
\end{tabular}

Figure 2. A. Schematic representation of full-length and cleaved (activated) ATF6. B. Detailed representation of the VN8-like region (amino acid 61-68) in ATF6. The methionine to valine substitution at position 67 (grey box), is associated with increased (LDL-) cholesterol levels and apolipoprotein B. Three ATF6 (1-373) constructs were created that only varied by their amino acid at position 67 (methionine (wildtype), valine (variant) and leucine (not detected in Dutch and Finnish subjects), and tested for their transcriptional potency. Site directed mutagenesis of amino-acids 62 and 64, was previously shown to cause a dramatically decreased ATF6-mediated transcription (27). 
The VN8 sequence was previously found of critical importance for transcriptional activity and degradation of ATF6 (27). To explore the possibility that the associated Met[67]Val polymorphism is a functional variant, we assessed the effect of amino-acid variations at position 67 on ATF6 levels and transcriptional activity of ATF6 in vitro. Notably, according to the NCBI SNP-database rs1058405 is in fact tri-allelic (A-G-T $\rightarrow$ Met-Val-Leu). Although the leucinevariant was not detected in our study sample, it may exist in other populations and we therefore tested it for potential functionality as well. Accordingly, three FLAG-tagged ATF6(1-373) constructs were prepared, which mimic the transcriptional active N-terminal part of ATF6 generated by ER-stress. These three constructs varied only by their amino acid at residue 67 (methionine, valine or leucine) (Figure 2B), and were tested in HeLa cells for their potency to induce luciferase expression through the GRP78 promoter. FLAG-ATF6(1373)-[67]-valine and FLAG-ATF6(1-373)-[67]-leucine activated the reporter to a greater extent (140\% and $250 \%$ respectively), compared to the construct with the wildtype methionine amino acid at residue 67 (Figure 3).
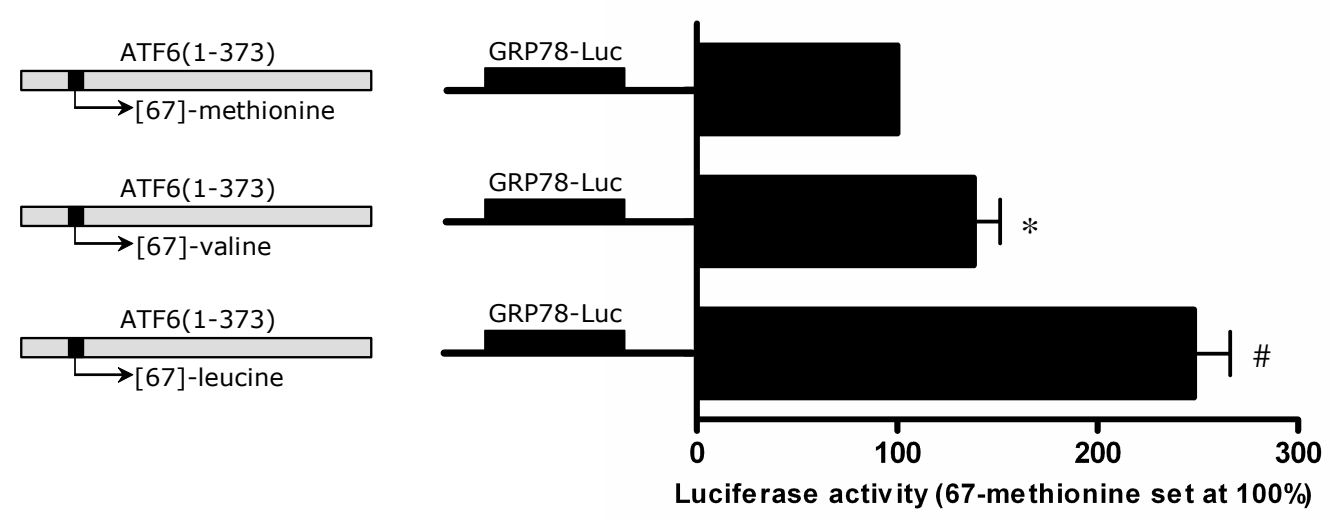

Figure 3. Potency of FLAG-ATF6(1-373)-[67]-methionine, FLAG-ATF6(1-373)-[67]-valine, and FLAG-ATF6(1-373)-[67]-leucine to induce luciferase expression in Hela cells through the GRP78 promoter. $* \mathrm{p}<0.05, \# \mathrm{p}<0.001$

As a complementary experiment, we also examined the potency of the various ATF6-constructs to induce expression of the endogenous ER-chaperone genes Grp78 and Grp94, which are direct transcriptional targets of ATF6. In agreement with results from the luciferase assay, the levels of Grp78 and Grp94 were significantly greater in cells transfected with FLAG-ATF6(1-373)-[67]- 
valine and FLAG-ATF6(1-373)-[67]-leucine, than those transfected with the wildtype construct (Figure 4A and 4B). Higher levels of Grp78 and Grp94 were observed in parallel with increased amounts of ATF6 protein. Together these data provide evidence that the Met[67]Val substitution in ATF6 is a functional variant, with a direct effect on ATF6 protein levels and its downstream targets.

A

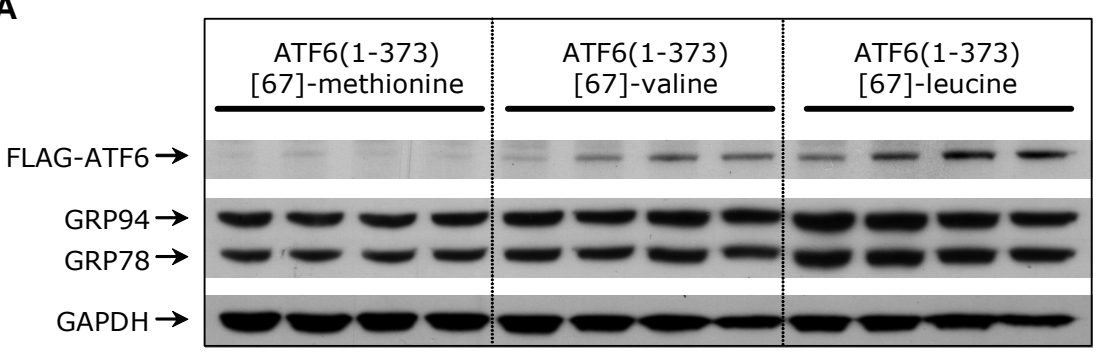

B
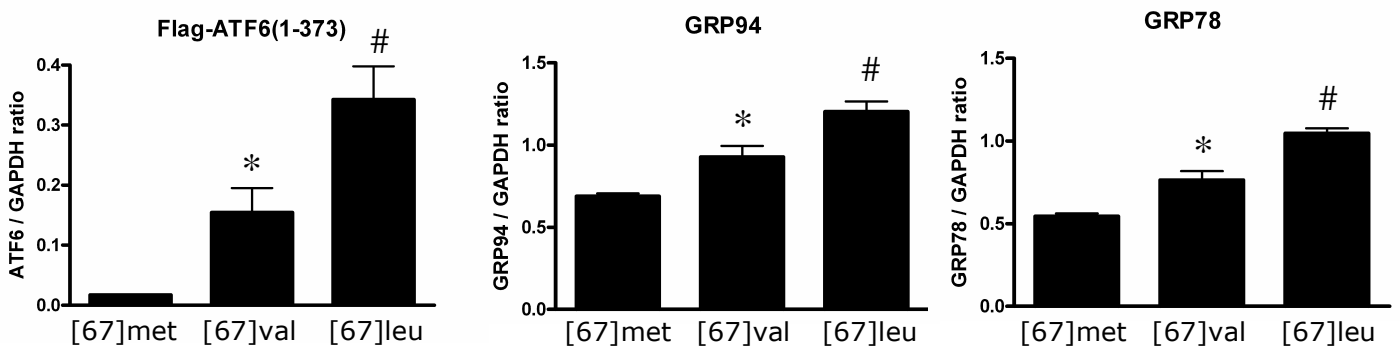

Figure 4. Potency of FLAG-ATF6(1-373)-[67]-methionine, FLAG-ATF6(1-373)-[67]-valine, and FLAG-ATF6(1-373)-[67]-leucine to induce endogenous GRP94 and GRP78 levels (panel $A$ : visualization by western blot, panel $B$ : quantification). $* p<0.05, \# p<0.01$

\section{Discussion}

The principal finding of this study is the association of the Met[67]Val amino acid substitution in ATF6 with increased apoB and plasma (LDL-)cholesterol levels. This finding was replicated in three independent samples, originating from two distinct populations, Dutch and Finnish. Despite a relatively modest number of individuals ( $\mathrm{N}$ combined $=1310$, the observed association with ATF6 was replicated in these various study samples consistently with a recessive mode of inheritance. In a recent publicly available genome wide association study with approximately 3000 subjects, five SNPs in the ATF6 gene were 
also significantly associated with apoB (www.broad.mit.edu/diabetes) (25), but, the use of an additive model and lack of genotyping information on the implicated SNP rs1058405 -or SNPs in strong LD- precludes the statement of replication in a strict statistical sense. Importantly, the genetic association with ATF6 is supported by biological data indicating a strong positive relationship between ATF6 protein levels in cultured human pre-adipocytes and plasma (LDL-)cholesterol concentrations in the corresponding patients. Moreover, we showed that the implicated polymorphism is a potentially functional variant, which augments ATF6 levels and its downstream transcriptional targets.

The Met[67]Val substitution in ATF6 (rs1058405) is a common variation. Minor allele frequencies range from 7\% in African American to 23\% and 29\% in Asian and European populations respectively (http://www.ncbi.nlm.nih.gov/SNP/).

The genetic model of Met[67]Val variant is close to recessive for the valine disease allele. Heterozygous subjects (Met/Val) have identical (LDL-) cholesterol levels as homozygous Met/Met subjects, while only homozygous Val//Val subjects present with significantly higher plasma (LDL-) cholesterol and apoB concentrations. Transfection experiments with mutated ATF6 constructs revealed that the [67]-valine variant increases ATF6 transcriptional activity in cultured cells, suggesting that it constitutes a gain-of-function polymorphism. According to the NCBI SNP-database rs1058405 is possibly tri-allelic (A-G-T $\rightarrow$ Met-Val-Leu). Remarkably, mutating amino acid 67 to leucine increased ATF6 levels even more, as well as its downstream transcriptional targets, Grp78 and Grp94. However, the [67]-leucine variant was not detected in our study sample, which precluded examination of the potential phenotypic consequences of this variation in vivo. The Met[67]Val substitution represents a priori an excellent candidate polymorphism that could functionally affect ATF6: it resides within a VN8-like domain of ATF6 (Figure 3), and a previous study showed that mutating residue 62 and 64 in VN8 dramatically affected degradation and transcriptional activity of ATF6 (27). Of special interest, a VN8 domain was first identified in the virion protein 16 (VP16) transcription factor (75\% homology with ATF6) from herpes simples virus type I (28). Also in VP16 the VN8 domain was found to be required for transcriptional activation and rapid proteosomal degradation (29). Together these data illustrate the critical importance of this domain and specifically amino acid 67 for ATF6 activity.

Zeng and colleagues recently elucidated a potential molecular mechanism through which ATF6 can modulate cholesterol homeostasis (10). Activated ATF6 can interact with SREBP2 and bind as a heterodimer to sterol response 
elements (SREs) in the promoters of cholesterogenic genes. Bound to SRE, the ATF6-SREBP2 heterodimer recruits HDAC1, and together they exert a major inhibitory effect on SREBP2-regulated transcription (10). The inhibitory effect of an enhanced ATF6 response due to the Met[67]Val gain-of-functionpolymorphism on SREBP2 activity, might further reduce the number LDL receptors that bind and internalize LDL and VLDL particles, and increases plasma cholesterol levels. In parallel with this mechanism, ATF6 may also modulate cholesterol- and lipoprotein metabolism more directly, since the promoter region of the apoB gene contains ATF6-binding elements (14). Other proteins of the unfolded protein response have also been implicated in human lipid- and cholesterol metabolism through activation and deregulation of SREBPs.(30-34) The fact that even in yeast and plants a coordinated regulation of ER stress related proteins and lipid metabolic enzymes has been reported, suggests a conserved common ancestral pathway $(35,36)$.

ER stress and activation of the UPR is linked with various components of the metabolic syndrome, including insulin resistance, beta-cell failure, inflammation and atherosclerosis $(13,14,37,38)$. We and others recently reported the replicated genetic association between variants in the ATF6-gene and type 2 diabetes $(16,39,40)$. This is especially interesting in light of the overlapping genetic and metabolic background between type 2 diabetes and FCHL. However, The Met[67]Val substitution was not reproducibly associated in our previous diabetes study (40), nor was it associated in Pima Indians (16). Thus, distinct genetic lesions in ATF6 may account for the disturbances in glucose and cholesterol metabolism. Association of the Met[67]Val substitution with plasma triglyceride levels was modest at best. The shared metabolic pathway and statistical correlation of triglycerides and cholesterol is a plausible explanation for this observation. Similarly, the modest association with the complex FCHL trait in the combined Dutch and Finnish FCHL samples is probably almost entirely accounted for by a profound effect on apoB and (LDL-) cholesterol levels.

In conclusion, we showed that Met[67]Val substitution in the ATF6-gene is associated in a threefold replication with (LDL-)cholesterol and apoB levels in samples of Dutch and Finnish ethnicity, implicating ATF6 as a novel gene contributing to variation in plasma cholesterol levels and hypercholesterolemia. Evidence from functional experiments indicates that the Met[67]Val substitution is a gain-of-function polymorphism that increases ATF6 transcriptional activity. The exact mechanism however, through which the Met[67]Val 
substitution in ATF6 affects cholesterol metabolism is a major challenge to be addressed in future studies. Also, the possibility that this variant may predispose homozygous carriers to develop cardiovascular disease, is an interesting hypothesis to be tested in prospective cohort studies.

\section{Acknowledgments}

We thank the patients and family members for their participation in this study. We also thank E. Nikkola for laboratory technical assistance.

This research was supported by an EFSD/Novo Nordisk research grant to CS, the NIH grants HL-28481, HL-70150 and HL082762 as well as the AHA grant to PP, the NIH grants HL-075573, NS-25037 and HL-085577 awarded to CCG. DW-V is supported by NHGRI grant T32 HG02536. SM was supported by a travel grant from the Netherlands Organization for Scientific Research (NWO) to visit the Glembotski laboratory.

\section{Disclosure information}

S.M, M.vG, T.A, R.V, C.vdK and T.dB are inventors on patent WO2006125513: "Genetic associations of polymorphisms in the ATF6-alpha gene with insulin resistance phenotypes". T.dB is employed by GlaxoSmithKline (GSK). GSK did not provide financial support for this study. The other authors have nothing to disclose.

\section{References}

1. Pekkanen J, Linn S, Heiss G, et al. 1990 Ten-year mortality from cardiovascular disease in relation to cholesterol level among men with and without preexisting cardiovascular disease. N Engl J Med 322:1700-7

2. Kannel WB, Dawber TR, Friedman GD, Glennon WE, McNamara PM 1964 Risk Factors in Coronary Heart Disease. An Evaluation of Several Serum Lipids as Predictors of Coronary Heart Disease; the Framingham Study. Ann Intern Med 61:888-99

3. 2002 Third Report of the National Cholesterol Education Program (NCEP) Expert Panel on Detection, Evaluation, and Treatment of High Blood Cholesterol in Adults (Adult Treatment Panel III) final report. Circulation 106:3143-421 
4. Sakai J, Rawson RB 2001 The sterol regulatory element-binding protein pathway: control of lipid homeostasis through regulated intracellular transport. Curr Opin Lipidol 12:2616

5. Brown MS, Goldstein JL 1997 The SREBP pathway: regulation of cholesterol metabolism by proteolysis of a membrane-bound transcription factor. Cell 89:331-40

6. Yang T, Espenshade PJ, Wright ME, et al. 2002 Crucial step in cholesterol homeostasis: sterols promote binding of SCAP to INSIG-1, a membrane protein that facilitates retention of SREBPs in ER. Cell 110:489-500

7. Yabe D, Brown MS, Goldstein JL 2002 Insig-2, a second endoplasmic reticulum protein that binds SCAP and blocks export of sterol regulatory element-binding proteins. Proc Natl Acad Sci U S A 99:12753-8

8. Brown MS, Goldstein JL 1999 A proteolytic pathway that controls the cholesterol content of membranes, cells, and blood. Proc Natl Acad Sci U S A 96:11041-8

9. Horton JD, Goldstein JL, Brown MS 2002 SREBPs: activators of the complete program of cholesterol and fatty acid synthesis in the liver. J Clin Invest 109:1125-31

10. Zeng L, Lu M, Mori K, et al. 2004 ATF6 modulates SREBP2-mediated lipogenesis. Embo J 23:950-8

11. Yoshida H, Matsui T, Yamamoto A, Okada T, Mori K 2001 XBP1 mRNA is induced by ATF6 and spliced by IRE1 in response to ER stress to produce a highly active transcription factor. Cell 107:881-91

12. Rutkowski DT, Kaufman RJ 2004 A trip to the ER: coping with stress. Trends Cell Biol 14:20-8

13. Ozcan U, Cao Q, Yilmaz E, et al. 2004 Endoplasmic reticulum stress links obesity, insulin action, and type 2 diabetes. Science 306:457-61

14. Zhang K, Shen X, Wu J, et al. 2006 Endoplasmic reticulum stress activates cleavage of CREBH to induce a systemic inflammatory response. Cell 124:587-99

15. Kruijshoop M, Feskens EJ, Blaak EE, de Bruin TW 2004 Validation of capillary glucose measurements to detect glucose intolerance or type 2 diabetes mellitus in the general population. Clin Chim Acta 341:33-40

16. Thameem F, Farook VS, Bogardus C, Prochazka M 2006 Association of Amino Acid Variants in the Activating Transcription Factor 6 Gene (ATF6) on 1q21-q23 With Type 2 Diabetes in Pima Indians. Diabetes 55:839-42

17. Meex SJ, van der Kallen CJ, van Greevenbroek MM, et al. 2005 Up-regulation of CD36/FAT in preadipocytes in familial combined hyperlipidemia. Faseb J 19:2063-65

18. Pajukanta P, Nuotio I, Terwilliger JD, et al. 1998 Linkage of familial combined hyperlipidaemia to chromosome 1q21-q23. Nat Genet 18:369-73

19. Purcell SN, B. Todd-Brown, K. Thomas, L. Ferreira, M.A.R. Bender, D. Maller, J. de Bakker, P.I.W. Daly, M.J. \& Sham, P.C. 2007 PLINK: a toolset for whole-genome association and population-based linkage analysis. Am J Hum Genet In press

20. 1980 The Lipid Research Clinics Population Studies Data Book.The Prevalence Study, Maryland. US DHHS, PHS, NIH Pub. Vol. 1:No. 80-1527

21. Barrett JC, Fry B, Maller J, Daly MJ 2005 Haploview: analysis and visualization of LD and haplotype maps. Bioinformatics 21:263-5

22. O'Connell JR, Weeks DE 1998 PedCheck: a program for identification of genotype incompatibilities in linkage analysis. Am J Hum Genet 63:259-66 
23. Eurlings PM, Van Der Kallen CJ, Geurts JM, Kouwenberg P, Boeckx WD, De Bruin TW 2002 Identification of differentially expressed genes in subcutaneous adipose tissue from subjects with familial combined hyperlipidemia. J Lipid Res 43:930-5

24. Thuerauf DJ, Hoover H, Meller J, et al. 2001 Sarco/endoplasmic reticulum calcium ATPase-2 expression is regulated by ATF6 during the endoplasmic reticulum stress response: intracellular signaling of calcium stress in a cardiac myocyte model system. J Biol Chem 276:48309-17

25. Saxena R, Voight BF, Lyssenko V, et al. 2007 Genome-wide association analysis identifies loci for type 2 diabetes and triglyceride levels. Science 316:1331-6

26. Taskinen MR 2003 Diabetic dyslipidaemia: from basic research to clinical practice. Diabetologia 46:733-49

27. Thuerauf DJ, Morrison LE, Hoover H, Glembotski CC 2002 Coordination of ATF6mediated transcription and ATF6 degradation by a domain that is shared with the viral transcription factor, VP16. J Biol Chem 277:20734-9

28. Tanaka M 1996 Modulation of promoter occupancy by cooperative DNA binding and activation-domain function is a major determinant of transcriptional regulation by activators in vivo. Proc Natl Acad Sci U S A 93:4311-5

29. Molinari E, Gilman M, Natesan S 1999 Proteasome-mediated degradation of transcriptional activators correlates with activation domain potency in vivo. Embo J 18:6439-47

30. Werstuck GH, Lentz SR, Dayal S, et al. 2001 Homocysteine-induced endoplasmic reticulum stress causes dysregulation of the cholesterol and triglyceride biosynthetic pathways. J Clin Invest 107:1263-73

31. Harding HP, Zhang Y, Khersonsky S, et al. 2005 Bioactive small molecules reveal antagonism between the integrated stress response and sterol-regulated gene expression. Cell Metab 2:361-71

32. Parker RA, Flint OP, Mulvey R, et al. 2005 Endoplasmic reticulum stress links dyslipidemia to inhibition of proteasome activity and glucose transport by HIV protease inhibitors. Mol Pharmacol 67:1909-19

33. Zhou H, Pandak WM, Jr., Lyall V, Natarajan R, Hylemon PB 2005 HIV protease inhibitors activate the unfolded protein response in macrophages: implication for atherosclerosis and cardiovascular disease. Mol Pharmacol 68:690-700

34. Sriburi R, Jackowski S, Mori K, Brewer JW 2004 XBP1: a link between the unfolded protein response, lipid biosynthesis, and biogenesis of the endoplasmic reticulum. J Cell Biol 167:35-41

35. Cox JS, Chapman RE, Walter P 1997 The unfolded protein response coordinates the production of endoplasmic reticulum protein and endoplasmic reticulum membrane. Mol Biol Cell 8:1805-14

36. Shank KJ, Su P, Brglez I, Boss WF, Dewey RE, Boston RS 2001 Induction of lipid metabolic enzymes during the endoplasmic reticulum stress response in plants. Plant Physiol 126:267-77

37. Scheuner D, Mierde DV, Song B, et al. 2005 Control of mRNA translation preserves endoplasmic reticulum function in beta cells and maintains glucose homeostasis. Nat Med 11:757-64

38. Feng B, Yao PM, Li Y, et al. 2003 The endoplasmic reticulum is the site of cholesterolinduced cytotoxicity in macrophages. Nat Cell Biol 5:781-92

39. Chu WS, Das SK, Wang H, et al. 2007 Activating transcription factor 6 (ATF6) sequence polymorphisms in type 2 diabetes and pre-diabetic traits. Diabetes 56:856-62 
40. Meex SJ, van Greevenbroek MM, Ayoubi TA, et al. 2007 Activating transcription factor 6 polymorphisms and haplotypes are associated with impaired glucose homeostasis and type 2 diabetes in dutch Caucasians. J Clin Endocrinol Metab 92:2720-5

41. Pajukanta P, Lilja HE, Sinsheimer JS, et al. 2004 Familial combined hyperlipidemia is associated with upstream transcription factor 1 (USF1). Nat Genet 36:371-6

42. Lee JC, Weissglas-Volkov D, Kyttala M, et al. 2007 USF1 Contributes to High Serum Lipid Levels in Dutch FCHL Families and U.S. Whites With Coronary Artery Disease. Arterioscler Thromb Vasc Biol 



\section{Chapter 6}

\section{Upstream Transcription Factor 1 (USF1) in Risk of Type 2 Diabetes: Association Study in 2000 Dutch Caucasians}

Type 2 diabetes (DM2) shares substantial genetic and phenotypic overlap with Familial Combined Hyperlipidemia (FCHL). Upstream stimulatory factor 1 (USF1), a well-established susceptibility gene for FCHL, is postulated to be such a shared genetic determinant. We evaluated two established FCHL-variants (rs2073658 and rs3737787) for association with DM2 in two Dutch case-control samples ( $N=2011)$. The first case-control sample comprised 501 subjects with DM2 from the Breda cohort and 920 healthy blood bank donors of Dutch Caucasian origin. The second case-control sample included 211 subjects with DM2, and 379 normoglycemic controls. SNP rs2073658 and SNP rs3737787 were in perfect linkage disequilibrium. In the first case-control sample, prevalence of the major allele was higher in patients than in controls $(75 \%$ versus $71 \%, O R=1.25, p=0.018)$. A similar effectsize and-direction was observed in the second casecontrol sample $(76 \%$ versus $72 \%$, OR $=1.22$,

$p=0.16)$. A combined analysis strengthened the evidence for association ( $O R=1.23, p=0.006)$. Notably, the increased risk for DM2 could be ascribed to the major allele, and its high frequency translated to a substantial population attributive risk of $14.5 \%$. In conclusion, the major allele of rs2073658 in the USF1 gene is associated with a modestly increased risk to develop DM2 in Dutch Caucasians, with considerable impact at the population level.

\author{
Steven J.R. Meex \\ Jana V. van Vliet-Ostaptchouk \\ Carla J.H. van der Kallen \\ Marleen M.J. van Greevenbroek \\ Casper G. Schalkwijk \\ Edith J.M. Feskens \\ Ellen E. Blaak \\ Timon W. van Haeften \\ Cisca Wijmenga \\ Marten H. Hofker \\ Coen D.A. Stehouwer \\ Tjerk W.A. de Bruin \\ Submitted for publication
}




\section{Introduction}

The first chromosomal locus for Familial Combined Hyperlipidemia (FCHL) on 1q21-23 in Finnish pedigrees led to the identification of Upstream Transcription Factor 1 (USF1), a transcriptional regulator critically involved in lipid and glucose homeostasis $(1,2)$. Since this original report, association of USF1 with FCHL was replicated in Mexican Americans and Utah Caucasians $(3,4)$ and subsequent studies in distinct ethnic population samples also linked variants in the USF1 gene to inherited susceptibility for hyperlipidemia, the metabolic syndrome and its component traits (5-7). Importantly, in a recent prospective study, specific alleles of the USF1 gene proved to modify CVD risk and contribute both to CVD and all-cause mortality at the population level (8).

Considerable genetic and phenotypic overlap exists between FCHL and Type 2 diabetes, and dyslipidemia is a very commonly observed phenomenon in patients with type 2 diabetes. FCHL and type 2 diabetes both develop against a background of insulin resistance and predispose to early cardiovascular disease. The USF1 chromosomal region 1q21-23 has not only been repeatedly attributed to FCHL $(1,9-11)$, but also represents the most consistently replicated locus in genome wide scans for linkage to type 2 diabetes (12-21). USF1 is therefore an attractive biological and positional candidate gene for type 2 diabetes. Yet, the direct contribution of the USF1 gene on type 2 diabetes susceptibility has been addressed in a more limited fashion and results are less unequivocal than for FCHL and lipid traits. Two studies thus far reported a significant genetic association with type 2 diabetes or its component traits with the same single nucleotide polymorphisms (SNPs) -or SNPs in tight LD- as identified for FCHL and lipid traits $(5,6)$. Data from the two most recent studies did not provide additional support for a statistically significant effect (22, 23). In order to adequately evaluate the contribution of USF1 risk alleles to type 2 diabetes in distinct populations, and provide robust assessment of effect size, replication studies in large, well-defined cohorts are required.

In the present study we investigated whether variants in the USF1 gene contribute to the inherited susceptibility for developing type 2 diabetes in 2011 subjects of the Dutch population, using two independent case-control samples comprising 712 patients with type 2 diabetes and 1299 healthy controls. 


\section{Methods}

\section{Subjects}

The first case-control sample comprised 501 subjects with type 2 diabetes from the Breda cohort (24) and 920 healthy blood bank donors of Dutch Caucasian origin (25). Patients were diagnosed according to the WHO criteria (random plasma glucose level $>11.1 \mathrm{mmol} / 1$ or a fasting plasma glucose level $>7.0$ $\mathrm{mmol} / \mathrm{l}$ ). The clinical characteristics of the patients (HbA1c, total cholesterol, HDL cholesterol and triglycerides) were available, as well as the level of obesity (body mass index) in each individual. Clinical characteristics of the first case-control sample are provided in Table 1.

Table 1. Clinical characteristics of case-control sample 1.

\begin{tabular}{|c|c|c|}
\hline Trait & Patient Group & Control group \\
\hline $\mathrm{N}$ (male/female) & $501\left(270^{a} / 230\right)$ & $920\left(354 / 557^{b}\right)$ \\
\hline Age at study (years) & $70.7 \pm 9.9$ & $47.8 \pm 12.7$ \\
\hline Age at diagnosis (years) & $57.6 \pm 14.4$ & - \\
\hline BMI $\left(\mathrm{kg} / \mathrm{m}^{2}\right)$ & $27.6 \pm 4.9$ & NA \\
\hline $\mathrm{HbA}_{1 \mathrm{c}}(\%)$ & $6.6 \pm 2.4$ & NA \\
\hline HDL-cholesterol (mmol/L) & $1.1 \pm 0.5$ & NA \\
\hline Total Cholesterol (mmol/L) & $4.9 \pm 1.8$ & NA \\
\hline Triglycerides (mmol/L) & $1.7 \pm 1.1$ & NA \\
\hline \multicolumn{3}{|c|}{ 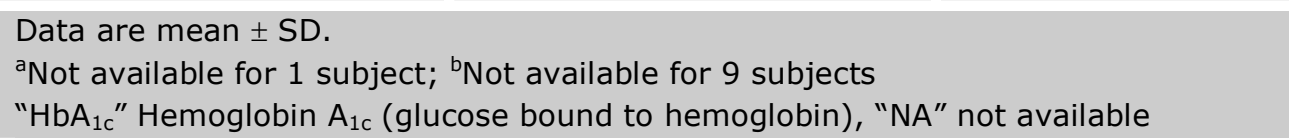 } \\
\hline
\end{tabular}

The second case-control sample was collected as described previously $(26,27)$. Briefly, more than 2700 subjects with one or more cardiovascular risk factors, including hypertension, BMI $>25 \mathrm{~kg} / \mathrm{m}^{2}$, a positive family history for type 2 diabetes mellitus, or a history of gestational diabetes, were screened for type 2 diabetes. Exclusion criteria were the use of medication that affects glucose metabolism and non-Caucasian ethnicity. The case-control sample comprised all newly diagnosed subjects with type 2 diabetes $(\mathrm{N}=211)$, and a random selection of 379 normoglycemic control subjects. Clinical characteristics of the second case-control sample are provided in Table 2. The Human Investigation Review Committee of the Academic Hospital Maastricht and the Medical Ethics Committee of the University Medical Center Utrecht approved the study protocol and all subjects gave written informed consent. 
Table 2. Clinical characteristics of case-control sample 2

\begin{tabular}{|c|c|c|}
\hline Trait & Patient Group & Control group \\
\hline N (male/female) & $211(67 / 144)$ & $379(157 / 222)$ \\
\hline Age & $59.7 \pm 6.5$ & $57.8 \pm 7.3$ \\
\hline BMI $\left(\mathrm{kg} / \mathrm{m}^{2}\right)$ & $30.7 \pm 4.4$ & $27.4 \pm 3.8^{b}$ \\
\hline Fasting glucose & $7.9 \pm 1.8$ & $5.3 \pm 0.4$ \\
\hline HDL-cholesterol (mmol/L) & $1.0^{\mathrm{a}} \pm 0.3$ & $1.3^{c} \pm 0.4$ \\
\hline Total Cholesterol (mmol/L) & $5.1^{a} \pm 1.0$ & $5.2^{c} \pm 0.9$ \\
\hline Triglycerides (mmol/L) & $2.0^{\mathrm{a}} \pm 1.1$ & $1.3^{c} \pm 0.6$ \\
\hline
\end{tabular}

\section{Genotyping.}

Previous studies that investigated the genetic contribution of USF1 to FCHL and type 2 diabetes identified two specific SNPs -or variants in tight LD with these SNPs- that were consistently most strongly associated with disease. These variants, rs2073658 and rs3737787 are 1239 bp apart and located in intron 7 and the $3^{\prime}$ untranslated region of the USF1 gene respectively. In previous reports both variants were in (almost) complete linkage disequilibrium. SNPs rs2073658 and rs3737787 were genotyped using Taqman assays (Applied Biosystems). Assays were performed according to the manufacturer's instructions. The DNA samples were processed in 384-well plates. Each plate contained eight negative controls and 16 genotyping controls. Genotypes were analyzed using a TaqMan 7900 HT (Applied Biosystems, Nieuwerkerk a/d IJssel, The Netherlands).

\section{Statistical Analyses}

Power calculations were performed using the genetic power calculator of Purcell et al (28) (available at http://pngu.mgh.harvard.edu/ purcell/gpc/).

Assuming a disease prevalence of 0.1 , a genotype relative risk of 1.25 and 1.50, and an allele frequency of 0.75 , the combined case-control sample afforded an estimated power of 0.77 at $\mathrm{p}<0.05$. Odds ratios and $\mathrm{p}$-values for case-control analyses were calculated using $\chi^{2}$ tests. $D^{\prime}$ and $r^{2}$ between the USF1 SNPs were calculated using Haploview. 


\section{Results}

We genotyped rs2073658 in all subjects from both cohorts. Genotype success rate was $>98 \%$, and the SNP was in Hardy Weinberg equilibrium. In addition, we genotyped SNP rs3737787 in a subset of 590 subjects. In accordance with previous studies both SNPs were in complete linkage disequilibrium $\left(D^{\prime}=1\right.$, r2=1). The results of SNP rs2073658, which has the best credentials as a potential causal variant in USF1 (29), are presented in Table 3.

Table 3. Genotype and allele frequencies in patients with type 2 diabetes and control subjects

\begin{tabular}{|c|c|c|c|c|c|}
\hline $\begin{array}{c}\text { Genotype } \\
\text { rs2073658 }\end{array}$ & DM2 (\%) & Control (\%) & $\begin{array}{l}\text { Odds } \\
\text { Ratio }\end{array}$ & 95\% C.I. & p-value \\
\hline \multicolumn{6}{|c|}{ Case-control sample $1(\mathrm{~N}=1421)$} \\
\hline $\begin{array}{l}\text { AA } \\
\text { AG } \\
\text { GG }\end{array}$ & $\begin{array}{c}35(7.2) \\
174(35.6) \\
280(57.3)\end{array}$ & $\begin{array}{c}87(9.6) \\
355(39.1) \\
465(51.3)\end{array}$ & $\begin{array}{c}1 \\
1.22 \\
1.50\end{array}$ & $\begin{array}{l}0.79-1.88 \\
0.98-2.28\end{array}$ & $\begin{array}{l}0.370 \\
0.058\end{array}$ \\
\hline $\begin{array}{l}\text { A-allele } \\
\text { G-allele }\end{array}$ & $\begin{array}{l}244(24.9) \\
734(75.1)\end{array}$ & $\begin{array}{c}529(29.2) \\
1285(70.8)\end{array}$ & $\begin{array}{c}1 \\
1.25\end{array}$ & $1.04-1.48$ & 0.018 \\
\hline \multicolumn{6}{|c|}{ Case-control sample $2(\mathrm{~N}=590)$} \\
\hline $\begin{array}{l}\text { AA } \\
\text { AG } \\
\text { GG }\end{array}$ & $\begin{array}{c}13(6.3) \\
74(35.6) \\
121(58.2)\end{array}$ & $\begin{array}{c}28(7.5) \\
152(40.8) \\
193(51.7)\end{array}$ & $\begin{array}{c}1 \\
1.05 \\
1.35\end{array}$ & $\begin{array}{l}0.51-2.14 \\
0.67-2.71\end{array}$ & $\begin{array}{l}0.896 \\
0.396\end{array}$ \\
\hline $\begin{array}{l}\text { A-allele } \\
\text { G-allele }\end{array}$ & $\begin{array}{l}100(24.0) \\
316(76.0)\end{array}$ & $\begin{array}{l}208(27.9) \\
538(72.1)\end{array}$ & $\begin{array}{c}1 \\
1.22\end{array}$ & $0.93-1.61$ & 0.155 \\
\hline \multicolumn{6}{|c|}{ Case-control sample $1+2$ combined $(N=2011)$} \\
\hline $\begin{array}{l}\text { AA } \\
\text { AG } \\
\text { GG }\end{array}$ & $\begin{array}{c}48(6.9) \\
248(35.6) \\
401(57.5)\end{array}$ & $\begin{array}{c}115(9.0) \\
507(39.6) \\
658(51.4)\end{array}$ & $\begin{array}{c}1 \\
1.17 \\
1.46\end{array}$ & $\begin{array}{l}0.81-1.70 \\
1.02-2.09\end{array}$ & $\begin{array}{l}0.400 \\
0.038\end{array}$ \\
\hline $\begin{array}{l}\text { A-allele } \\
\text { G-allele }\end{array}$ & $\begin{array}{c}344(24.7) \\
1050(75.3)\end{array}$ & $\begin{array}{c}737(28.8) \\
1823(71.2)\end{array}$ & $\begin{array}{c}1 \\
1.23\end{array}$ & $1.06-1.43$ & 0.006 \\
\hline
\end{tabular}

In the first case-control sample, prevalence of the major allele was higher in patients than in controls $(75 \%$ versus $71 \%$, odds ratio $1.25, \mathrm{p}=0.018)$. In the second case-control sample, a similar frequency difference and concomitant odds ratio were observed: $76 \%$ in patients versus $72 \%$ in control subjects, odds ratio 1.22. Although insufficient power of the second case-control sample prevented this frequency difference to meet the threshold for statistical significance $(p=0.16)$, the effect-size and -direction were identical to the first casecontrol sample and a combined analysis of both samples further strengthened the evidence for association (odds ratio 1.23, $\mathrm{p}=0.006$ ). Importantly, the increased risk for type 2 diabetes susceptibility can be ascribed to the major allele, and its high frequency translates to a considerable population attributive 
risk of $14.5 \%$. Together, these data indicate that the major allele of rs2073658 is associated with a modest but consistent increased risk for developing type 2 diabetes in Dutch Caucasians, with substantial impact at the population level.

\section{Discussion}

USF1 is a positional and functional candidate gene for type 2 diabetes. The main finding of this study is that a polymorphism within the USF1-gene with strongest prior odds for association, and best credentials for functional involvement (rs2073658) is associated with type 2 diabetes in an analysis with 2011 Dutch Caucasian subjects. The observed effect size of the USF1 risk allele is modest (OR $\approx 1.25)$, but consistent in the two independent Dutch case-control samples.

USF1 is a ubiquitously expressed transcription factor of the basic helix-loophelix leucine zipper family and regulates the expression of some 40 genes, several of them involved in lipid and glucose metabolism. USF1 mediates its transcriptional regulation through binding to E-box motifs in the promoter region of target genes with the consensus sequence CACGTG, either as homodimer but in most cases as a heterodimer with the related transcription factor USF2 (30).

USF1 was originally identified as a major susceptibility gene for FCHL, underlying the linkage signal on 1q21-23 in Finnish families with the disease (2). Two polymorphisms in USF1, rs2073658 and rs3737787, in strong LD with each other, were the most strongly associated variants. Subsequent replication studies in various FCHL samples of distinct ethnicities implicated the same polymorphisms (or variants in tight $\mathrm{LD}$ ) in the genetic background of FCHL $(3,4,31)$. Furthermore, differential expression of USF1-regulated genes in adipose tissue from subjects with different allelic variants has been reported (29). Complementary to these findings, significant associations with lipid traits, parameters of adipose tissue metabolism, and the metabolic syndrome in populations not specifically ascertained for FCHL, further extended the potential significance of USF1 as a cardiovascular risk determinant $(6,7,32-34)$. Recent important data from a prospective follow up study demonstrate that USF1 risk alleles confer an approximately two fold increased risk to cardiovascular disease and all-cause mortality in women from two independent Finnish cohorts representative of the general population (8). These latter data provide impor- 
tant decisive evidence and illustrate how a gene originally identified in highrisk families proves to be important also at the population level.

No amino acid changes have been detected in the USF1 gene that could functionally account for the observed associations. However, rs2073658 resides in a 20-basepair DNA sequence that binds nuclear proteins and possibly represents a transcriptional regulatory element (29). In all studies to date rs2073658 and rs3737787 were among the strongest associated variants, suggesting that -irrespective of whether one of these SNP is a true etiological variant- they represent reliable markers for FCHL across populations of different ethnicity.

Triggered by the convincing results of USF1 variants in relation to FCHL and lipid traits, some research groups scrutinized the USF1 gene for its potential contribution to inherited DM2 susceptibility. Four studies thus far investigated the potential association of USF1 SNPs with type 2 diabetes or related traits (5, $6,22,23$ ). Putt et al were the first to report haplotypic associations (comprising SNPs in tight LD with rs3737787 and rs2073658) with glucose levels during an oral glucose tolerance test (5). In Hong Kong Chinese subjects rs3737787 was associated with type 2 diabetes in family cases with 1q-linkage but no association was found in a second case-control cohort (6). Recent analyses in French Caucasian subjects and in several populations with evidence of chromosome 1q linkage found no significant associations $(22,23)$.

Although the USF1 risk allele in the present study confers only a modest risk to individuals carrying the risk variant, it may have a substantial impact at the population level. As much as $\sim 75 \%$ of subjects carry the risk allele, which translates to a population attributive risk (PAR) of $14 \%$. This means, that if the population were monomorphic for the protective allele, the prevalence of type 2 diabetes would be $14 \%$ lower. This resembles the established type 2 diabetes variant Pro12Ala in PPAR $\gamma$, which confers modest risk for the individual $(\mathrm{OR}=1.25)$, but high risk at the population level (PAR=25\%) (35).

From our present study and the available data thus far, we conclude that the diabetogenic properties of USF1 polymorphisms are likely modest at the level of the individual, but may be considerable at the population level.

\section{Acknowledgements}

We wish to thank all patients who participated in this study. 


\section{References}

1. Pajukanta P, Nuotio I, Terwilliger JD, et al. 1998 Linkage of familial combined hyperlipidaemia to chromosome 1q21-q23. Nat Genet 18:369-73

2. Pajukanta P, Lilja HE, Sinsheimer JS, et al. 2004 Familial combined hyperlipidemia is associated with upstream transcription factor 1 (USF1). Nat Genet 36:371-6

3. Huertas-Vazquez A, Aguilar-Salinas C, Lusis AJ, et al. 2005 Familial combined hyperlipidemia in Mexicans: association with upstream transcription factor 1 and linkage on chromosome 16q24.1. Arterioscler Thromb Vasc Biol 25:1985-91

4. Coon H, Xin Y, Hopkins PN, Cawthon RM, Hasstedt SJ, Hunt SC 2005 Upstream stimulatory factor 1 associated with familial combined hyperlipidemia, LDL cholesterol, and triglycerides. Hum Genet 117:444-51

5. Putt W, Palmen J, Nicaud V, et al. 2004 Variation in USF1 shows haplotype effects, gene : gene and gene : environment associations with glucose and lipid parameters in the European Atherosclerosis Research Study II. Hum Mol Genet 13:1587-97

6. Ng MC, Miyake K, So WY, et al. 2005 The linkage and association of the gene encoding upstream stimulatory factor 1 with type 2 diabetes and metabolic syndrome in the Chinese population. Diabetologia 48:2018-24

7. Hoffstedt J, Ryden M, Wahrenberg H, van Harmelen V, Arner P 2005 Upstream transcription factor-1 gene polymorphism is associated with increased adipocyte lipolysis. J Clin Endocrinol Metab 90:5356-60

8. Komulainen K, Alanne M, Auro K, et al. 2006 Risk alleles of USF1 gene predict cardiovascular disease of women in two prospective studies. PLoS Genet 2:e69

9. Pei W, Baron H, Muller-Myhsok B, et al. 2000 Support for linkage of familial combined hyperlipidemia to chromosome 1q21-q23 in Chinese and German families. Clin Genet 57:29-34

10. Huertas-Vazquez A, del Rincon JP, Canizales-Quinteros S, et al. 2004 Contribution of chromosome 1q21-q23 to familial combined hyperlipidemia in Mexican families. Ann Hum Genet 68:419-27

11. Coon H, Myers RH, Borecki IB, et al. 2000 Replication of linkage of familial combined hyperlipidemia to chromosome 1q with additional heterogeneous effect of apolipoprotein A-I/C-III/A-IV locus. The NHLBI Family Heart Study. Arterioscler Thromb Vasc Biol 20:2275-80

12. Elbein SC, Hoffman MD, Teng K, Leppert MF, Hasstedt SJ 1999 A genome-wide search for type 2 diabetes susceptibility genes in Utah Caucasians. Diabetes 48:1175-82

13. Hsueh WC, St Jean PL, Mitchell BD, et al. 2003 Genome-wide and fine-mapping linkage studies of type 2 diabetes and glucose traits in the Old Order Amish: evidence for a new diabetes locus on chromosome 14q11 and confirmation of a locus on chromosome 1q21q24. Diabetes 52:550-7

14. Wiltshire S, Hattersley AT, Hitman GA, et al. 2001 A genomewide scan for loci predisposing to type 2 diabetes in a U.K. population (the Diabetes UK Warren 2 Repository): analysis of 573 pedigrees provides independent replication of a susceptibility locus on chromosome 1q. Am J Hum Genet 69:553-69

15. Meigs JB, Panhuysen CI, Myers RH, Wilson PW, Cupples LA 2002 A genome-wide scan for loci linked to plasma levels of glucose and $\mathrm{HbA}(1 \mathrm{c})$ in a community-based sample of Caucasian pedigrees: The Framingham Offspring Study. Diabetes 51:833-40 
16. Ng MC, So WY, Cox NJ, et al. 2004 Genome-wide scan for type 2 diabetes loci in Hong Kong Chinese and confirmation of a susceptibility locus on chromosome 1q21-q25. Diabetes 53:1609-13

17. Du W, Sun H, Wang H, et al. 2001 Confirmation of susceptibility gene loci on chromosome 1 in northern China Han families with type 2 diabetes. Chin Med J (Engl) 114:876-8

18. Langefeld CD, Wagenknecht LE, Rotter JI, et al. 2004 Linkage of the metabolic syndrome to 1q23-q31 in Hispanic families: the Insulin Resistance Atherosclerosis Study Family Study. Diabetes 53:1170-4

19. Hanson RL, Ehm MG, Pettitt DJ, et al. 1998 An autosomal genomic scan for loci linked to type II diabetes mellitus and body-mass index in Pima Indians. Am J Hum Genet 63:1130-8

20. Vionnet N, Hani El H, Dupont S, et al. 2000 Genomewide search for type 2 diabetessusceptibility genes in French whites: evidence for a novel susceptibility locus for earlyonset diabetes on chromosome 3q27-qter and independent replication of a type 2diabetes locus on chromosome 1q21-q24. Am J Hum Genet 67:1470-80

21. Xiang K, Wang Y, Zheng T, et al. 2004 Genome-wide search for type 2 diabetes/impaired glucose homeostasis susceptibility genes in the Chinese: significant linkage to chromosome 6q21-q23 and chromosome 1q21-q24. Diabetes 53:228-34

22. Gibson F, Hercberg S, Froguel P 2005 Common polymorphisms in the USF1 gene are not associated with type 2 diabetes in French Caucasians. Diabetes 54:3040-2

23. Zeggini E, Damcott CM, Hanson RL, et al. 2006 Variation within the gene encoding the upstream stimulatory factor 1 does not influence susceptibility to type 2 diabetes in samples from populations with replicated evidence of linkage to chromosome 1q. Diabetes 55:2541-8

24. van Tilburg JH, Sandkuijl LA, Strengman E, et al. 2003 A genome-wide scan in type 2 diabetes mellitus provides independent replication of a susceptibility locus on 18p11 and suggests the existence of novel Loci on 2q12 and 19q13. J Clin Endocrinol Metab 88:222330

25. Monsuur AJ, de Bakker PI, Alizadeh BZ, et al. 2005 Myosin IXB variant increases the risk of celiac disease and points toward a primary intestinal barrier defect. Nat Genet 37:1341-4

26. van Dam RM, Hoebee B, Seidell JC, Schaap MM, de Bruin TW, Feskens EJ 2005 Common variants in the ATP-sensitive K+ channel genes KCNJ11 (Kir6.2) and ABCC8 (SUR1) in relation to glucose intolerance: population-based studies and meta-analyses. Diabet Med 22:590-8

27. Kruijshoop M, Feskens EJ, Blaak EE, de Bruin TW 2004 Validation of capillary glucose measurements to detect glucose intolerance or type 2 diabetes mellitus in the general population. Clin Chim Acta 341:33-40

28. Purcell S, Cherny SS, Sham PC 2003 Genetic Power Calculator: design of linkage and association genetic mapping studies of complex traits. Bioinformatics 19:149-50

29. Naukkarinen J, Gentile M, Soro-Paavonen A, et al. 2005 USF1 and dyslipidemias: converging evidence for a functional intronic variant. Hum Mol Genet 14:2595-605

30. Casado M, Vallet VS, Kahn A, Vaulont S 1999 Essential role in vivo of upstream stimulatory factors for a normal dietary response of the fatty acid synthase gene in the liver. J Biol Chem 274:2009-13 
31. van der Vleuten GM, Isaacs A, Hijmans A, van Duijn CM, Stalenhoef AF, de Graaf J 2007 The involvement of upstream stimulatory factor 1 in Dutch patients with familial combined hyperlipidemia. J Lipid Res 48:193-200

32. Shoulders CC, Naoumova RP 2004 USF1 implicated in the aetiology of familial combined hyperlipidaemia and the metabolic syndrome. Trends Mol Med 10:362-5

33. Choquette AC, Bouchard L, Houde A, Bouchard C, Perusse L, Vohl MC 2007 Associations between USF1 gene variants and cardiovascular risk factors in the Quebec Family Study. Clin Genet 71:245-53

34. Kantartzis K, Fritsche A, Machicao F, et al. 2007 Upstream transcription factor 1 gene polymorphisms are associated with high antilipolytic insulin sensitivity and show genegene interactions. J Mol Med 85:55-61

35. Altshuler D, Hirschhorn JN, Klannemark M, et al. 2000 The common PPARgamma Pro12Ala polymorphism is associated with decreased risk of type 2 diabetes. Nat Genet 26:76-80 


\section{Chapter 7}

General Discussion

Years of intensive research in the field of insulin resistance, hyperlipidemia and type 2 diabetes have substantially improved our knowledge of their pathophysiological mechanisms. However, the present level of know-

ledge does not yet allow individualized treatment according to differences in genetic make-up. In light of the emerging shift in medicine towards "personalized medicine" and the coinciding search for novel biomarkers, contributions in this area of research are keenly awaited. Studies, designed to understand the genetic background of disease, can also draw our attention to molecular pathways that would otherwise remain unconsidered, especially when they are led by unbiased,

hypothesis free approaches such as gene expression

studies or genetic linkage- and positional cloning analyses. In this thesis we aimed to identify new genes and molecular pathways underlying insulin resistance.

In particular we used type 2 diabetes and Familial Combined Hyperlipidemia (FCHL) as two complementary genetic models for insulin resistance.

This chapter is divided in 2 main sections. In the first part, we offer a perspective on an emerging novel pathway in the pathophysiology of the metabolic syndrome, which is strongly related to one of the major findings of this thesis: The endoplasmic reticulum (ER) stress response or unfolded protein response (UPR). In the second part of this chapter, our study approach, its

strengths and limitations, as well as the potential impact and implications of our results are discussed. 


\section{Part 1}

In this thesis the proximal ER stress sensor ATF6, was identified as a novel susceptibility gene for type 2 diabetes and FCHL (Chapter 4 and 5). The value of genetic research beyond an improved understanding of the complex genetic background that underlies these diseases, is that it can expose previously unexplored pathways. The implication of ATF6 in the pathophysiology of type 2 diabetes and FCHL coincides with preliminary insights in literature that link ER stress to multiple components of the metabolic syndrome. In the following section we discuss these scientific developments, preceded by a short introductory paragraph that describes the basic physiological role of the unfolded protein response, deployed by the joint action of its three main branches. At the appropriate passages we integrate our ATF6 related findings in type 2 diabetes and FCHL in the broader research area of ER stress and the metabolic syndrome.

\section{ER stress and activation of the unfolded protein response: an emerging pathway linked with multiple components of the metabolic syndrome}

ER stress and activation of the UPR is implicated in diverse cellular and physiological processes (secretory apparatus, plasma cell differentiation, apoptosis) (1-10), as well as in various pathologies including genetic misfolding diseases (osteogenesis imperfecta, Wolcott-Rallison syndrome), cancer (11-14), and neurodegenerative disorders such as Alzheimer disease (15-17) and Parkinson disease. (18-20) Very recently, several independent discoveries implicated ER stress and activation of the unfolded protein response in various pathologies associated with the metabolic syndrome, including type 2 diabetes (both insulin resistance and beta cell failure) (21-23), dyslipidemia $(24,25)$, hepatic steatosis $(26,27)$, inflammation (28) and atherosclerosis (29).

The ER is a membranous network that functions in the maturation and folding of most secretory and membrane proteins. The flux of proteins that enter the ER as unfolded polypeptide chains can change rapidly in response to 


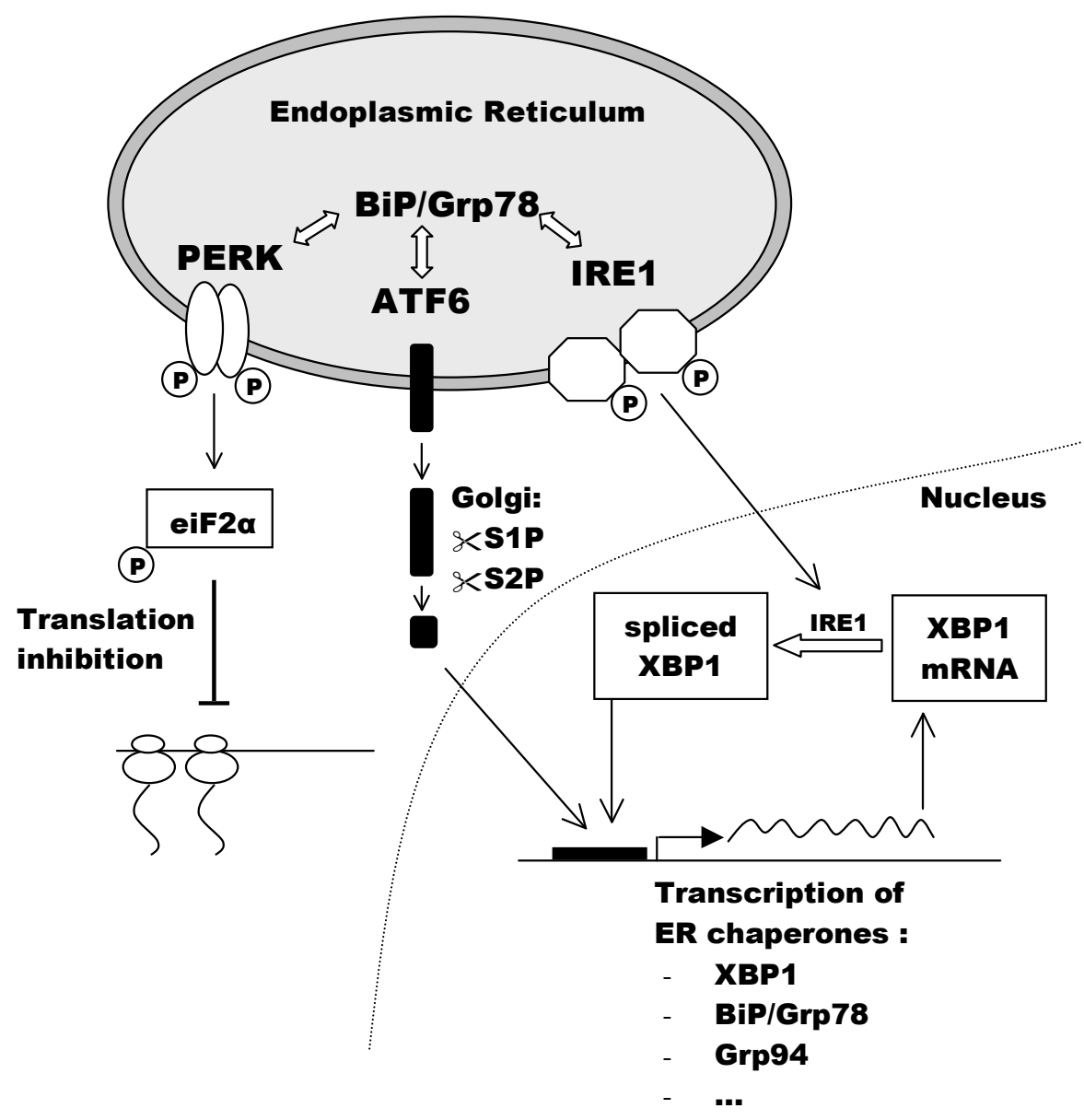

Figure 1.The ER chaperone protein BiP/Grp78 serves as a master UPR regulator and plays an essential role in activation of the transmembrane proteins IRE1, PERK and ATF6 (31). In the absence of ER stress, BiP is associated with IRE1, PERK and ATF6. When unfolded proteins accumulate in the ER lumen, BiP dissociates from the ER transmembrane proteins and binds the unfolded proteins. This is followed by activation of IRE, PERK and ATF6. BiP release permits IRE1 and PERK to undergo spontaneous homodimerization mediated by their luminal domains and subsequently trans-autophosphorylation by their endogenous kinase activities (32). Activated PERK phosphorylates eukaryotic translation initiation factor 2 (eiF2) on the a subunit, thereby reducing the general rate of translation initiation and preventing the entry of new proteins in the already saturated ER. Activation of IRE is characterized by induction of its endoribonuclease activity. This activity catalyzes the removal of a small (26-nucleotide) intron from the unspliced XBP1 mRNA, which changes the translational reading frame of XBP1 and yields a potent active and stable transcription factor for UPR responsive genes. In addition, upon release of BiP, ATF6 translocates to the Golgi compartment where it subsequently undergoes cleavage by S1P and S2P (33). Cleaved ATF6 is a potent transcription factor for UPR responsive genes, including X-Box-Binding-protein 1 (XBP1), BiP, and Grp94. Noteworthy, two different ATF6 genes exist: ATF6-alpha and ATF6 beta. ATF6-alpha, located on chromosome 1 is responsible for actual UPR activation, whereas ATF6-beta - a different gene on chromosome 6- is opposing to ATF6-alpha and may serve as a transcriptional repressor, functioning in part to regulate the strength and duration of ATF6 alpha-mediated transcription in the UPR (34). The isoform studied in this thesis is ATF6-alpha. 
mental conditions. Cells can handle this dynamic situation because protein folding capacity in the ER can be adapted according to the load of unfolded proteins in the ER lumen. The signaling pathway that mediates this adaptation is called the ER stress response or unfolded protein response $(30,31)$. "ER stress" refers to the cellular state in which the ER machinery fails to cope with the load imposed by newly synthesized proteins, resulting in progressive accumulation of unfolded proteins in the ER lumen. Subsequent activation of the unfolded protein response is initiated by three proximal ER stress sensors: inositol requiring 1 (IRE1), PKR-like endoplasmic reticulum kinase (PERK), and activating transcription factor 6 (ATF6) (Figure 1). Restoration of ER homeostasis is achieved by the combined effect of these three signaling pathways. First, general protein translation is strongly inhibited, preventing the entry of novel polypeptides in the already saturated ER (reviewed in (35)). Second, unfolded or misfolded proteins in the ER lumen are retrotranslocated through the translocon to the cytoplasm, where they are ubiquitinated and degraded by the proteasome, a process called ER stress associated protein degradation (ERAD) $(36,37)$. Third, a transcriptional program is induced including genes that aid in the folding process of proteins (molecular chaperones) and boost the capacity of the ER (reviewed in (35) and (38)). Finally, if ER-homeostasis cannot be re-established by means of these adaptive responses, the UPR activates pro-apoptotic pathways $(9,39,40)$.

\section{The UPR in relation to type 2 diabetes}

Animal studies have shown that the IRE1 and PERK initiated pathways of the UPR, play an important role in the development of type 2 diabetes through effects on peripheral insulin resistance and beta cell function respectively. (2, 21)

\section{The UPR and peripheral insulin resistance}

Classical ER stress triggers include glucose or nutrient deprivation, oxidative stress, viral infections and increased synthesis of secretory proteins. Recently it was shown that obesity poses a chronic strain on the ER machinery, and initiates the UPR in genetic and diet induced mouse models of obesity (21). This is particularly the case for adipose tissue, which undergoes severe changes in tissue architecture, increases in protein and lipid synthesis, and perturbations 
in intracellular nutrient and energy fluxes. Obesity induced activation of the UPR slows protein synthesis and boosts the capacity of the ER, but does so at the expense of glucose homeostasis. Ozcan et al showed that the IRE1 initiated pathway of the UPR confers this negative side effect (Figure 2). Activated IRE1, apart from having endoribonuclease activity (Ire1 splices XBP1, figure 1), is a kinase that activates c-jun N-terminal kinase (JNK). The serine kinase JNK subsequently serine-phosphorylates insulin receptor substrate-1 (IRS1), thereby reducing insulin receptor signaling (Figure 2) (21). Thus, obesity induced ER stress can directly affect insulin signaling and induce cellular insulin resistance.

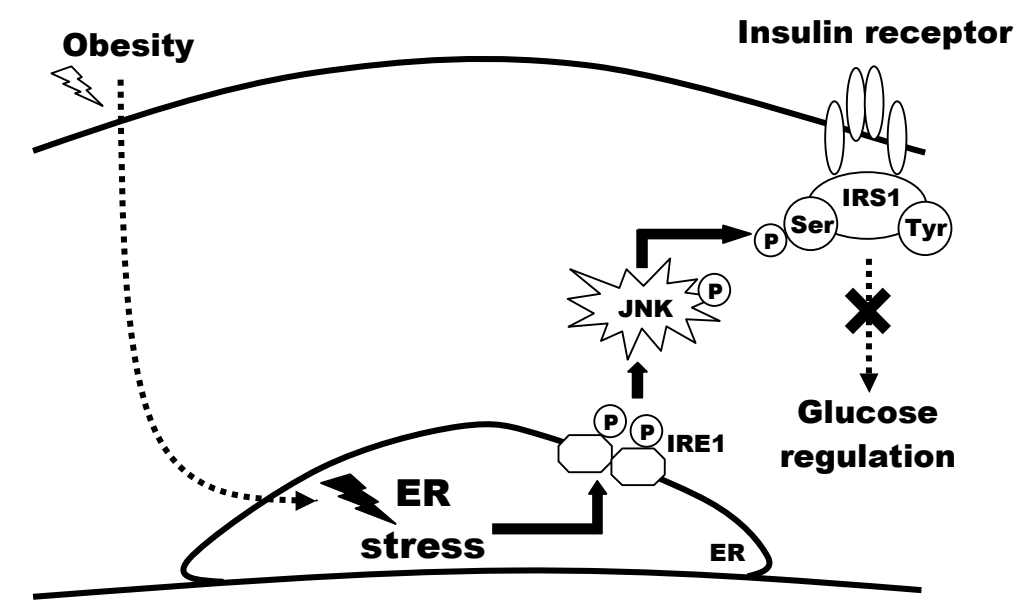

Figure 2. The Ire branch of the UPR contributes to cellular insulin resistance

Another observation published by Nakatani and colleagues supports these findings. They reported improved insulin resistance and ameliorated glucose tolerance upon overexpression of oxygen related protein (ORP150) a molecular chaperone in the ER (23). This chaperone reduces ER stress, and correspondingly restores insulin signaling. The mechanistic link between ER stress and insulin resistance holds promises as a novel therapeutic target: oral administration of chemical chaperones alleviated ER stress in cells and whole animals. Moreover, treatment of obese and diabetic mice with these chaperones resulted in normalization of hyperglycemia, restoration of systemic insulin sensitivity, resolution of fatty liver disease, and enhancement of insulin action in liver, muscle, and adipose tissue (22). 


\section{The UPR and beta cell function}

In addition to the link between ER stress and peripheral insulin resistance, evidence emerged for a role of the UPR in beta cell function. PERK activation and subsequent phosphorylation of eiF $2 \alpha$ is of critical importance for translational regulation of insulin secretion by the beta cell. A $50 \%$ decrease of eiF $2 \alpha$ phosphorylation at serine 51, induces obesity and type 2 diabetes in mice on a high fat diet (2). Of note, two mutations in PERK have been shown to cause Wolcott-Rallison syndrome, a rare autosomal disorder characterized by islet beta cell dystrophy and infantile diabetes mellitus (18).

It can be seen that the impact of UPR signaling to the development of type 2 diabetes is not straightforward. At the level of the pancreas, the UPR protects the beta cell by maintaining the balance between pro-insulin synthesis and ER folding capacity (2). Conversely, in liver and adipose tissue, obesity induced ER stress and activation of the unfolded protein response causes peripheral insulin resistance (21). Although provocative, it seems not impossible that genetic variation in genes regulating the UPR, for instance ATF6, could have opposite effects in terms of insulin sensitivity and beta cell function. Such effect would partly explain how genetic variation accounts for differences between individuals regarding their natural propensity to initially develop hyperlipidemia or hyperglycemia in the presence of insulin resistance.

\section{ER stress and lipid metabolism}

The mechanistic activation of Sterol Regulatory Element Binding Proteins (SREBPs) and ATF6 in response to sterol deprivation and ER stress respectively, may have evolved from a common ancestral pathway. Sterol Regulatory Element Binding Protein 2 (SREBP2) is an ER resident transcription factor with a central role in cholesterol homeostasis. When cellular cholesterol levels are normal, SREBP2 is anchored to the ER membrane $(41,42)$. In response to cellular demand for cholesterol, SREBP undergoes a proteolytic activation process, identical to that of ATF6, known as regulated intramembrane proteolysis (RIP). The transcriptionally active amino terminal domain of SREBP2 is released in the cytoplasm and migrates to the nucleus where it binds sterol response element (SRE) sequences in the promoter region of target genes, including cholesterogenic enzymes and the LDL receptor (43). Importantly, ATF6 can serve as an inhibitor of this process (24). Activated ATF6 can interact 
with SREBP2 and bind as a heterodimer to sterol response elements (SREs) in the promoters of cholesterogenic genes. Bound to SRE, the ATF6-SREBP2 heterodimer recruits $\mathrm{HDAC1}$, and together they exert an inhibitory effect on SREBP2-regulated transcription. This represents one of the hypothetic mechanisms through which the methionine[67]valine gain of function polymorphism in ATF6 could increase plasma cholesterol levels. Other possibilities exist, illustrated by the presence of ATF6 binding elements in the promoter region of the apoB gene (28).

Antagonistic effects between activation of the UPR and sterol metabolism have also been demonstrated for the PERK-initiated arm of the UPR, centered on eIF $2 \alpha$ serine 51 phosphorylation and also known as "the integrated stress response" (ISR). Phosphorylation of this unit adapts mammalian cells to a variety of stressful conditions, but simultaneously reduces the level of active SREBP and sterol regulated mRNA's. On the other hand, a mutation in eIF2 $\alpha$ that prevented phosphorylation of this residue enhanced activation of sterolregulated genes (25). Together, these findings suggest that ATF6- and ISRmediated inhibition of SREBP activation fine-tunes cholesterol biosynthesis to the circumstances of ER-stressed cells.

\section{ER stress and hyperhomocysteinemia}

Hyperhomocysteinemia triggers the ER stress response. Epidemiological surveys have suggested a relationship between serum homocysteine levels and the development of cardiovascular disease. A mechanistic link for these correlative observations was provided by Werstuck et al, reporting a direct effect of homocysteine induced ER stress on triglyceride and cholesterol biosynthetic pathways (27). In line with these observations, a pharmaceutical intervention with valproate, a small molecule drug that protects cells from ER stress induced dysfunction, increased the resistance of cells to ER stress-induced lipid accumulation (26). This mechanism may explain in part the development and progression of hepatic steatosis, and the authors suggested that a similar mechanism could also contribute to atherosclerotic lesion formation observed in hyperhomocysteinemia. 


\section{ER stress and inflammation}

The metabolic syndrome is characterized by a state of low-grade inflammation and production of multiple pro-inflammatory cytokines by liver and adipose tissue (44). The first evidence for a link between ER stress and inflammation came from a genetic association study. Curran and colleagues identified a promoter polymorphism in the selenoprotein S gene (SEPS1, SELS), which is implicated in the ER stress response. (45) In their study, a direct mechanistic link between the SELS -105 G/A variant and altered production of inflammatory cytokines IL-6, IL-1 $\beta$ and TNF $\alpha$ was demonstrated. In 2006, researches from the Kaufman-laboratory discovered a novel ER stress-response pathway initiating an acute inflammatory response (28). CREBH was identified as liver specific transcription factor that is cleaved upon ER stress and required to induce expression of acute phase response genes. Identical to ATF6 and SREBPs, CREBH is anchored to the ER membrane and activated by regulated intramembrane proteolysis (RIP). Pro-inflammatory cytokines (IL6 and IL1 $\beta$ ), and LPS can induce cleavage of CREBH and activate the acute phase response and the UPR in the liver in vivo. Importantly, Activated CREBH and ATF6 can interact and synergistically induce transcription of target genes in hepatocytes upon ER stress (28). These data extend the physiological role of ATF6, suggesting that ATF6 could be a general ER stress-activated dimerization partner for RIP regulated transcription factors such as SREBPs and CREBH, hence modulating their transcriptional effects on genes involved in lipid metabolism and inflammation. The possibility that genetic variants in ATF6 could modulate the inflammatory response is intriguing and warrants further study. Additional evidence that the UPR is a mediator of inflammation has been recently reported. In an attempt to identify novel pathways through which oxPAPC induces inflammatory genes in endothelial cells, the ATF4 (downstream of PERK) and XBP1 branches of the UPR pathway were found to mediate vascular inflammation and endothelial cell dysfunction in atherosclerosis $(46,47)$.

\section{ER stress and atherosclerosis}

The paragraphs above suggest an indirect effect of ER stress and activation of the UPR on the progression of atherosclerosis, via a modulating effect on many of its risk factors. However, endoplasmic reticulum stress is also directly 
implicated in the progression of atherosclerosis. At least two pathways have been suggested through which ER stress catalyses the atherosclerotic process. The first is related to ER stress induced vascular inflammation and possibly disturbances in lipid fluxes in atherosclerotic lesions, $(46,47)$ as mentioned previously. Another well-described pathway has been described in macrophages. Free cholesterol accumulation in macrophages in atherosclerotic lesions causes macrophage apoptosis and foam cell formation, a process that is believed to drive the progression of atherosclerosis. The ER has been identified as the culprit organelle for cholesterol-induced apoptosis. In contrast to the plasma membrane, the ER membrane is fluid, low in cholesterol (48), and particularly sensitive to the effects of free cholesterol enrichment. Even modest levels of free cholesterol were sufficient to activate the PERK-arm of the UPR in macrophages, and PERK-/- macrophages were hypersensitive to free cholesterol loading (29). Cholesterol loading depleted the calcium stores in the ER. Subsequent activation of the UPR and changes in PERK activation led to activation of CHOP/GADD153, which finally induces apoptosis (29). 


\section{Part 2}

\section{Gene expression profiling: An unbiased approach for dissecting complex diseases}

A pre-adipocyte gene expression study on patients with FCHL and healthy control subjects is the basis of this thesis (Chapter 3). An inherent limitation of gene expression profiles from "in vivo" human tissue samples is the difficulty to discriminate between primary genetic modifications that cause FCHL, and secondary changes resulting from cellular adaptations to hyperlipidemia. In the study presented in Chapter 3, we used a novel approach in an attempt to enrich for primary genetic alterations, or the direct cellular consequences thereof. Instead of using "fresh adipocytes" for gene expression profiling, we isolated the pre-adipocytes from liposuction samples and cultured them for several weeks under standardized experimental conditions. This design is based on the assumption that noise in the gene expression pattern due to previous metabolic influences is repressed, while genetic effects are preserved and expressed in vitro. Using this approach, CD36, a gene with known functions involved in fat metabolism, was implicated in the pathophysiology of FCHL (Chapter 3). The approach applied in Chapter 3 still has some limitations: although variation in gene expression due to environmental noise was probably efficiently reduced, it was not feasible to discriminate between gene expression differences from genetic or epigenetic origin. Another drawback is that not all genetic alterations might have been detected in a "standardized cell-culture environment". According to the current thinking, the phenotype of Familial Combined Hyperlipidemia (and the metabolic syndrome in general) is the result of complex interactions between genes and environment. Therefore, a genetically predisposed individual, or a primary cell culture from such an individual, may not express its phenotype in the absence of environmental trigger. An interesting follow up experiment would be to measure the gene expression pattern in pre-adipocytes of FCHL patients and control subjects under various challenging conditions such as high glucose, free fatty acids, cholesterol loading, or with addition of compounds that induce oxidative stress or endoplasmic reticulum stress. 


\section{Integrating data from gene expression studies and genetic linkage analyses}

Another valuable tool for unraveling complex genetic diseases are genome wide linkage analyses. Especially when combined with data from gene expression studies, a complementary methodology arises, unbiased by preconceived ideas about pathophysiological mechanisms. In the following paragraph we describe how this integrated approach led to the identification of ATF6 as a novel susceptibility gene for type 2 diabetes and FCHL in this thesis (Chapter 4-5).

Correlation analyses of gene expression data from cultured human preadipocytes described in Chapter 3 revealed a positive relation between GRP94 mRNA expression levels and fasting plasma glucose levels that had been measured in the corresponding subjects, in vivo. A similar gene expression study with cultured human EBV transformed lymphoblast cell-lines (49) revealed a positive correlation between GRP78 (BiP) mRNA expression levels and in vivo plasma glucose levels. GRP94 and GRP78 are both endoplasmic reticulum chaperone proteins and master regulators of the endoplasmic reticulum stress response or unfolded protein response (UPR). The unexpected positive correlation could not be the result of the well-known response of GRP94 and GRP78 expression to glucose (50), since all cells had been cultured for several weeks under standardized, isoglycemic conditions. Based on these observations we hypothesized that the intrinsic cellular UPR capacity may partially determine a subject's plasma glucose level, and that genetic variation in UPR-genes could contribute to the development of type 2 diabetes. An attractive UPR candidate gene to consider was Activating Transcription Factor 6 (ATF6). First, ATF6 is the common transcriptional regulator of GRP78 and GRP94. Second, ATF6 is one of the proximal sensors of endoplasmic reticulum stress and a critical initiator of the unfolded protein response. Third, ATF6 maps to chromosome 1q23.3, the most replicated chromosomal locus for type 2 diabetes(51-57). With these facts in mind we performed a genetic association study and identified ATF6 as a novel type 2 diabetes susceptibility gene (Chapter 4). 


\section{Evidence for a common genetic background in DM2 and FCHL}

The parallel use of patient groups with type 2 diabetes and FCHL to study the genetic background of insulin resistance and the metabolic syndrome, provided a unique opportunity to investigate whether established and novel susceptibility genes for DM2 also confer increased risk to FCHL and vice versa.

In Chapter 5 we screened the ATF6 gene for its potential involvement in the genetic background of FCHL. An amino acid substitution (methionine[67]valine) was associated with increased risk of hypercholesterolemia and elevated apolipoprotein-B levels. Consistent results were obtained in two independent Dutch samples with increased cardiovascular risk and Familial Combined Hyperlipidemia (FCHL) respectively, and replicated in 715 individuals from 61 extended Finnish FCHL families. Notably, causality could be ascribed to this polymorphism by means of functional experiments. The genetic implication of ATF6 in both DM2 and FCHL supports the concept of a shared genetic background for these disorders.

USF1 is the first identified major gene for FCHL, and accounted for the linkage signal on 1q21-23 in Finnish families with the disease, especially in hypertriglyceridemic males (58). Triggered by the overwhelming evidence for USF1 as a susceptibility gene for FCHL and lipid traits (58-66), some research groups have explored the direct contribution of the USF1 gene on type 2 diabetes susceptibility (67-70). However, results thus far were equivocal and replication studies in statistically powerful and phenotypically well-defined cohorts were critically needed. Therefore, in chapter 6, we evaluated the impact of USF1 risk alleles in 2 large Dutch case control samples comprising more than 2000 individuals. Our results appeared robust and straightforward and supported the hypothesis that USF1 also contributes to the genetic background of DM2. Additional studies in distinct populations and a meta-analysis would be helpful to draw decisive conclusions about USF1.

A third example in favor of the postulated overlapping genetic background in FCHL and type 2 diabetes is HNF4alpha. Originally identified as one of the genes that cause Maturity-Onset Diabetes of the Young (71), HNF4alpha is now a generally accepted susceptibility gene for common type 2 diabetes as well (72-80). Recently, the impact of HNF4alpha was extended to the metabolic syndrome, due to its association with increased serum lipid levels in families with Familial Combined Hyperlipidemia from Finland and Mexico (81). 


\section{What is the impact at the population level?}

A major goal of studying the genetic background of families or individuals with an explicit genetic predisposition, such as in FCHL, is to also demonstrate any potential impact of allelic variants at the population level. Translation of these finding to the general population requires large prospective follow up studies. Until now, USF1 is the only FCHL-gene that has successfully endured multiple validation steps, including prospective ascertainment. In the original study, two USF1 polymorphisms rs2073658 and rs3737787, in strong LD with each other, were the most strongly associated variants (58). Subsequent replication studies in various FCHL samples of distinct ethnicities implicated the same polymorphisms (or variants in tight LD) in the genetic background of FCHL $(60,62,66)$. Complementary to these findings, significant associations with lipid traits, parameters of adipose tissue metabolism, and the metabolic syndrome in populations not specifically ascertained for FCHL, further extended the potential significance of USF1 as a cardiovascular risk determinant $(59,61,63,69,82)$. Finally, recent important data from a prospective follow up study demonstrate that USF1 risk alleles confer an approximately two fold increased risk to cardiovascular disease and all-cause mortality in women from two independent Finnish cohorts representative of the general population (64). These latter data provide important decisive evidence and illustrate how a gene originally identified in high-risk families proves to be important also at the population level. Noteworthy, as much as $\sim 75 \%$ of subjects carry the risk allele, which translates to a population attributive risk (PAR) of $14 \%$ in our study. This means, that if the population were monomorphic for the protective allele, the prevalence of type 2 diabetes would be 14\% lower. Thus, although the impact of USF1 is modest at the level of the individual -which is true for most susceptibility genes that underlie complex diseases- the effect at the population level is substantial.

\section{Implications and future directions}

In this thesis three genes were addressed in relation to type 2 diabetes and FCHL: CD36, ATF6 and USF1. A valuable insight arising from the demonstrated up-regulation of CD36 in FCHL-pre-adipocytes, is that genetic defects have measurable cellular consequences in adipose tissue. Hence, this study 
provided proof at the cellular level for the concept of defective FCHL adipose tissue, which was largely underpinned by observations from epidemiological studies $(83,84)$. From a functional viewpoint the fatty acid transporter CD36 is a logical and attractive candidate gene for FCHL. However, in contrast to USF1 and ATF6, CD36 is more likely the manifestation of an underlying genetic alteration, rather than harboring the defect by itself. With our long-term goal in mind -the genetic dissection of FCHL and type 2 diabetes- future research should be directed by USF1- and especially our ATF6-related research findings. The cellular role of ATF6 in relation of insulin resistance is currently unexplored, but represents one of the research questions that we shall address in the near future.

More than 2 years and many replications in various populations were needed for USF1 from identification as FCHL candidate gene until its present general acceptance as established CVD susceptibility gene. The potential effect of USF1 on type 2 diabetes susceptibility has not even been unequivocally established until now. Compared to USF1, the identification of ATF6 as a candidate gene for FCHL and type 2 diabetes is still in its infancy. Despite the fact that the genetic association is robust and supported by functional data, a stringent path of validation similar to USF1 will be required before it meets the current high standards in genetic epidemiology. Nevertheless, the demonstrated involvement of ATF6 in two of the largest FCHL samples worldwide, is an important contribution to our understanding of the complex FCHL genetics, and promising in terms of its potential impact on cardiovascular risk in the general population. Noteworthy, the identification of ATF6 as a novel susceptibility gene for type 2 diabetes and FCHL coincides with preliminary insights that now emerge in the scientific literature, pointing out that ATF6 and the UPR in general represents an important novel pathway linked with multiple components of the metabolic syndrome. A theoretical perspective on these exciting developments has been provided in part 1 of this chapter.

We assured the potential use of ATF6 as diagnostic marker for predictive genetic testing, as well as a novel cellular target for treatment modalities by pharmaceutical interventions ${ }^{1}$ (85). Apart from the ethical considerations, the debate about whether genetic markers for complex genetic diseases could be informative for clinical use is ongoing. In a recent study by Florez and colleagues it was demonstrated that the TCF7L2 risk alleles, the strongest and

${ }^{1}$ W02006125513 
best replicated DM2 susceptibility gene to date, predict the risk of diabetes prospectively, beyond that conferred by clinical risk factors (86). Other researchers however dispute the predictive power and applicability of genetic markers for complex diseases (87). Fact remains however that in current clinical practice a patient's family history for cardiovascular disease or type 2 diabetes considerably influences the clinicians appraisal regarding further medical policy for that patient. Therefore, it is not inconceivable that detailed genetic patient information will one day be superior over the classical family history, and assist medical doctors in their clinical judgment.

\section{References}

1. Harding HP, Zeng H, Zhang Y, et al. 2001 Diabetes mellitus and exocrine pancreatic dysfunction in perk-/- mice reveals a role for translational control in secretory cell survival. Mol Cell 7:1153-63

2. Scheuner D, Mierde DV, Song B, et al. 2005 Control of mRNA translation preserves endoplasmic reticulum function in beta cells and maintains glucose homeostasis. Nat Med 11:757-64

3. Zhang K, Wong HN, Song B, Miller CN, Scheuner D, Kaufman RJ 2005 The unfolded protein response sensor IRE1alpha is required at 2 distinct steps in B cell lymphopoiesis. J Clin Invest 115:268-81

4. Reimold AM, Iwakoshi NN, Manis J, et al. 2001 Plasma cell differentiation requires the transcription factor XBP-1. Nature 412:300-7

5. Reimold AM, Ponath PD, Li YS, et al. 1996 Transcription factor B cell lineage-specific activator protein regulates the gene for human X-box binding protein 1. J Exp Med 183:393401

6. Zong WX, Li C, Hatzivassiliou G, et al. 2003 Bax and Bak can localize to the endoplasmic reticulum to initiate apoptosis. J Cell Biol 162:59-69

7. Scorrano L, Oakes SA, Opferman JT, et al. 2003 BAX and BAK regulation of endoplasmic reticulum Ca2+: a control point for apoptosis. Science 300:135-9

8. McCullough KD, Martindale JL, Klotz LO, Aw TY, Holbrook NJ 2001 Gadd153 sensitizes cells to endoplasmic reticulum stress by down-regulating Bcl2 and perturbing the cellular redox state. Mol Cell Biol 21:1249-59

9. Ma Y, Brewer JW, Diehl JA, Hendershot LM 2002 Two distinct stress signaling pathways converge upon the $\mathrm{CHOP}$ promoter during the mammalian unfolded protein response. J Mol Biol 318:1351-65

10. Oyadomari S, Araki E, Mori M 2002 Endoplasmic reticulum stress-mediated apoptosis in pancreatic beta-cells. Apoptosis 7:335-45

11. Ma Y, Hendershot LM 2004 The role of the unfolded protein response in tumour development: friend or foe? Nat Rev Cancer 4:966-77

12. Koumenis C, Naczki C, Koritzinsky M, et al. 2002 Regulation of protein synthesis by hypoxia via activation of the endoplasmic reticulum kinase PERK and phosphorylation of the translation initiation factor eIF2alpha. Mol Cell Biol 22:7405-16 
13. Koritzinsky M, Magagnin MG, van den Beucken T, et al. 2006 Gene expression during acute and prolonged hypoxia is regulated by distinct mechanisms of translational control. Embo J 25:1114-25

14. Bi M, Naczki C, Koritzinsky M, et al. 2005 ER stress-regulated translation increases tolerance to extreme hypoxia and promotes tumor growth. Embo J 24:3470-81

15. Katayama T, Imaizumi K, Sato N, et al. 1999 Presenilin-1 mutations downregulate the signalling pathway of the unfolded-protein response. Nat Cell Biol 1:479-85

16. Katayama T, Imaizumi K, Honda A, et al. 2001 Disturbed activation of endoplasmic reticulum stress transducers by familial Alzheimer's disease-linked presenilin-1 mutations. J Biol Chem 276:43446-54

17. Katayama T, Imaizumi K, Manabe T, Hitomi J, Kudo T, Tohyama M 2004 Induction of neuronal death by ER stress in Alzheimer's disease. J Chem Neuroanat 28:67-78

18. Delepine M, Nicolino M, Barrett T, Golamaully M, Lathrop GM, Julier C 2000 EIF2AK3, encoding translation initiation factor 2-alpha kinase 3, is mutated in patients with Wolcott-Rallison syndrome. Nat Genet 25:406-9

19. Kitada T, Asakawa S, Hattori N, et al. 1998 Mutations in the parkin gene cause autosomal recessive juvenile parkinsonism. Nature 392:605-8

20. Imai Y, Soda M, Takahashi R 2000 Parkin suppresses unfolded protein stress-induced cell death through its E3 ubiquitin-protein ligase activity. J Biol Chem 275:35661-4

21. Ozcan U, Cao Q, Yilmaz E, et al. 2004 Endoplasmic reticulum stress links obesity, insulin action, and type 2 diabetes. Science 306:457-61

22. Ozcan U, Yilmaz E, Ozcan L, et al. 2006 Chemical chaperones reduce ER stress and restore glucose homeostasis in a mouse model of type 2 diabetes. Science 313:1137-40

23. Nakatani Y, Kaneto H, Kawamori D, et al. 2005 Involvement of endoplasmic reticulum stress in insulin resistance and diabetes. J Biol Chem 280:847-51

24. Zeng L, Lu M, Mori K, et al. 2004 ATF6 modulates SREBP2-mediated lipogenesis. Embo J 23:950-8

25. Harding HP, Zhang Y, Khersonsky S, et al. 2005 Bioactive small molecules reveal antagonism between the integrated stress response and sterol-regulated gene expression. Cell Metab 2:361-71

26. Kim AJ, Shi Y, Austin RC, Werstuck GH 2005 Valproate protects cells from ER stressinduced lipid accumulation and apoptosis by inhibiting glycogen synthase kinase-3. J Cell Sci 118:89-99

27. Werstuck GH, Lentz SR, Dayal S, et al. 2001 Homocysteine-induced endoplasmic reticulum stress causes dysregulation of the cholesterol and triglyceride biosynthetic pathways. J Clin Invest 107:1263-73

28. Zhang K, Shen X, Wu J, et al. 2006 Endoplasmic reticulum stress activates cleavage of CREBH to induce a systemic inflammatory response. Cell 124:587-99

29. Feng B, Yao PM, Li Y, et al. 2003 The endoplasmic reticulum is the site of cholesterolinduced cytotoxicity in macrophages. Nat Cell Biol 5:781-92

30. Bernales S, Papa FR, Walter P 2006 Intracellular signaling by the unfolded protein response. Annu Rev Cell Dev Biol 22:487-508

31. Schroder M, Kaufman RJ 2005 ER stress and the unfolded protein response. Mutat Res 569:29-63

32. Liu CY, Schroder M, Kaufman RJ 2000 Ligand-independent dimerization activates the stress response kinases IRE1 and PERK in the lumen of the endoplasmic reticulum. J Biol Chem 275:24881-5 
33. Ye J, Rawson RB, Komuro R, et al. 2000 ER stress induces cleavage of membrane-bound ATF6 by the same proteases that process SREBPs. Mol Cell 6:1355-64

34. Thuerauf DJ, Morrison LE, Hoover H, Glembotski CC 2002 Coordination of ATF6mediated transcription and ATF6 degradation by a domain that is shared with the viral transcription factor, VP16. J Biol Chem 277:20734-9

35. Harding HP, Calfon M, Urano F, Novoa I, Ron D 2002 Transcriptional and translational control in the Mammalian unfolded protein response. Annu Rev Cell Dev Biol 18:575-99

36. Travers KJ, Patil CK, Wodicka L, Lockhart DJ, Weissman JS, Walter P 2000 Functional and genomic analyses reveal an essential coordination between the unfolded protein response and ER-associated degradation. Cell 101:249-58

37. Friedlander R, Jarosch E, Urban J, Volkwein C, Sommer T 2000 A regulatory link between ER-associated protein degradation and the unfolded-protein response. Nat Cell Biol 2:379-84

38. Ron D 2002 Translational control in the endoplasmic reticulum stress response. J Clin Invest 110:1383-8

39. Yoneda T, Imaizumi K, Oono K, et al. 2001 Activation of caspase-12, an endoplastic reticulum (ER) resident caspase, through tumor necrosis factor receptor-associated factor 2dependent mechanism in response to the ER stress. J Biol Chem 276:13935-40

40. Morishima N, Nakanishi K, Takenouchi H, Shibata T, Yasuhiko Y 2002 An endoplasmic reticulum stress-specific caspase cascade in apoptosis. Cytochrome c-independent activation of caspase-9 by caspase-12. J Biol Chem 277:34287-94

41. Yabe D, Brown MS, Goldstein JL 2002 Insig-2, a second endoplasmic reticulum protein that binds SCAP and blocks export of sterol regulatory element-binding proteins. Proc Natl Acad Sci U S A 99:12753-8

42. Yang T, Espenshade PJ, Wright ME, et al. 2002 Crucial step in cholesterol homeostasis: sterols promote binding of SCAP to INSIG-1, a membrane protein that facilitates retention of SREBPs in ER. Cell 110:489-500

43. Horton JD, Goldstein JL, Brown MS 2002 SREBPs: activators of the complete program of cholesterol and fatty acid synthesis in the liver. J Clin Invest 109:1125-31

44. Shoelson SE, Lee J, Goldfine AB 2006 Inflammation and insulin resistance. J Clin Invest 116:1793-801

45. Curran JE, Jowett JB, Elliott KS, et al. 2005 Genetic variation in selenoprotein S influences inflammatory response. Nat Genet 37:1234-41

46. Gargalovic PS, Gharavi NM, Clark MJ, et al. 2006 The unfolded protein response is an important regulator of inflammatory genes in endothelial cells. Arterioscler Thromb Vasc Biol 26:2490-6

47. Gargalovic PS, Imura M, Zhang B, et al. 2006 Identification of inflammatory gene modules based on variations of human endothelial cell responses to oxidized lipids. Proc Natl Acad Sci U S A 103:12741-6

48. Bretscher MS, Munro S 1993 Cholesterol and the Golgi apparatus. Science 261:1280-1

49. Morello F, de Bruin TW, Rotter JI, et al. 2004 Differential gene expression of bloodderived cell lines in familial combined hyperlipidemia. Arterioscler Thromb Vasc Biol 24:2149-54

50. Shiu RP, Pouyssegur J, Pastan I 1977 Glucose depletion accounts for the induction of two transformation-sensitive membrane proteinsin Rous sarcoma virus-transformed chick embryo fibroblasts. Proc Natl Acad Sci U S A 74:3840-4 
51. Hanson RL, Ehm MG, Pettitt DJ, et al. 1998 An autosomal genomic scan for loci linked to type II diabetes mellitus and body-mass index in Pima Indians. Am J Hum Genet 63:1130-8

52. Elbein SC, Hoffman MD, Teng K, Leppert MF, Hasstedt SJ 1999 A genome-wide search for type 2 diabetes susceptibility genes in Utah Caucasians. Diabetes 48:1175-82

53. Hsueh WC, St Jean PL, Mitchell BD, et al. 2003 Genome-wide and fine-mapping linkage studies of type 2 diabetes and glucose traits in the Old Order Amish: evidence for a new diabetes locus on chromosome 14q11 and confirmation of a locus on chromosome 1q21q24. Diabetes 52:550-7

54. Wiltshire S, Hattersley AT, Hitman GA, et al. 2001 A genomewide scan for loci predisposing to type 2 diabetes in a U.K. population (the Diabetes UK Warren 2 Repository): analysis of 573 pedigrees provides independent replication of a susceptibility locus on chromosome 1q. Am J Hum Genet 69:553-69

55. Meigs JB, Panhuysen CI, Myers RH, Wilson PW, Cupples LA 2002 A genome-wide scan for loci linked to plasma levels of glucose and $\mathrm{HbA}(1 \mathrm{c})$ in a community-based sample of Caucasian pedigrees: The Framingham Offspring Study. Diabetes 51:833-40

56. Ng MC, So WY, Cox NJ, et al. 2004 Genome-wide scan for type 2 diabetes loci in Hong Kong Chinese and confirmation of a susceptibility locus on chromosome 1q21-q25. Diabetes 53:1609-13

57. Du W, Sun H, Wang H, et al. 2001 Confirmation of susceptibility gene loci on chromosome 1 in northern China Han families with type 2 diabetes. Chin Med J (Engl) 114:876-8

58. Pajukanta P, Lilja HE, Sinsheimer JS, et al. 2004 Familial combined hyperlipidemia is associated with upstream transcription factor 1 (USF1). Nat Genet 36:371-6

59. Choquette AC, Bouchard L, Houde A, Bouchard C, Perusse L, Vohl MC 2007 Associations between USF1 gene variants and cardiovascular risk factors in the Quebec Family Study. Clin Genet 71:245-53

60. Coon H, Xin Y, Hopkins PN, Cawthon RM, Hasstedt SJ, Hunt SC 2005 Upstream stimulatory factor 1 associated with familial combined hyperlipidemia, LDL cholesterol, and triglycerides. Hum Genet 117:444-51

61. Hoffstedt J, Ryden M, Wahrenberg H, van Harmelen V, Arner P 2005 Upstream transcription factor-1 gene polymorphism is associated with increased adipocyte lipolysis. J Clin Endocrinol Metab 90:5356-60

62. Huertas-Vazquez A, Aguilar-Salinas C, Lusis AJ, et al. 2005 Familial combined hyperlipidemia in Mexicans: association with upstream transcription factor 1 and linkage on chromosome 16q24.1. Arterioscler Thromb Vasc Biol 25:1985-91

63. Kantartzis K, Fritsche A, Machicao F, et al. 2007 Upstream transcription factor 1 gene polymorphisms are associated with high antilipolytic insulin sensitivity and show genegene interactions. J Mol Med 85:55-61

64. Komulainen K, Alanne M, Auro K, et al. 2006 Risk alleles of USF1 gene predict cardiovascular disease of women in two prospective studies. PLoS Genet 2:e69

65. Naukkarinen J, Gentile M, Soro-Paavonen A, et al. 2005 USF1 and dyslipidemias: converging evidence for a functional intronic variant. Hum Mol Genet 14:2595-605

66. van der Vleuten GM, Isaacs A, Hijmans A, van Duijn CM, Stalenhoef AF, de Graaf J 2007 The involvement of upstream stimulatory factor 1 in Dutch patients with familial combined hyperlipidemia. J Lipid Res 48:193-200

67. Zeggini E, Damcott CM, Hanson RL, et al. 2006 Variation within the gene encoding the upstream stimulatory factor 1 does not influence susceptibility to type 2 diabetes in sam- 
ples from populations with replicated evidence of linkage to chromosome 1q. Diabetes 55:2541-8

68. Putt W, Palmen J, Nicaud V, et al. 2004 Variation in USF1 shows haplotype effects, gene : gene and gene : environment associations with glucose and lipid parameters in the European Atherosclerosis Research Study II. Hum Mol Genet 13:1587-97

69. Ng MC, Miyake K, So WY, et al. 2005 The linkage and association of the gene encoding upstream stimulatory factor 1 with type 2 diabetes and metabolic syndrome in the Chinese population. Diabetologia 48:2018-24

70. Gibson F, Hercberg S, Froguel P 2005 Common polymorphisms in the USF1 gene are not associated with type 2 diabetes in French Caucasians. Diabetes 54:3040-2

71. Yamagata K, Furuta H, Oda N, et al. 1996 Mutations in the hepatocyte nuclear factor4alpha gene in maturity-onset diabetes of the young (MODY1). Nature 384:458-60

72. Silander K, Mohlke KL, Scott LJ, et al. 2004 Genetic variation near the hepatocyte nuclear factor- 4 alpha gene predicts susceptibility to type 2 diabetes. Diabetes 53:1141-9

73. Weedon MN, Owen KR, Shields B, et al. 2004 Common variants of the hepatocyte nuclear factor-4alpha P2 promoter are associated with type 2 diabetes in the U.K. population. Diabetes 53:3002-6

74. Hansen SK, Rose CS, Glumer C, et al. 2005 Variation near the hepatocyte nuclear factor (HNF)-4alpha gene associates with type 2 diabetes in the Danish population. Diabetologia 48:452-8

75. Vaxillaire M, Dina C, Lobbens S, et al. 2005 Effect of common polymorphisms in the HNF4alpha promoter on susceptibility to type 2 diabetes in the French Caucasian population. Diabetologia 48:440-4

76. Bagwell AM, Bento JL, Mychaleckyj JC, Freedman BI, Langefeld CD, Bowden DW 2005 Genetic analysis of HNF4A polymorphisms in Caucasian-American type 2 diabetes. Diabetes 54:1185-90

77. Mohlke KL, Boehnke M 2005 The role of HNF4A variants in the risk of type 2 diabetes. Curr Diab Rep 5:149-56

78. Muller YL, Infante AM, Hanson RL, et al. 2005 Variants in hepatocyte nuclear factor 4alpha are modestly associated with type 2 diabetes in Pima Indians. Diabetes 54:3035-9

79. Hara K, Horikoshi M, Kitazato H, et al. 2006 Hepatocyte nuclear factor-4alpha P2 promoter haplotypes are associated with type 2 diabetes in the Japanese population. Diabetes 55:1260-4

80. Andrulionyte L, Laukkanen O, Chiasson JL, Laakso M 2006 Single nucleotide polymorphisms of the HNF4alpha gene are associated with the conversion to type 2 diabetes mellitus: the STOP-NIDDM trial. J Mol Med 84:701-8

81. Weissglas-Volkov D, Huertas-Vazquez A, Suviolahti E, et al. 2006 Common hepatic nuclear factor-4alpha variants are associated with high serum lipid levels and the metabolic syndrome. Diabetes 55:1970-7

82. Shoulders CC, Naoumova RP 2004 USF1 implicated in the aetiology of familial combined hyperlipidaemia and the metabolic syndrome. Trends Mol Med 10:362-5

83. Voors-Pette C, de Bruin TW 2001 Excess coronary heart disease in Familial Combined Hyperlipidemia, in relation to genetic factors and central obesity. Atherosclerosis 157:481-9

84. van der Kallen CJ, Voors-Pette C, de Bruin TW 2004 Abdominal obesity and expression of familial combined hyperlipidemia. Obes Res 12:2054-61 
85. Meex SJ, van der Kallen CJ, de Bruin T, van Greevenbroek MM, Vlietinck R, Ayoubi TA 2006 Genetic association of polymorphisms in the ATF6-alpha gene with insulin resistance phenotypes. WO 2006125513, The Netherlands

86. Florez JC, Jablonski KA, Bayley N, et al. 2006 TCF7L2 polymorphisms and progression to diabetes in the Diabetes Prevention Program. N Engl J Med 355:241-50

87. Janssens AC, Gwinn M, Khoury MJ, Subramonia-Iyer S 2006 Does genetic testing really improve the prediction of future type 2 diabetes? PLoS Med 3:e114; author reply e127 


\section{Summary}

Over the past two decades, a dramatic worldwide increase in the number of people with obesity has been observed. The obesity pandemic is the driving force behind the high incidence of cardiovascular disease. The term "metabolic syndrome" defines the clustering of various obesity-associated cardiovascular risk factors (hypertension, disturbed glucose homeostasis and atherogenic dyslipidemia) with insulin resistance as a central component A combination of environmental (nutrition, physical activity) and genetic factors determines the risk for a given individual to develop the metabolic syndrome. Two subgroups of patients with the metabolic syndrome, those with type 2 diabetes (DM2) and familial combined hyperlipidemia (FCHL), are at particularly high risk for premature cardiovascular disease. Nearly two-thirds of individuals with FCHL, and $80-90 \%$ of patients with type 2 diabetes, meet the diagnostic criteria of the metabolic syndrome. The marked presence of a genetic component in type 2 diabetes and FCHL, reflected by their familial clustering, provides us with two excellent models to study the genetic background of insulin resistance and may benefit millions of people with the metabolic syndrome.

The central aim of this thesis was to identify novel genes and molecular pathways that underlie the pathophysiology of insulin resistance. In particular DM2 and FCHL were used as two complementary genetic models for insulin resistance. Since DM2 and FCHL are postulated to share some of their genetic components, our side by side research design also provided a unique opportunity to investigate whether established and novel DM2 susceptibility genes confer also increased risk to FCHL and vice versa.

In chapter 2 we discussed the various approaches that can be employed to dissect the genetic background of complex diseases, and the contribution of each method to our present understanding of the genetic background of familial combined hyperlipidemia (FCHL) and type 2 diabetes (DM2)

The first experimental chapter (Chapter 3) is the basis of this thesis. It describes a gene expression study conducted on cultured pre-adipocytes from patients with FCHL and healthy control subjects. The use of cultured human cells instead of freshly isolated adipocytes allowed us to suppress adaptive gene expression differences and preserve the (epi)genetic effects. This approach re- 
vealed increased CD36-expression and CD36-functionality as a novel, potentially important feature of FCHL adipose tissue, which may be of genetic origin

Combined information from gene-expression data in chapter 3, another FCHL expression array with immortalized lymphoblast cell lines, and data from genetic linkage analyses led to the identification of a new candidate gene for type 2 diabetes: Activating Transcription Factor 6 (ATF6). The potential significance of ATF6 is extended in Chapter 5 were we demonstrate association of an exonic variant in ATF6 with FCHL in three independent samples from Dutch and Finnish origin. In vitro studies support the genetic data and unequivocally implicate the ATF6 exon polymorphism as a causal variant. Together, results from chapter 4 and 5 provide proof for the postulated shared genetic background in FCHL and type 2 diabetes, and highlight the endoplasmic reticulum stress response, a novel pathway in the pathophysiology of insulin resistance and dyslipidemia. Chapter 6 evaluates the well-established FCHL-susceptibility gene Upstream Stimulatory Factor 1 (USF1), for its potential role in type 2 diabetes in two large Dutch case control samples comprising more than 2000 individuals. In Chapter 7 we put all data in perspective, discuss their potential relevance for diagnostic or screening purposes, and integrate them with emerging insights in the field of insulin resistance, with emphasis on the endoplasmic reticulum stress response. 


\section{Samenvatting}

Het aantal mensen met overgewicht neemt wereldwijd explosief toe. Deze pandemie is de drijvende kracht achter de hoge incidentie van hart- en vaatziekten. Mensen met overgewicht lijden vaak aan het zogenaamde "metabool syndroom", een cluster van cardiovasculaire risicofactoren (hypertensie, hyperglycemie, en een atherogeen lipoprotein phenotype) met als centrale component "insuline resistentie". Het risico om als individu het metabool syndroom te ontwikkelen -en daarmee dus een sterk verhoogd risico op hart- en vaatziekten - wordt bepaald door een combinatie van levensstijl (voeding, lichaamsbeweging) en erfelijkheid. Twee subgroepen met het metabool syndroom hebben een bovengemiddelde erfelijke belasting, en daarmee een nog hoger risico op hart- en vaatziekten: het betreffen patiënten met familiair gecombineerde hyperlipidemie (FGH) en type 2 diabetes (DM2). Deze twee patientengroepen zijn vanwege hun duidelijke genetische component een uitstekend model om de erfelijke aspecten van insuline resistentie en het metabool syndroom te onderzoeken. Bijna 2/3 van de patiënten met FGH en zelfs $80-90 \%$ van de DM2-patienten voldoen aan de criteria van het metabool syndroom. Een beter begrip van de genetische variaties die ten grondslag liggen van deze aandoeningen is dus niet alleen van belang voor deze twee specifieke populaties, maar heeft een mogelijke draagwijdte voor miljoenen patiënten met het metabool syndroom.

De centrale doelstelling van dit proefschrift was het identificeren van nieuwe genen en cellulaire routes die aan de basis liggen van insuline resistentie. Hiervoor werden DM2 en FGH gebruikt als twee complementaire genetische modellen voor insuline resistentie. Omdat verondersteld wordt dat DM2 en FGH een gedeeltelijk overlappende genetische achtergrond hebben, bood onze onderzoeksopzet bovendien de unieke mogelijkheid om het effect van bestaande en nieuwe "diabetesgenen" te verifiëren in FGH, en omgekeerd.

In hoofdstuk 2 zijn de verschillende mogelijke benaderingen beschreven die gebruikt kunnen worden voor de ontrafeling van complexe genetische aandoeningen, en de bijdrage van elke methode aan de huidige inzichten in de genetische achtergrond van DM2 en FGH. 
Hoofdstuk 3 vormt de experimentele basis van deze thesis. Hier werd een genexpressiestudie uitgevoerd met gekweekte pre-adipocyten (voorlopers van vetcellen) van patiënten met FGH en gezonde controlepersonen. De keuze voor gekweekte pre-adipocyten in plaats van verse adipocyten, direct uit de patiënt, maakte het mogelijk om adaptieve genexpressieverschillen te onderdrukken, en alleen de genetische en epigenetische effecten te selecteren. Middels deze aanpak werd in cellen afkomstig van FGH patiënten een verhoogde expressie van CD36, en toegenomen vetzuurtransport via dit molecuul, aangetoond. Dit is wellicht een reflectie van insulineresistentie bij FGH, die reeds in een zeer vroeg stadium detecteerbaar is en mogelijk een genetische oorsprong heeft.

Het combineren van informatie uit genexpressiestudies (o.a. uit hoofdstuk 3) en genetisch koppelingsonderzoek, heeft geleid tot de identificatie van een nieuw kandidaatgen voor type 2 diabetes in hoofdstuk 4: Activatie Transcriptie Factor 6 (ATF6). De mogelijke relevantie van ATF6 werd in hoofdstuk 5 nog verder uitgebreid door aan te tonen dat een veelvuldig voorkomende aminozuursubstitutie in dit gen geassocieerd is met FGH, en vooral invloed heeft op plasma (LDL-)cholesterol en apolipoprotein B. Deze vinding werd robuust gerepliceerd in drie onafhankelijke Nederlandse en Finse patiëntencohorten. Samen met een serie in vitro experimenten wijzen deze data eenduidig het polymorfe aminozuur 67 in het ATF6-eiwit aan als de causale variant. Hoofdstukken 4 en 5 bieden gezamenlijk enig bewijs voor de veronderstelde overlappende genetische achtergrond van type 2 diabetes en familiair gecombineerde hyperlipidemie. Nog belangrijker is dat de data een nieuwe cellulaire route impliceerden voor insuline resistentie en dyslipidemie: "de endoplasmatisch reticulum stress response".

Eveneens in functie van de mogelijke genetische overlap tussen type 2 diabetes en FGH, werd in hoofdstuk 6 het gevestigde en meest gerepliceerde FGH risico gen USF1 bestudeerd in relatie tot zijn mogelijke betrokkenheid bij type 2 diabetes. Een bescheiden, maar significante associatie met type 2 diabetes werd hierbij aangetoond. In hoofdstuk 7 plaatsten we alle verkregen data in perspectief, bediscussieerden hun mogelijke relevantie in een tijdperk waar "gepersonaliseerde geneeskunde" steeds belangrijker wordt, en focusten op nieuwe inzichten in de rol van endoplasmatisch reticulum stress in bijna alle componenten van het metabool syndroom. 


\section{Dankwoord}

Allereerst woorden van dank voor mijn promotores, prof. dr. C. Stehouwer en prof. dr. T. de Bruin. Beste Tjerk, bij jou is het allemaal begonnen met een "uitde-hand-gelopen" afstudeerstage. Jouw betrokkenheid en enthousiasme zijn ongeëvenaard. Nadat je halverwege het promotietraject emigreerde naar de VS werden onze contacten vanzelfsprekend minder frequent, maar op de belangrijke momenten was je er altijd. Je bent begaan met de carrière van je promovendi. Ik zal jouw mooie aanbevelingsbrief voor het lab van dr. Fisher niet vergeten. Beste Coen, als hoofd van de afdeling Interne Geneeskunde werd $\mathrm{u}$ na het vertrek van Tjerk ook mijn promotor. U staat voor leiderschap en efficiëntie. Dank voor uw steun tijdens mijn promotietraject en uw betrokkenheid bij mijn verdere carrière-planning.

Copromotores, dr. C. van der Kallen en dr. M. van Greevenbroek. Carla en Marleen, graag wil ik jullie danken voor de dagelijkse begeleiding, maar ook voor de vrijheid die jullie mij gaven en het vertrouwen dat jullie in mij stelden. Altijd waren jullie bereid mijn manuscripten te lezen, en stond jullie deur open voor vragen, advies, of om mij van tegengas te voorzien als ik "het" weer eens had opgelost. Hierbij wil ik ook het hoofd van het lab, dr. C. Schalkwijk, betrekken. Beste Casper, hartelijk dank voor je oprechte steun, vertouwen en interesse.

Alle leden van de leescommissie: Prof. dr. M. Daemen, prof. dr. W. Buurman, prof. dr. N. Schaper, prof. dr. P. Slagboom en prof. dr. B. Wouters, wil ik bedanken voor het lezen en goedkeuren van mijn manuscript.

Collega AIO's van lab "Metabolism and Vascular Medicine": Katrien, Olaf, Marjon, Roel, Lian, Johanna: veel succes met jullie promotie-onderzoek. Verder wil ik alle (oud)medewerkers danken voor de de afgelopen jaren: Anna, Dany, Eric, Ellen, Joséphine, Lonneke, Marjo, Martijn, Mohammed, Margee, Margriet, Petra, Petra, Riny en Vicky.

Prof. dr. J. Glatz en dr. J. Luiken, beste Jan en Joost. Dank voor de waardevolle CD36-samenwerking, het is mede dankzij jullie een prachtig artikel geworden! Mohammed, dank voor je hulp bij de CD36 inbouwexperimenten. Dr. C. Eve- 
lo, beste Chris, dank voor je hulp bij de annotatie van de arrays. Dr. P. Lindsey, dear Patrick, thanks for writing a program in " $R$ " to analyze my arraydata. Prof dr. R. Vlietinck en dr. T. Ayoubi. Beste Bob en Torik, jullie waren vanaf het begin betrokken bij mijn ATF6-onderzoek. Dank voor alles, in het bijzonder voor jullie advies bij de octrooiaanvraag. Prof M. Hofker en J. van Vliet-Ostaptchouk, Beste Marten en Jana, dank voor de prettige samenwerking in Maastricht. Ik wens jullie een succesvolle voortzetting in Groningen. Prof. Dr. B. Wouters, dear Brad, thank you for valuable research and "grantwriting" advise. Good luck in Toronto. Prof. dr C. Wijmenga en dr. T van Haeften, dank voor het beschikbaar stellen van het Breda cohort voor mijn onderzoek. Leden van de CoDAM stuurgroep, dank voor het beschibaar stellen van het CoDAM cohort. Dr. E. Feskens, Beste Edith dank voor specifiek advies van tijd tot tijd.

Biomedbooster, dr H. Lichtenbeld en dr. J Muijrers. Dank voor de financiële ondersteuning van het octrooi en begeleiding bij de commerciële en technische aspecten ervan.

Dr. C. Glembotski, dear Chris. Knowing you only from literature as a pioneering "ATF6-researcher", I sent you an email to suggest a collaboration on my ATF6 question. The three months I spent in your lab in San Diego were such a valuable and unforgettable experience. I admire you as a scientist and as a person. I know you wanted me to come back to your lab as a postdoc... sorry for not being able to do so. To the Glembotski lab members: Archana, Donna, Jack, John, Jung Kang, Kat, Marie, Matt, Mimi, Pete, Ross, Shirin and Susan. Thank you for the great time and racketball competition! Shirin, thank you for always being so helpful (airport, housing). Donna, cornerstone of the lab, special thanks to you for introducing me in the world of cloning and transfection experiments. Long, long bike rides and even some races during the weekends in San Diego: dear Nick and Steve, it was lots of fun riding with you in the San Diego mountains. The Cuyamaca fire-road was my steepest climb ever! Best of luck to both of you and don't forget to join me in the Alps one day.

From San Diego to Los Angeles. Dr. P. Pajukanta and D. Weissglas-Volkov. Dear Païvi, you are a great geneticist, it is an honor to have been able to work with you. Daphna, statistical genius, thank you for your effort and commitment. The high quality of chapter 5 is also thanks to you! 
Ha Martijn, waar moet ik beginnen? Collega, kamergenoot, vriend, vertrouweling. Verhitte wetenschappelijke discussies hebben we gehad in het lab (zodanig dat Vicky voorzichtig om de hoek kwam vragen of het "nog wel OK was?"), en die werden vervolgens vrolijk verder gezet in de stad, kroeg of zelfs in de Albert Heijn. Maar meestal zijn we het toch gewoon roerend met elkaar eens! Ik weet niet zeker of we FGH nu al helemaal opgelost hebben, maar naar mijn bescheiden inschatting zijn we toch al een heel eind op weg...! Fantastisch dat we nu samen promoveren: STIMMUNG.

Ook veel meer dan collega's: Dennis en Twan, Geweldig leuk om in dezelfde periode als jullie onderzoek te hebben gedaan, en nog veel meer: het wekelijkse "kook-klupje", stapavonden, wijnproeven in Frankrijk,... onvergetelijk! Dennis veel succes met de opleiding tot internist, ook daar heb je weer uitstekend je draai gevonden. Twan, veel succes met je postdoc in Toronto! Collega AIO's van pathologie: Kitty, Linda, Marjo, Natasja, Suzanne. Leuke stapavonden, AIO-cursussen en BBQ's. Succes met jullie carrières.

Het mag ondertussen al duidelijk zijn. Wielrennen is een basisbehoefte. Bij voorkeur in de vorm van fietsvakanties of lange tochten met vrienden waarbij uitsluitend flauwe zever verteld wordt. Jeroen, Tim, Nico, Krist, Godfried: de traditionele dinsdagavond-tochten zorgden voor de noodzakelijke ontspanning tijdens de week (en voor brakke woensdagochtenden met tunnelzicht en een hongerklop). Ook buiten het wielrennen trouwens super vrienden met onvoorwaardelijke loyaliteit. Tim en Jeroen... fantastisch om jullie aan mijn zijde te hebben als paranimf! Helaas minder frequent in contact, maar zeer gewaardeerd: David, Roel, Martino, Sylvie, Mirjan... telkens weer leuk als ik jullie zie. Sjaak, Rita, Esther, Tarkan, bedankt voor jullie interesse, altijd leuk om bij jullie langs te komen. Esther, neem jij straks op het promotiefeest maar een baco extra... dat heb je wel verdiend.

Ruth, jij bent ondertussen aardig op weg...straks nog een doctor aan de familietafel! Lieve mama en papa, jullie onvoorwaardelijke steun en liefde is niet te verwoorden. Dit alles is dankzij en voor jullie!

Tot slot, lieve Judith, altijd recht uit het hart, boordevol plannen en zo mogelijk nog meer ambities dan ikzelf. Ik kon het niet beter treffen! 


\section{Curriculum Vitae}

Steven J.R. Meex was born on december 3rd, 1979 in Genk, Belgium. In 1997 he completed secundary school (Latin-Sciences) in Maasmechelen, Belgium. The same year he started to study "Health Sciences" at the University of Maastricht. After graduation in biological health sciences in 2002 (he completed two separate master programs in molecular biology and epidemiology respectively), Steven started his PhD at the department of internal medicine, Maastricht University, to identify novel genes and molecular patways underlying Familial Combined Hyperlipidemia and type 2 diabetes. In 2006, Steven was awarded a European EFSD/Novo Nordisk research grant, which he wrote in the capacity of PhD student under the name of his promoter, Prof dr Stehouwer. In 2007 he spent three months in the Glembotski Laboratory (San Diego, USA), supported by an NWO travel grant. Steven is now appointed as a postdoctoral fellow at the department of internal medicine supported by a "Kootstra fellowship". 


\section{Scientific output}

\section{List of publications}

Schutte B, Henfling M, Kolgen W, Bouman M, Meex S, Leers MP, Nap M, Bjorklund V, Bjorklund P, Bjorklund B, Lane EB, Omary MB, Jornvall H, Ramaekers FC. Keratin 8/18 breakdown and reorganization during apoptosis. Exp Cell Res. 297(1), 2004, 11-26.

Meex SJ, van der Kallen CJ, van Greevenbroek MM, Eurlings PM, El Hasnaoui M, Evelo CT, Lindsey PJ, Luiken JJ, Glatz JF, de Bruin TW. Up-regulation of CD36/FAT in preadipocytes in familial combined hyperlipidemia. FASEB J. 19(14), 2005, 2063-5.

Meex SJ, van Greevenbroek MM, Ayoubi TA, Vlietinck R, van VlietOstaptchouk JV, Hofker MH, Vermeulen VM, Schalkwijk CG, Feskens EJ, Boer JM, Stehouwer CD, van der Kallen CJ and de Bruin TW. ATF6, a key regulator of the unfolded protein response is associated with type 2 diabetes. J Clin Endocrinol Metab. 92(7), 2007, 2720-5.

Meex SJ, van der Kallen CJ, Weissglas-Volkov D, Thuerauf DJ, van Greevenbroek MM, Schalkwijk CG, Stehouwer CD, de Bruin TW, Heldens L, Ayoubi TA, Hofker MH, Wouters BG, Vlietinck R, Taskinen MR, Pajukanta P, Glembotski CG. "The ATF6-Met[67]Val Substitution is Associated with Increased Apolipoprotein B Levels and Plasma Cholesterol". Submitted

Meex SJ, van Vliet-Ostaptchouk JV, van der Kallen CJ, van Greevenbroek MM, Schalkwijk CG, Feskens EJ, Blaak EE, van Haeften TW, de Bruin TW, Wijmenga C, Hofker MH, Stehouwer CD. Upstream transcription factor 1 (USF1) in risk of type 2 diabetes: association study in 2000 dutch caucasians. Submitted

\section{$\underline{\text { Patents }}$}

Meex SJ, van der Kallen CJ, van Greevenbroek MJ, Vlietinck R, Ayoubi TA, de Bruin TW. Patent WO2006125513. Genetic association of polymorphisms in the ATF6-alpha gene with insulin resistance phenotypes. 
It is not the strongest or the smartest that survive, but those most able to adapt to change.

Charles Darwin 